\title{
The \\ Itinerary of High Density Lipoproteins through Endothelial Cells
}

\author{
Dissertation \\ zur \\ Erlangung der naturwissenschaftlichen Doktorwürde \\ (Dr. sc. nat.) \\ vorgelegt der \\ Mathematisch-naturwissenschaftlichen Fakukltät \\ der \\ Universität Zürich \\ von \\ Damir Perisa \\ von \\ Beromünster LU \\ Promotionskomitee: \\ Prof. Arnold von Eckardstein (Vorsitz, Leitung der Dissertation) \\ Dr. Lucia Rohrer \\ Prof. Urs Greber \\ Prof. Michael Detmar \\ Prof. Felix Tanner
}

Zürich, 2015 
"Seeing, contrary to popular wisdom, isn't believing. It's where belief stops, because it isn't needed any more." Pyramids, Terry Pratchett 


\section{Table of Contents}

The Itinerary of High density lipoproteins through Endothelial Cells 1

2 Abstract 6

3 Introduction $\quad \mathbf{1 0}$

3.1 The circulation system and endothelium 10

3.2 The endothelium as an active barrier 11

3.3 Endocytosis 12

3.4 Targeted sorting inside eukaryotic cells 13

3.5 Exocytosis 14

3.6 Transcytosis 15

3.7 Lipoproteins 16

$\begin{array}{lll}3.7 .1 & \text { Apolipoproteins } & 17\end{array}$

$\begin{array}{ll}3.7 .2 & \text { Lipoprotein metabolism } \\ \end{array}$

3.8 High density Lipoproteins 19

3.8.1 The multitude of potential ApoA1 and HDL receptors 19

3.8.2 ApoA-I and HDL in Atherosclerosis 23

3.9 Need for a method to visualize $1.4 \mathrm{~nm}$ nanogold in HPF-FSF electron microscopy 24

3.10 Aims of this Thesis 26

4 Materials and methods $\quad 27$

$\begin{array}{lll}4.1 .1 & \text { Cell culture } & 27\end{array}$

4.1.2 Preparation and labeling of lipoproteins $\quad 27$

4.1.3 Lipoprotein uptake studies by fluorescence light (FLM) and electron microscopy (EM) 27

4.1.4 Fixation for FLM 29

4.1.5 Indirect Immunostainings for FLM 29

4.1.6 Preparation for FLM and image acquisition 29

4.1.7 High pressure freezing (HPF) and freeze substitution fixation (FSF) for EM 30

$\begin{array}{lll}4.1 .8 & \text { Silver enhancement } & 30\end{array}$

4.1.9 Embedding and preparation for TEM and EM image acquisition 30

5 Results $\quad 32$

5.1 Trafficking route of HDL/ApoA-I in endothelial cells 32

5.1.1 ApoA-I and HDL are binding to endothelial cells 32

5.1.2 Uptake of ApoA-I and HDL 33 
5.1.3 Co-localization of ApoA-I and HDL with markers of endocytosis

5.1.4 HDL is trafficking through different compartments over a period of 4 hours

5.1.5 HDL is passing the endothelial monolayer faster than it accumulates inside the vesicles identified

5.1.6 Colocalization of HDL with organelles

5.1.7 Role of the cytoskeleton on HDL trafficking 50

5.2 Volume enhancement of $1.4 \mathrm{~nm}$ Nanogold-HDL for visualization in EM 50

5.2.1 Increased detection sensitivity of volume silver enhancement of $1.4 \mathrm{~nm}$ nanogold HDL after HPF and FSF compared to classical on-section silver enhancement

5.2.2 $1.4 \mathrm{~nm}$ nanogold LDL and $1.4 \mathrm{~nm}$ nanogold Albumin 52

5.2.3 High background on badly frozen samples, very low on well-frozen samples $\quad 52$

5.3 Cellular localization of ABCA1, ABCG1, SR-BI and EL in endothelial cells and in bovine endothelium 54

5.4 Modulation of trafficking of HDL/ApoA-I by SR-BI and HDL itself 56

5.4.1 Phosphoprotein-Profiles in ECs after exposure to HDL or ApoA-I 58

\section{Discussion}

6.1 Novel methodological developments $\quad 61$

6.2 What is the trafficking route of HDL and ApoA-I in endothelial cells? 63

6.2.1 HDL co-localizes with lipid-free ApoA-I 63

6.2.2 Time dependent trafficking of HDL through ECs 63

6.2.3 Evidence for very fast transcytosis $\quad 64$

6.2.4 Role of clathrin. caveolae and fluid phase for HDL uptake by 65

6.2.5 HDL does not go to lysosomes 65

6.2.6 No co-localization with organelles and main sorting vesicular pathways 66

6.2.7 HDL uptake and sorting depends on the cytoskeleton and dynamin 67

6.3 What is the cellular localization of ABCA1, ABCG1, SR-BI and EL in endothelial cells? 68

6.4 How is the trafficking of HDL and ApoA-I modulated? 69

7 Conclusion and Outlook $\quad 74$

8 Acknowledgements, $\quad 76$

$\begin{array}{lll}10 & \text { List of Figures } & 77\end{array}$

$\begin{array}{llr}11 & \text { List of Tables } & 81\end{array}$

12 References, $\quad 82$ 


\section{Abstract}

Atherosclerosis results from a progressive accumulation of lipids in the arterial intima leading to plaque formation. Epidemiological studies show an inverse association of high density lipoprotein (HDL) cholesterol with cardiovascular events. HDL and its main apolipoprotein A-I (ApoA-I) have multiple anti-atherogenic functions. Some of them are exerted within the vessel wall, notably the classical function of HDL, namely the mediation of cholesterol efflux from macrophage foam cells. To get access to the intima and the lipid-laden macrophages, HDL has to pass the endothelial barrier. Previously, we showed that ApoA-I transcytosis is modulated by ATP binding cassette transporter (ABC) $A 1$, and HDL transcytosis is modulated by ABCG1, scavenger receptor $B I$ (SR-BI) and endothelial lipase (EL).

To elucidate the itinerary of ApoA-I and HDL through endothelial cells (ECs), we investigated the cellular localization of ApoA-I and HDL, which was labelled either fluorescently, or with $1.4 \mathrm{~nm}$ Nanogold by using fluorescent microscopy and electron microscopy (EM), respectively. For EM, we used high pressure freezing to avoid artefacts and lipid extraction. Nanogold was detected by silver enhancement after fixation in $\mathrm{OsO}_{4}$. HDL as well as ApoA-I are taken up by ECs, and ApoA-I and HDL co-localize indicating the same route of trafficking. We compared the trafficking of ApoA-I and HDL with Transferrin and Albumin, which were used as tracers for clathrin- and caveolin-mediated endocytosis, respectively. Both pathways showed partial colocalization indicating a nonclassical pathway for HDL trafficking.

Further experiments showed that HDL is targeted neither to lysosomes nor to the Golgi nor to the endoplasmatic reticulum. Only a small amount can be detected in early endosomes (Rab5) and endosome to trans-golgi network (Rab9), but not at all with late endosomes (Rab7), the recycling endosomes (Rab11a) or vesicles involved in trans-Golgi network sorting (Syntaxin6). EM ultrastructure showed HDL to be located mainly in multivesicular bodies.

We performed pharmacological inhibitions and found that HDL uptake is cytoskeleton dependent but only weakly affected by blocking the fluid phase uptake with Amiloride or EIPA. Neither did we observe any colocalization of HDL with dextran as the marker of fluid phase uptake. 
HDL was found to stimulate its own uptake into ECs. We identified several HDL and/or ApoA-I induced changes in the phosphorylation of signaling molecules, which however still remain to be linked to HDL endocytosis.

In conclusion HDL transport into and through ECs seems to follow a non-classical trafficking route. It appears to be regulated by positive rather than negative feedback.. 


\section{Abstrakt}

Atherosklerosis entsteht durch eine fortschreitende Anhäufung von Lipiden in der Intima von Blutgefässen und trägt somit zur Entstehung von Plaques bei. Epidemiologische Studien zeigten eine negative Korrelation vom Lipoprotein hoher Dichte (high density lipoprotein - HDL) mit kardiovaskulären Ereignissen. HDL und dessen primäres apolipoprotein A-I (ApoA-I) haben vielfache anti-atherogene Funktionen. Einige davon können nur in im Inneren der Blutgefässwand stattfinden, insbesondere die Abführung von Cholesterin aus den Schaumzellen-Makrophagen innerhalb der Intima. Um dahin zu gelangen, muss aber HDL die endotheliale Barriere überqueren.

Vorhergehend haben wir gezeigt, dass die Transzytose von ApoA-I durch den ABCTransporter A1, und die Transzytose von HDL durch ABCG1, Scavenger Receptor B I (SR-BI) und die Endotheliale Lipase (EL) moduliert sind.

Um die Route von ApoA-I und HDL durch die Endothelzellen (ECs) aufzuklären, haben wir die zelluläre Lokalisation von ApoA-I und HDL studiert, welche wir entweder mit Fluoreszent-Farbstoffen oder mit $1.4 \mathrm{~nm}$ Nanogold markiert haben für Fluoreszenz- und Elektronenmikroskopie (EM). Für EM haben wir die Proben durch Hochdruckgefrieren präpariert um Artefakte und Lipidextraktion zu minimieren. Nanogold haben wir dann mittels Silberverstärkung direkt nach der Fixation in $\mathrm{OsO}_{4}$ für das EM detektierbar gemacht.

Sowohl HDL als auch ApoA-I werden durch ECs aufgenommen und co-lokalisieren miteinander, deutend auf die gleiche Route. Wir haben den Transport von ApoA-I und HDL mit Transferrin und Albumin verglichen, welche stellvertretend waren für die Clathrin- and Caveolin-mediierte Endozytose. Beide zeigten partielle Co-Lokalisation, was auf einen nicht-klassischen Pfad für HDL deutet.

In weiteren Experimenten zeigten wir, das HDL weder in Lysosomen, noch ins Golgi oder das endoplasmatische Retikulum geht. Nur ein kleiner Anteil kann in frühen Endosomen (Rab5) und Endosomen-zu-Trans-Golgi-Netzwerk (Rab9) detektiert werden. Es findet sich jedoch kein HDL in den späten Endosomen (Rab7) und rezyklierenden Endosomen (Rab11a) oder im Trans-Golgi-Netzwerk Sortiervesikeln (Syntaxin 6).

Im EM finden wir HDL primär in multivesikulären Körpern. Wir haben dann pharmakologische Inhibition durchgeführt und fanden HDL Aufnahme in ECs benötigt ein funktionierendes Zytoskelett. HDL geht vermutlich nicht via Flüssigphasen-Aufnahme in die ECs, weil Amiloride und EIPA wenig Effekt hatten und HDL auch nicht mit Flüssigphase-Markern wie $40 \mathrm{kDa}$ Dextran co-lokalisiert. 
Weiter fanden wir, das HDL selber die eigene Aufnahme in ECs positiv beeinflusst. Wir identifizierten diverse HDL und/oder ApoA-I induzierte Veränderungen in der Phosphorylierung von Signalmolekülen, welche wir jedoch noch nicht in direkten Zusammenhang mit Endozytose bringen konnten.

Zusammenfassend kann festgehalten werden, dass HDL Transport in und durch die ECs einen nicht-Klassischen Weg geht und positiver statt negativer Selbstregulation unterliegt. 


\section{Introduction}

\subsection{The circulation system and endothelium}

According to the roman physician Claudius Galenus (129-200), inhaled and exhaled air, nutrients, and blood all flow through the same blood vessels. He and his contemporaries believed that the vascular system of the human body is open ended. The heart was considered to be the exchange point of the two tubing systems, which provide all organs, provided with gas and nutrients.

Andreas Vesalius (31 December 1514 - 15 October 1564), William Harvey (1 April 1578 3 June 1657) and others realized that the blood system is not open. They observed that the heart septum is tight and closed and thereby precludes any option of fluid exchange between the two tubing systems. They also discovered valves in the veins but not in the arteries and thereby discriminated the two different systems. Interestingly their circulation model was accepted generally only after lenses and microscopes were developed and allowed to visualize the microvasculature and their connections throughout the body. Although Galenus, Hippokrates, and their contemporary colleagues were wrong with their assumption of an open blood system rather than a circulation, they correctly referred to the importance of arteries and veins for the regulation and maintenance of body homeostasis.

The closed circulation model (shared by all vertebrates) adds complexity to the model of Galenius by not allowing the blood components to leave freely into the extravascular space of organs.

Xavier Bichat and Wilhelm His attempted to map all membranes of the human body and specifically focused on developmental stages. The formation of cavities in the differentiating mesodermal tissues resulted in inner "membranes", which could not be called epithelia since they formed the inner rather than outer surfaces. Therefore they termed these membranes "endothelia" (His 1865). Later Waldeyer (Waldeyer 1900) excluded all the other "thelia" derived from the mesoderm which do not develop into the innermost layer of blood and lymp vessels (and the posterior lining of the cornea). Later electron microscopy studies (Hibbs et al. 1958; WEIBEL \& PALADE 1964) showed variation in the structure and function of capillaries and arterioles. The endothelium adapts structure and function site specifically to the niche it is residing in. When removed from their native niche either by vessel transplantation or by in vitro culture, endothelial cells 
(ECs) undergo phenotypic drift (Sandow \& Grayson 2009) and lose many of their original properties and acquire new ones, depending on the signals they are receiving.

ECs develop from the mesoderm and are the driving force in vascular development and maintainence as well as reactants to exceptional situations. Both endothelial progenitor cells and differentiated endothelial cells drive vasculogenesis, i.e. the formation of new blood vessels during embryonic development, and in later life revascularization and angiogenesis, i.e. the expansion of blood vessels. These processes directly influence organ development which in turn feeds back to the specialization and fine tuning of EC's according to their niche (Weinstein 2002; Nikolova \& Lammert 2003; Park et al. 2013). Once the blood vessel is completely formed, angiogenesis and vasculogenesis are shut down. The ECs are then maintaining the vessel by lining the lumen and forming a smooth surface containing heparan sulfate and other proteoglycans which inhibit coagulation and thrombogenesis by activating antithrombin (Teien et al. 1976; Marcum \& Rosenberg 1984; Shimada \& Ozawa 1985). Further the ECs are crucially involved in blood pressure regulation by inducing vasodilation in response to acetylcholine and other vasoactive hormones (Chand \& Altura 1981).

ECs also play a central role in the immune system (Pober \& Sessa 2007). Of particular importance, the endothelium regulates the migration of leukocytes from the blood into the tissue (Wautier et al. 1990). To do this, the endothelium actively allows binding of leukocytes to endothelial cells by receptors, which elicit opening of intercellular junctions and thereby allow blood borne cells to pass the endothelial monolayer into the tissue or subendothelial space.

The protein family of tetraspanins associate with several transmembrane proteins forming microdomains involved in intercellular adhesion and migration. Intercellular adhesion molecule-1 (ICAM-1) and vascular cell adhesion molecule-1 (VCAM-1) act as receptors mediating leukocyte adhesion and transendothelial migration (Barreiro et al. 2005; Barreiro et al. 2008) in which also the endothelial glycokalyx is playing an important function (Mulivor \& Lipowsky 2002).

The barrier as such is therefore an active and highly regulated function exerted by the endothelium.

\subsection{The endothelium as an active barrier}

The endothelium is a very dynamic and selective barrier and its permeability is highly regulated under physiological and pathological conditions. The integrity of the monolayer 
depends on the cytoskeleton and cell-cell interaction complexes as well as the interaction with the extracellular matrix on both the basolateral and luminal sides of the vessel. Adherent junction complexes separate the basolateral and luminal plasma membranes. They hinder uncontrolled movement and mixture of these two membranes and thereby trigger the polarization of the ECs and establish the closed monolayer.

During development the triade of cerebral cavernous malformation 1 (CCM1), VE-cadherin and Rap1 define the vascular lumen and polarization of ECs (Lampugnani et al. 2010). The selectivity of the endothelium is regulated in three layers: First, the extracellular matrix consisting of a thick complex glycokalyx (Ebong et al. 2011) directly exposed to the blood flow; second, the endothelial cells forming a tight monolayer with cell-cell junctions; and third, the basal matrix and together with the intima. The glycokalyx is a steric filter (Levick \& Michel 2010) as well as an interaction platform for a variety of enzymes, which modulate and interact with other molecules in the blood stream.

The endothelial cell monolayer enables the fast and highly flexible modulation of permeability. For allowing anything to pass the endothelium, the ECs have either to open membrane channels, or disassemble adherent and tight junctions or to take up the molecule by endocytosis for intracellular transport and secretion on the basolateral site. Channels - for example aquaporins - allow transport through the luminal and basolateral plasma membranes (Levick \& Michel 2010). Paracellular transport - for example of monocytes - is regulated by opening and closing of tight and adherence junctions. Finally vesicles allow transcellular transport of cargo between the luminal and basal plasma membranes.

\subsection{Endocytosis}

Every cell has the ability to take up material from the environment or niche it is residing in. Uptake mechanisms have developed several times during evolution so that a variety of independent and sometimes redundant mechanisms have emerged. Phagocytosis describes the uptake of entire organisms, for example bacteria by macrophages. Pinocytosis is a receptor-independent pathway resembling to drinking of surrounding liquids. Endocytosis is the uptake of extracellular molecules into intracellular vesicles by receptor membrane domains of protein complexes. As the general principle, the cargo is engulfed into a vesicle, which is pinching off from the plasma membrane.

Clathrin coated vesicles were the first distinct structures detected by EM (Friend \& Farquhar 1967) and classified as such (Pearse 1976). The process of clathrin dependend endocytosis was studied in detail and led to the idenfitication of adapter proteins (Pearse 
\& Robinson 1984) which bridge the clathrin coat to the receptor or platform binding the cargo (Sorkin 2004).

All other endocytotic events are primarily classified as clathrin-independent. However, it is much more difficult to address them, since unlike clathrin coats they cannot be distinguished by EM and since the cell has hundreds of different vesicular machineries which we are still beginning to understand. Caveolae (Yamada 1955; Palade \& Bruns 1968) were early observed by shape, but it took some time to identify the most prominent proteins associated with them, the Caveolins Cav1, Cav2, and Cav3 (Rothberg et al. 1992) and even longer to identify their origin in the plasma membrane and thereby their involvement in endocytosis (Schnitzer et al. 1995; Schnitzer et al. 1996). The albumin receptor GP60 was identified as the first one mediating cav1 dependent endocytosis (Vogel et al. 2001). Only recently the first "adapter protein" in the cav1 dependent endocytotic pathway was unrevealed. KIF13b recruits the LDL receptor like protein 1 (LRP1) into caveolae for association with cav1 and uptake of LDL (Kanai et al. 2014). Dynamin 1 is needed to pinch off both clathrin-vesicles and cav1 vesicles from the plasma membrane, whereas dynamin 2 contributes to plasma membrane invaginations involved in fluid-phase micropinocytosis (McClure \& Robinson 1996; Sweitzer \& Hinshaw 1998; Cao et al. 2007). There are also clathrin and dynamin independent carriers (CLICs) (Kirkham et al. 2005), which may end up into glycosyl phosphatidylinositol-anchored proteins enriched in early endosomal compartments.

With some exceptions (for example diphtheria toxin) the cholesterol content of the plasma membrane is an important determinant of endocytosis by modulating membrane fluidity (Skretting et al. 1999). Furthermore, some GTPases like CDC42, RhoA or ARF6 (Schweitzer et al. 2009; D'Souza-Schorey \& Chavrier 2006) regulate endocytosis of some cargo by recruitment of coat proteins, modulation of lipid composition and actin filament formation at the plasma membrane. Only recently has been shown that the ARF6 exchange factor (EFA6) interacts directly with endophilin at the plasma membrane to modulate clathrin-mediated endocytosis (Boulakirba et al. 2014).

\subsection{Targeted sorting inside eukaryotic cells}

Once internalized, the cargo is transported within a vesicle, which either fuses with a target membrane for the release of the cargo or hands the cargo over to another acceptor. The specificity of a trafficking route through the cell is organized in a modular set-up. Vesicles contain complexes, which associate with dyneins or kinesins to transport the vesicle along microtubules either towards or away from microtubule organizing centers or 
centrosomes. On the way across the cell they encounter different membranes, which they may or may not interact with.

The membrane identification and interaction is mediated by GTPases of the Rab/Arf, Ral and Rho family (Zerial \& McBride 2001). The Rabs define the identity of a membrane. About 70 different Rabs exist in mammalian cells. Some of them are tissue and cell specific others are more ubiquitously expressed. Structure and recruited binding partners of different Rab-complexes are known (Khan \& Ménétrey 2013).

The control of fusion of a membrane with another is triggered by SNARE (Soluble Nethylmaleimide-sensitive factor attachment protein receptor) proteins about 60 of which are expressed by mammalian cells. The SNAREs facilitate fusion. When two opposing membranes meet with the correct vesicle-SNARE (v-SNARE) and target-SNARE (tSNARE) they form together with the SNAP25 protein the fusion initiation complex (WalchSolimena et al. 1995; Jahn \& Scheller 2006; Hong \& Lev 2014). By its own conformational change, this complex is then aiding the two membranes to undergo the conformational changes needed for the fusion of the two membranes. This process is calcium dependent but it is yet not clear how exactly it happens, as modeling of membrane fusions is difficult. Since the $t$ - and v-SNARE nomenclature is purely functional, most of the SNAREs are now classified by their structural identity ( $r$-SNARE, q-SNARE for arginine or glutamine critically involved in complex assembly). Alternatively they are classified by historical family names, for example the syntaxins in mammals).

\subsection{Exocytosis}

For exocytosis, Rabs and SNAREs control the targeting of vesicles to the plasma membrane for fusion as described before. Rab3 is directly involved in exocytotic/secretory events in neurons (Fischer von Mollard et al. 1994). Syntaxin4 and SNAP23 clustering is needed for the fusion with the endothelial basolateral plasma membrane (Predescu et al. 2005). Exocytosis depends on the plasma membrane cholesterol content. Depletion of cholesterol is reducing exocytosis events whereas enrichment with cholesterol is restoring function (Rituper et al. 2012). When vesicles fuse with the plasma membrane, the excess material is recycled by bulk endocytosis. This maintenance of the plasma membrane lipid homeostasis links endocytosis and exocytosis. An exception is the so-called just kiss-nrun membrane fusion: after release of the cargo the vesicle dispatches entirely from the plasma membrane. 


\subsection{Transcytosis}

Any transcellular transport of molecules is termed transcytosis. In general, transcellular transport is not well understood although the term was already used 31 years ago in the literature to describe transcellular transport in thyroid epithelia (Herzog 1983).

Williams et al showed for the first time that isolated endothelium is useful to study transcytosis of albumin since it reaches a steady state of balancing endo- and exocytosis after 40 minutes (Williams et al. 1984).

The transcytosis of albumin was studied by thin frozen section electron microscopy of gold-labelled monomeric albumin perfused through murine lung, heart endothelium and diaphragm (Milici et al. 1987; Ghitescu et al. 1986). Monomeric albumin was found to bind with low affinity to the luminal surface of the capillary endothelium. After transport in plasmalemmal vesicles it appeared in the pericapillary space less than $15 \mathrm{~s}$ after starting perfusion. The gold-albumin was limited to some microdomains within plasamalemmal structures. This indication that albumin is transported by a receptor mediated mechanism was later proven by the identification of gp60(Vogel et al. 2001).

Endothelial transcytosis of low density lipoproteins (LDL) was studied extensively by the Simionescu lab. The uptake and transport of LDL was visualized and quantified by electron microscopy identifying the dual route of traffic and transcytosis (Vasile et al. 1983). Their findings in the lung alveolar capillary endothelium indicated that LDL is taken up both by a receptor-mediated mechanism into clathrin-coated pits and a receptor independent process involving the direct formation of plasmalemmal vesicles, which they named "fluid endocytosis". They stated, that both mechanisms deliver LDL to lysosomes for cellular cholesterol supply but that in addition the majority of LDL is transcytosed through the endothelial cells to be delivered to other cells in the vessel wall. (Nistor \& Simionescu 1986)

Kishimoto et al studied the hepatic trafficking of the Fe-Transferrrin complex and revealed that the liver first transcytoses the Fe-Trf complex through its endothelium before uptake into hepatocytes (Kishimoto \& Tavassoli 1987). Transcytosis is also the process by which proteins are shuttled from the circulation across the blood-brain-barrier (BBB) as has been firstly shown for Fe-Trf (Fishman et al. 1987).

Transcytosis of molecules across the BBB has been intensively studied to be exploited for drug delivery to the brain. There are attempts to couple the drug of interest to transferrin (Yan et al. 2013), colloidal particles (Tucker et al. 2012) or other means (Ghaffarian \& Muro 2013; Bell \& Ehlers 2014). Unfortunately, all these methods are not specific for the BBB. It will be important to understand how the endothelia of the different organs 
specifically regulate transcytosis. For the time being, these new drug delivery systems are ways vehicles to penetrate endothelia randomly.

\subsection{Lipoproteins}

The vascular circulation system is transporting the hydrophilic medium called blood. Within this aqueous environment hydrophobic molecules can be transported either by blood cells (erythrocytes, leukocytes and platelets) or complexed to amphiphilic structures. These complexes are called lipoproteins. They contain apolipoproteins, which easily associate themselves with phospholipids. These amphiphilic complexes can accommodate even more hydrophobic lipids either on the surface (cholesterol) or core (triglycerides, cholesterol esters). Thereby conceptually the lipoproteins are platforms that enable the otherwise aqueous blood plasma to contain and distribute hydrophobic molecules.

Traditionally, the lipoproteins are classified by their buoyancy upon ultracentrifugation in defined density solutions. The more triglycerides they are carrying, the bigger they are and also the less proteins they have per total mass of particle. The cutoff densities (Barter et al. 2003) and particle sizes (Sakurai et al. 2010) are descripted in Table 1 for the typical lipoproteins in humans. Higher resolution into subclasses has been reached by nuclear magnetic resonance spectroscopy, non-denaturing gradient gel electrophoresis, or density gradient ultracentrifugation.

Table 1: Human Lipoproteins

\begin{tabular}{|l|c|c|}
\hline & $\begin{array}{c}\text { Density cutoffs } \\
\mathbf{( g / m l )}\end{array}$ & $\begin{array}{c}\text { Particle diameter } \\
\mathbf{( n m})\end{array}$ \\
\hline Chylomicrons (CM) & $<0.95$ & $600-200$ \\
\hline Very low density lipoproteins (VLDL) & $0.95-1.006$ & $200-80$ \\
\hline Intermediate density lipoproteins (IDL) & $1.006-1.019$ & $80-30$ \\
\hline Low density lipoproteins (LDL) & $1.019-1.063$ & $25-18$ \\
\hline High density lipoproteins 2 (HDL2) & $1.063-1.125$ & $12-9$ \\
\hline High density lipoproteins 3 (HDL3) & $1.125-1.210$ & $9-7.7$ \\
\hline Very high density lipoproteins (VHDL) & $1.210-1.250$ & $7.7-7.0$ \\
\hline
\end{tabular}




\subsubsection{Apolipoproteins}

The major apolipoproteins are structural prerequisites to form lipoproteins, namely ApoA-I for HDL, ApoB100 for LDL and VLDL, and ApoB48 for chylomicrons (CM). The typical apolipoproteins (ApoA-I, ApoA-II, ApoB, AboC's and ApoE) - except apoB - have emerged from one ancestral gene during evolution and are characterized by the presence of multiple amphipathic alpha-helices and the absence or low-abundance of short betasheets. In addition to lipid solubilization they exert specific functions like receptor binding (ApoB and ApoE) and enzyme activation (ApoA-I and ApoC-II). In addition to the typical apolipoproteins other proteins (for example ApoM, ApoD, ApoH) associate with lipoproteins and exert specific functions within and beyond lipid transport and metabolism. For example apoM binds sphingosine-1-phosphate (Christoffersen et al. 2012). HDL's are particularly diverse with more than 85 different proteins being associated with (Shah et al. 2013).A brief overview of the main functions of human apolipoproteins is given in Table 2.

Table 2: Lipoprotein associations and main functions of apolipoproteins

\begin{tabular}{|l|c|l|l|}
\hline Apoprotein & Mw (kDa) & localization & Function \\
\hline ApoA-I & 28 & HDL & $\begin{array}{l}\text { Formation of HDL, interaction with HDL } \\
\text { binding proteins (ABCA1, SR-BI), activation } \\
\text { of Lecithin:cholesterol acyltransferase } \\
\text { (LCAT) }\end{array}$ \\
\hline ApoA-II & 17.4 & HDL & Enhances hepatic lipase activity \\
\hline ApoA-IV & 46 & CM, HDL & $\begin{array}{l}\text { Protection of lipids from oxidation, activation } \\
\text { of LCAT, assembly of CMs }\end{array}$ \\
\hline ApoAV & 39 & HDL, VLDL, & $\begin{array}{l}\text { Facilitates the lipolysis of triglyceride rich } \\
\text { lipoproteins by LPL }\end{array}$ \\
\hline Apo B48 & 241 & CM & Assembly and secretion of CM \\
\hline Apo B100 & 512 & LDL, VLDL & Formation of VLDL and LDL, binds to LDL \\
receptor
\end{tabular}




\begin{tabular}{|c|c|c|c|}
\hline ApoC-III & 8.7 & VLDL, CM & Inhibits LPL \\
\hline Apo D & 33 & HDL & $\begin{array}{l}\text { Associated with LCAT, progesterone } \\
\text { binding }\end{array}$ \\
\hline $\begin{array}{l}\text { Apo E (3 } \\
\text { isoforms) }\end{array}$ & 34 & HDL & Binds to LDL receptor \\
\hline Apo(a) & $300-800$ & LDL, Lp(a) & $\begin{array}{l}\text { Linked by disulfide bond to apo B100 and } \\
\text { similar to plasminogen }\end{array}$ \\
\hline Apo H & 38.3 & $\begin{array}{l}\text { HDL, CM, } \\
\text { unclear }\end{array}$ & Binds cardiolipin, modulates coagulation \\
\hline $\begin{array}{l}\text { Apo J } \\
\text { (clusterin) }\end{array}$ & 40 & $\begin{array}{l}\text { blood } \\
\text { plasma, milk, } \\
\text { urine, CSF, } \\
\text { semen, found } \\
\text { on HDL, } \\
\text { unclear if } \\
\text { others }\end{array}$ & $\begin{array}{l}\text { Binds immunoglobins, heparin, complement } \\
\text { proteins, paraoxonase, lipids, various } \\
\text { functions suggested }\end{array}$ \\
\hline $\begin{array}{l}\text { Apo L } \\
\text { (family with } \\
7 \text { proteins) }\end{array}$ & & HDL & Trypanolytic factor \\
\hline $\begin{array}{l}\text { Apo M (2 } \\
\text { isoforms) }\end{array}$ & $21.3 / 13$ & HDL, LDL & $\begin{array}{l}\text { Isoform 1: binds sphingosine-1-phosphate } \\
\text { Isoform 2: unclear }\end{array}$ \\
\hline
\end{tabular}

\subsubsection{Lipoprotein metabolism}

Dietary lipids are absorbed by the epithelium of the small intestine, where they are assembled with ApoB48 and ApoE to form CMs. They are released into the lymph. In addition CMs carry ApoC-II, which activates lipoprotein lipase (LPL) to hydrolyse the triglycerides into free fatty acids and glycerols for uptake and usage by the adipose tissue and skeletal and cardiac muscle and for energy storage or production. The remnants of the CMs are removed from the circulation by the liver. ApoE plays a key role for efficient endocytosis of remnants by hepatic LDL receptor and LRP1 (Brown et al. 1981). At low exogenous supply of lipids during periods of fasting, the liver is the main source of lipogenesis and lipoproteins to the body. The liver produces VLDL, which contains 
ApoB100 in addition to ApoC-II, ApoC-III and ApoE. As in CMs, LPL is hydrolyzing the triglycerides upon activation by ApoC-II on VLDL. By losing triglycerides and enrichment with cholesterol IDL and LDL are formed, which are then cleared by the liver through LDLreceptor mediated endocytosis.

\subsection{High density Lipoproteins}

The only way the body can get rid of excess cholesterol and other sterols is via the liver and bile. Here HDL is believed to play a crucial part as the transporter of cholesterol from the periphery back to the liver by a mechanism termed the reverse cholesterol transport (RCT) (Norum et al. 1983; Rothblat et al. 1986). However, the HDL cholesterol concentration does not reflect the amount of cholesterol undergoing RCT (Hellerstein \& Turner 2014). Infusions of artificial HDL increased the fecal excretion of sterols.

Besides just removing cholesterol from macrophage foam cells, HDL plays important roles in the redox state of plasma (Yin et al. 2013; Kelesidis et al. 2012), the modulation of inflammation (Tabet \& Rye 2009; De Nardo et al. 2013; Barter et al. 2004; Navab et al. 2005) as well as the removal of lipopolysacherides and other endotoxins (Ma et al. 2004). For the mediation of cholesterol efflux from macrophages and the delivery of cholesterol to hepatocytes but also for various cytoprotective effects, HDL has to cross the endothelium.

\subsubsection{The multitude of potential ApoA1 and HDL receptors}

Receptors for HDL were searched in different cells by different approaches. In one, a protein-A-ApoA-I fusion protein was expressed in Escherichia coli and revealed high affinity binding to a $110 \mathrm{kDa}$ cell surface protein (Bond \& Howell 1987). The authors further indicated that the ApoA-I portion of HDL is responsible for the binding to this cell surface protein which was also postulated to be expressed in hepatocytes (Rifici \& Eder 1984).

Two $110 \mathrm{kDa}$ and $130 \mathrm{kDa}$ proteins were found by ligand blot analysis (Hokland et al. 1992) to bind HDL. Both seem to be glycosylated. A $95 \mathrm{kDa}$ protein was identified (Bocharov et al. 2001) which binds HDL with high affinity and resides mainly inside cells since trypsin treatment of cells affect its binding to HDL only by minor degree. Further deglycosylation of the hepatocytes used in the study did not abolish the binding implicating that glycosylation is not required for the binding to HDL. Interaction of HDL with ECs has been studied now since tree decades without yet having a satisfactory model. It has been observed that ECs bind and internalize HDL differently to LDL. HDL is not degraded like LDL. Furthermore the binding of HDL can be partially 
competed by LDL indicating that binding sites are either overlapping or shared (Tauber, Goldminz \& Gospodarowicz 1981; Tauber, Goldminz, Vlodavsky, et al. 1981).

\subsubsection{SR-BI}

SR-BI was found in Chinese hamster ovary $(\mathrm{CHO})$ cells to work as a scavenger receptor for HDL (Krieger 1999; Acton et al. 1996) in addition to LDL, VLDL and a variety of ligands such as modified (acetylated or oxidized) lipoproteins, maleylated bovine serum albumin, advanced glycation end-product modified proteins, anionic phospholipids, and apoptotic cells (Rigotti et al. 2003). It was later verified, that SR-BI is responsible for uptake of HDL into $\mathrm{CHO}$ cells (Rhode et al. 2004).

The selective cholesterol and cholesterol ester transport into hepatocytes independently of particle uptake is the classical function mediated by SR-BI. Cysteine residues in the outer loop of SR-BI are crucial for doing so (Papale et al. 2011). Furthermore the N-terminal SR$\mathrm{BI}$ contains a glycine dimerization motif essential for lipid transport (Gaidukov et al. 2011). SR-BI also contributes to cholesterol efflux by binding cholesterol and inducing signaling via the c-terminal PDZ-interacting domain (Assanasen et al. 2005; Kocher \& Krieger 2009). The PDZK signaling of HDL via SR-BI has been shown as one of the key factors for maintenance of the endothelial monolayer (Zhu et al. 2008).

$\mathrm{SR}-\mathrm{BI}$ is functioning as a cholesterol sensor for the plasma membrane and regulates thereby efflux and signaling (Saddar et al. 2013).

Eckhardt et at showed that the second isoform of SR-BI (SCARB1.2) is also binding and internalising HDL (Eckhardt et al. 2004). This splice variant has a dileucine motif, in which the C-terminus is responsible for interaction with clathrin indicating that the internalization is at least partially clathrin dependent (Eckhardt et al. 2006).

In addition, HDL binding to SR-BI (probably SCARB1.1 only) stimulates the endothelial nitric oxide synthase (eNOS, NOS3) which leads to NO dependent relaxation of the vessel and release of superoxide and other radicals by NO degradation (Yuhanna et al. 2001). Our laboratory identified SR-BI as a modulator of HDL uptake and transport through endothelial cells, (Rohrer et al. 2009b). Using siRNA knockdown, SR-BI was shown to play this role together with ABCG1. The mechanism, by which SR-BI is facilitating HDL holoparticle uptake into ECs is not resolved.

\subsubsection{CD36}

Originally CD36 was identified as the macrophage receptor for apoptotic cells in Drosophila, giving it the suitable name Croquemort (Franc et al. 1996; Franc 1999). 
As members of the same protein family CD36 and SR-BI are sharing high homology and architecture. Cholesteryl-ester uptake from HDL is mediated by both SR-BI and CD36 via binding of $\mathrm{HDL}$ to the extracellular domain but the $\mathrm{C}$-terminal domain of SR-BI enhances the efficiency of cholesteryl-ester uptake 7 fold compared to CD36 (Connelly 1999). OxLDL, also a ligand to both SR-BI and CD36 has been shown to be differently taken up and transported when internalized by the one or the other receptor (Sun et al. 2007).

\subsubsection{ABCA1}

ATP-binding cassette protein A1 (ABCA1) facilitates the transfer of free cholesterol and phospholipids to ApoA-I for the formation of HDL (Yokoyama 2005; Yokoyama 2006). It contains two intracellular nucleotide binding domains (NBD) which after binding of ApoA-I, hydrolyse ATP and thereby trigger conformational changes (Nagao et al. 2012). The cterminus of ApoA-I is essential for specific binding to ABCA1 (Ohnsorg et al. 2011). It has been shown that $A B C A 1$ activity creates 2 types of apoA-I binding sites at the cell surface. Low capacity binding involves the direct apoA-I/ABCA1 interaction and exerts regulatory effects. The much higher capacity site generated involves apoA-I/lipid interactions and leads to the assembly of nascent HDL particles (Vedhachalam et al. 2007).

The association of apoA-I with lipids reduces its ability to interact with ABCA1 (Denis et al. 2004). During generation of HDL, lipid free ApoA-I is lipidated and stabilizes ABCA1 to support this via feedback regulation. Weakly lipidated small HDL are still acceptors for cholesterol and lipids from ABCA1 (Favari et al. 2009). Mature, spherical HDL only under certain conditions or modifications HDL can be recognized by ABCA1. For example, lipid rich spherical HDL with lipidated apoproteins which are oxidized ex vivo by peroxidasegenerated tyrosyl radical can behave like lipid-free apoA-I to increase ABCA1 protein levels and activity (Hossain et al. 2012).

The interaction of lipid free ApoA-I with ABCA1 is impaired, if ApoA-I is oxidized by myeloperoxidases (Shao et al. 2010; Shao 2012).

Binding of lipid-free and lipid-poor ApoA-I to ABCA1 induces the autophosphorylation of the Janus kinase 2 (JAK2) which leads to the phosphorylation of signal transducer and activator of transcription 3 (STAT3) to translocate into the nucleus to initiate anti-apoptotic and anti-inflammatory signals (Liu \& Tang 2012).

The lipidation of ApoA-I by interaction with $A B C A 1$ in macrophages generates an interaction partner for another ABC-transporter, namely ABCG1 (Lorenzi et al. 2008). As in macrophages, this cascade enhances cholesterol efflux in endothelial cells. This two 
steps contribute to transcytosis of ApoA-I (Cavelier, Rohrer, et al. 2006; Ohnsorg et al. 2011)

Traditionally the interaction of ApoA-I with $A B C A 1$ is thought to happen on the cell surface. However, it has been suggested that lipid efflux takes place inside vesicles intracellular via retro-endocytosis. According to this model, ApoA-I is taken up by cells in a ABCA1 and clathrin dependent manner as it is found in Rab5 endosomes and then Rab4 dependently exocytosed again (Azuma et al. 2009).

\subsubsection{ABCG1}

$A B C G 1$ belongs to a different class of $A B C$ transporters. In contrast to $A B C A 1$ it is a half transporter that needs to (homo)dimerize to be active. Moreover it interacts with lipidated HDL particles rather than with lipid free ApoA-I. It functions mainly as an intracellular sterol transporter (Tarling \& Edwards 2011; Tarling 2013). It has been found that the dimer of ABCG1/ABCG4 is involved in cholesterol transport to HDL (Wang et al. 2008; Cavelier, Lorenzi, et al. 2006) although this would contradict the more recent works of Tarling and Edwards. Its knockdown in ECs results in a modulation of HDL binding, cell association and transport (Rohrer et al. 2009b) by probably indirect means which are still to be resolved.

\subsubsection{F1-ATPase}

In hepatocytes and endothelial cells, the plasma membrane localized F1-ATPase was identified to bind ApoA-I (Radojkovic et al. 2009; Vantourout et al. 2010) and facilitate HDL endocytosis via RhoA/ROCK1 signaling (Malaval et al. 2009; Esteve et al. 2003). In endothelial cells it was identified to bind ApoA-I and thereby hydrolyse ATP to ADP which then further signals via P2Y receptors to modulate lipidated ApoA-I and HDL uptake and transcytosis through the endothelium (Cavelier et al. 2012).

\subsubsection{GPI-HBP1}

Glycosylphosphatidylinositol-anchored High Density Lipoprotein-binding Protein 1 (GPIHBP1) was isolated by expression cloning of a murine hepatic cDNA library as a receptor for HDL in $\mathrm{CHO}$ cells (loka et al. 2003). Although originally identified as an HDL binding protein, GPI-HBP1 of capillary endothelial cells was found to bind lipoprotein lipase (LPL) in the subendothelial space for transcellular transports to the capillary lumen (Gin et al. 2011; Young et al. 2011). Furthermore it is stabilizing LDL and prevents its inhibition by angiopoietin-like 3 and angiopoietin-like 4 (Sonnenburg et al. 2009). 


\subsubsection{Endothelial Lipase}

Endothelial lipase (EL) hydrolyses phospholipids and thereby converts larger HDL into smaller HDL particles (Jahangiri et al. 2005). EL was also shown to to mediate the cellular binding and uptake of HDL independently of its enzymatic activity via a heparan sulfate proteoglycan-mediated pathway (Fuki et al. 2003). Interleukin 6 stimulates EL expression and thereby the transendothelial transport of HDL (Robert et al. 2013).

\subsubsection{Cubilin/Megalin}

Cubilin is a modular endocytic receptor which works together with Megalin (LDL receptor related protein 2 - LRP2) especially in renal proximal tubules for uptake of albumin (Zhai et al. 2000) ApoA-I and HDL (Hammad 2000) which would otherwise be lost to the body. Cubilin deficiency reduces renal recovery of albumin as well as ApoA-I, decreasing their blood levels (Aseem et al. 2013). In addition to the reabsorbtion, the cubilin-megalin complex has been shown to play a crucial role as an HDL receptor during development. Disruption of cubilin is lethal. Mutant mouse embryos develop uncomplete somites and endoderm and also fail to absorb and transport maternal HDL to the embryo (Smith et al. 2006). Further alveolar cells type 2 take up HDL via the cubilin-megalin system (Kolleck et al. 2002). During the development the endothelium expresses megalin but not cubilin (Drake et al. 2004). However it is not yet clear if the two receptors have any function in the mature endothelium.

\subsubsection{ApoA-I and HDL in Atherosclerosis}

Atherosclerosis is characterized by progressive accumulation of lipids in the arterial intima leading to plaque formation. The plaque consists not only of free cholesterol chrystals and agglomerated proteins such as oxidized ApoA-I (Didonato et al. 2013) but also macrophages which are recruited to the intima to remove the extracellular cholesterol. Epidemiological studies show an inverse association of HDL cholesterol with cardiovascular events. However the causality of this relationship is controversially disputed. Raising HDL concentrations by blocking cholesteryl ester transfer protein inhibition failed to lower the risk of cardiovascular events (Schwartz et al. 2012). It has hence been argued that low HDL cholesterol is only a bystander of another proatherogenic condition notably hypertriglyceridemia. Alternatively, HDL cholesterol measurements are not sufficient to explain the anti-atherogenic properties of HDL, which may vary in different disease states.

Classically HDL has been postulated to be key carrier and acceptor of cholesterol (Rothblat et al. 1986; Marcel et al. 2008; Hellerstein \& Turner 2014). It is removing the 
cholesterol from plaques of the intima. In addition, HDL was found to exert many antiinflammatory, anti-oxidative and anti-thrombotic as well as many vasoprotective activities. Many of these activieis are exerted in the vascular wall rather than in the plasma. Therefore HDL has to pass the endothelium of blood (Rohrer et al. 2009a) and lymphatic vessels (Lim et al. 2013; Martel et al. 2013) to get into contact with the cholesterol loaded macrophages in the intima and plaque.

\subsection{Need for a method to visualize $1.4 \mathrm{~nm}$ nanogold in HPF-FSF electron microscopy}

Intracellular trafficking is of major importance for both the metabolism and function of lipoproteins. In particular, relatively small HDL and LDL can be tracked neither by light nor by electron microscopy without labeling. For bright field and fluorescence microscopy, a variety of tracers has been established for the detection of lipoproteins within cellular compartments of interest. Potential impact of these tracers on the outcome is negligible since their size is usually below the spatial resolution of diffraction limited light microscopes. However, the enhanced resolution of electron microscopy (EM) and super resolution nanoscopy has the power to make the effects of the label visible.

The risk of interference of biological properties by the ligand increases with its size. Bare colloidal gold particles are phagocytosed and pinocytosed (França et al. 2011) and are known to self-aggregate and thereby to appear clustered rather than as single particles. These interferences might become a serious issue, especially when the cellular itinerary of interest is little characterized or ligand-receptor interactions are weak. Colloidal gold was used in a variety of traditional EM studies for following a number of proteins and gave insight into their trafficking (Handley et al. 1981; Morris \& Saelinger 1984; Kikuta \& Rosen 1994; Sawaguchi et al. 2001). The use of nanogold instead of the classical colloidal gold to label ligands for tracking studies (Morphew et al. 2008; Prescianotto-Baschong \& Riezman 2002) may prevent unwanted effects. However, the small size of nanogold limits its direct detection by EM. Silver (Stierhof et al. 1991; Danscher 1981) and gold (Pohl \& Stierhof 1998) based enhancement methods were developed for the use in immuno-EM detection of antibodies on the surface of thin sections of embedded samples. However, the accessibility of nanogold for silver enhancement is limited to gold particles exposed at the surface of a section and leaves the nanogold within the section unaffected. Therefore, it is essential to enhance nanogold in the entire sample to benefit from novel threedimensional EM technologies such as ion beam scanning EM (FIB-SEM) or automated ultrathin sectioning in scanning EM (SEM). Slam freezing or high pressure freezing (HPF) 
are state of the art techniques to stop biological processes quickly while preserving the ultrastructure without generating ice crystals (Kellenberger 1991; Sartori et al. 1993). However, nanogold enlargement with silver or gold after HPF and FSF processed and embedded samples using classical methods results in very low detection rates and high background due to self-nucleation of the enhanced material.

Recently, two methods were developed for the enhancement of small gold particles in the whole volume of chemically fixed and freeze substituted samples after HPF (He et al. 2007; Morphew et al. 2008). However, these methods require several days of incubation in acetone at $-60^{\circ} \mathrm{C}$ during freeze substitution, several washing and handling steps, as well as the use of water and methanol (Morphew et al. 2008). 


\subsection{Aims of this Thesis}

High density lipoproteins (HDL) and their main protein constituent, apolipoprotein A-I (ApoA-I), are known to be atheroprotective. According to the reverse cholesterol transport (RCT) model, HDL removes cholesterol from the vessel wall to the liver for recycling or excretion.

However it is unclear how HDL passes the endothelium to reach and leave the intima. The understanding of these pathways may advance our knowledge on the pathogenesis of atherosclerosis and open avenues for treatment and prevention. Our lab has previously shown that transendothelial transport of ApoA-I and HDL is a regulated and specific process involving the activities of ABCA1 (Cavelier, Rohrer, et al. 2006), F1-ATPase (Cavelier et al. 2012), ABCG1, SR-BI (Rohrer et al. 2009b) and EL (Robert et al. 2013). However on the spatial level, neither the interactions of ApoA-I or HDL with these proteins nor the intracellular itinerary of $\mathrm{HDL}$ and $\mathrm{ApoA}-\mathrm{I}$ have been resolved yet.

To this end, my thesis addresses the following questions:

- What is the trafficking route of HDL/ApoA-I in endothelial cells?

- What are the subcellular localization and HDL/ApoA-I interaction sites of ABCA1, ABCG1, SR-BI and EL in endothelial cells? 


\section{Materials and methods}

\subsubsection{Cell culture}

Primary Bovine Aortic Endothelial cells (EC) were cultured in Dulbecco's modified eagle's medium (DMEM) with $5 \%$ fetal bovine serum at $37^{\circ} \mathrm{C}$ in $5 \% \mathrm{CO} 2$ and passaged every $7-8$ days $1: 1$. A $10 \mathrm{~cm}$ cell culture treated petri dish was populated with $2.5-3 \times 10^{6}$ cells. Cells were pelleted for freezing by centrifugation at $200 \mathrm{~g}$ for 5 minutes at room temperature (rt). The pellets were gently resuspended in vials of $0.5 \mathrm{ml}$ per $3 \times 10^{6}$ cells in the freeze mix solution consisting of the growth medium supplemented with $10 \%$ DMSO. Freezing of stocks to liquid nitrogen storage was performed in isopropanol containing nalgene boxes at $-80^{\circ} \mathrm{C}$ starting from room temperature (rt). Thawing of cells was performed by immediately heating up the cryo vial to $37^{\circ} \mathrm{C}$ for 2 minutes and then transferring the contents gently to a new $10 \mathrm{~cm}$ petri dish containing $10 \mathrm{ml}$ of growth medium, which was exchanged after the cells adhered to the surface to remove the DMSO.

\subsubsection{Preparation and labeling of lipoproteins}

HDL and LDL were isolated from normolipidemic human plasma (blood bank of cantonal hospital Schaffhausen) by sequential ultracentrifugation following the protocol described by Tong et al (Tong et al. 1998) and stored at $4{ }^{\circ} \mathrm{C}$. Lipid free ApoA-I was generated by delipidation of HDL by ethanol-ether (Brown et al. 1969) and purification over an anion exchanger column (Mono-Q) on the Äkta FPLC (GE Healthcare). Qualitative purity control was performed by SDS-PAGE, coomassie-staining verifying the HDL and ApoA-I fractions to be void of visible albumin and $A p o B$ (LDL) bands.

Lipoproteins were labeled with $1.4 \mathrm{~nm}$ nanogold (Nanoprobes USA) or fluorescent Atto dyes obtained as succimidyl-ester (Atto-Tec, Germany) and set to $\mathrm{pH} 8.0$ by $1 \mathrm{M} \mathrm{NaHCO}_{3}$ to a final concentration of $0.1 \mathrm{M}$. The reaction was performed in the dark at room temperature for 2 hours. The labeled lipoproteins were separated from free label by gel filtration chromatography (Nap5 column GE).

\subsubsection{Lipoprotein uptake studies by fluorescence light (FLM) and electron microscopy} (EM)

For fluorescence light and electron microscopy experiments, collagen I coated transwell inserts (0.4 um low density, BD) or round Nr 1.0 glass coverslips (Metzler Glass / Thermo Fisher) of $12 \mathrm{~mm}$ diameter were seeded 48-96 hours before the experiments with 10'000 
cells per 24 well insert and coverslip, respectively. To analyze the subcellular distribution, the labeled lipoproteins were added to the cells for 30 minutes at $37^{\circ} \mathrm{C}$ in $5 \% \mathrm{CO} 2$ if not otherwise indicated followed by rinsing with ice cold PBS++ (PBS 7.4 with $1 \mathrm{mM} \mathrm{CaCl}_{2}$ and $0.1 \mathrm{mM} \mathrm{MgCl}_{2}$ ). For binding experiments, the cells were incubated at $4{ }^{\circ} \mathrm{C}$ in a humidified closed box. Subsequently, cells were either chemically fixed for fluorescence microscopy or high pressure freezing (HPF) for EM analysis.

\begin{tabular}{|c|c|c|c|}
\hline Epitope & Antibody & Dillution & Company \\
\hline $\begin{array}{l}\text { 58kDa Golgi } \\
\text { Protein }\end{array}$ & $\begin{array}{c}\text { m-58kGolgi ab27043 } \\
58 k-9\end{array}$ & $1: 400$ & Abcam \\
\hline ABCA1 & $\begin{array}{c}\text { m-ABCA1 ab18180 } \\
\text { AB.H10 }\end{array}$ & $1: 50$ & Abcam \\
\hline ABCG1 & $\begin{array}{c}\text { Rab-ABCG1 sc20795 } \\
\text { H65 }\end{array}$ & $1: 200$ & Santa Cruz \\
\hline Actin & betaActin AC15 & $1: 500$ & Sigma \\
\hline Calnexin & Rab-calnexin Sigma & $1: 400$ & Sigma \\
\hline Caveolin 1 & Rab-Cav1 ab2910 & $1: 250$ & Abcam \\
\hline CDC42 & m-CDC42 ab41429 & $1: 600$ & Abcam \\
\hline Clathrin & m-Clathrin ab2731 X22 & $1: 400$ & Abcam \\
\hline $\begin{array}{l}\text { F1F0 alpha } \\
\text { ATPase }\end{array}$ & m-F1F0alpha MS502 & $1: 800$ & Mitosciences \\
\hline $\begin{array}{l}\text { LIPG (endothelial } \\
\text { lipase) }\end{array}$ & Rab-EL nb400-111 A4 & $\begin{array}{l}1: 200, \\
\text { probably } \\
\text { offtarget } \\
\text { binding }\end{array}$ & Novus \\
\hline $\begin{array}{l}\text { LIPG (endothelial } \\
\text { lipase) }\end{array}$ & Rab-LIPG HPA016966 & $1: 500$ & $\begin{array}{c}\text { Sigma-Aldrich } \\
\text { (Human Protein } \\
\text { Atlas) }\end{array}$ \\
\hline Rab11a & Rab-rab11a ab65200 & $1: 500$ & Abcam \\
\hline Rab5 & Rab-rab5 ab13253 & $1: 400$ & Abcam \\
\hline Rab7 & Abcam XP anti Rab7 & $1: 800$ & Abcam \\
\hline Rab9 & m-rab9 ab2810 Mab9 & $1: 800$ & Abcam \\
\hline
\end{tabular}




\begin{tabular}{|l|c|l|c|}
\hline SR-BI & $\begin{array}{c}\text { Rab-srb1 ab3, } \\
\text { discontinued }\end{array}$ & $1: 500$ & Abcam \\
\hline SR-BI & Rab-srb1 ab24603 & $1: 200$ & Abcam \\
\hline SR-BI & $\begin{array}{c}\text { Rab-srb1 nb400-104 H6 } \\
\text { or M3 }\end{array}$ & $1: 400$ & Novus \\
\hline Syntaxin 6 & Abcam XP anti Stx6 & $1: 800$ & Abcam \\
\hline TJP1 & Rab-TJP1 HPA001636 & $1: 400$ & $\begin{array}{c}\text { Sigma-Aldrich } \\
\text { (Human Protein } \\
\text { Atlas) }\end{array}$ \\
\hline ZO1 & m-Z01 33-9100 & $1: 500$ & Novex \\
\hline
\end{tabular}

Table 3: Immunostaining Antibodies used

\subsubsection{Fixation for FLM}

Chemical fixation for FLM was performed with 3.75\% formaldehyde in PBS at room temperature (rt) for 20-30 minutes for monolayers of cells and one hour for $7-18 \mu \mathrm{m}$ thick cryosections of tissues. The free fixative was then quenched by a brief wash with 0.5 M TrisHCL 8.0 followed by two washes with PBS. Then either additional stainings were performed or the sample was embedded directly for microscopy.

\subsubsection{Indirect Immunostainings for FLM}

Coverslips or transwell inserts with fixed cells were preincubated with $0.1 \%$ saponin in PBS at pH 7.4 at rt for 15 minutes if permeabilisation was needed for antibody staining. The primary antibody was incubated for one hour at $\mathrm{rt}$ or $16 \mathrm{~h}$ at $4{ }^{\circ} \mathrm{C}$, the cells were then washed tree times with PBS and then incubated with the secondary antibody for $30-45$ minutes at $r$ in the dark. Antibody dilutions were made always in PBS with $1 \%$ Donkey Serum (Sigma Aldrich) and $5 \%$ BSA. Concentrations were determined beforehand using an antibody by trying 1:200 - 1:10000 dilutions.

\subsubsection{Preparation for FLM and image acquisition}

After all desired stainings had been done, the coverslips were directly mounted upside down on glass slides with ProLong Gold antifade solution (Life technologies, USA).

Transwells were cut out with a scalpel Nr11 from the bottom side and placed with the cells upwards between a glass slide and a 25x50 mm Nr 1.0 coverslip (Metzler Glass / Thermo Fisher) with a drop of ProLong Gold inbetween.

Images were acquired with a Hamamatsu ORCA-ER EMCCD camera (C4742) at full resolution and fixed exposure time of 10 to $800 \mathrm{~ms}$ to have the signal histogram of the 
(positive) control in the middle of the 12 bit sensitivity range of the chip and this exposure was kept throughout the acquisition session.

\subsubsection{High pressure freezing (HPF) and freeze substitution fixation (FSF) for EM}

The membrane of the transwell containing a monolayer of endothelial cells was punched out with a biopsy-punch of $5 \mathrm{~mm}$ diameter. The isolated membrane was carefully inserted into a $6 \mathrm{~mm}$ aluminium specimen carrier with an indentation of $100 \mu \mathrm{m}$, sandwiched with a flat carrier wetted with 1-hexadecene (Sigma Aldrich, $\mathrm{CH}$ ) and immediately high pressure frozen using an automated Leica EM HPM100 high pressure freezing machine (Leica Microsystems, Vienna, Austria). Samples were stored in liquid nitrogen until further processing.

HPF frozen discs containing membranes with cell monolayers were transferred to $2 \mathrm{ml}$ safe-lock Eppendorf tubes containing 1\% OsO4 at $-90{ }^{\circ} \mathrm{C}$. Substitution was performed in an automated substitution machine (Leica EM AFS) at $-90^{\circ} \mathrm{C}$ for $7 \mathrm{~h},-60^{\circ} \mathrm{C}$ for $6 \mathrm{~h},-30^{\circ} \mathrm{C}$ for $5 \mathrm{~h}$ and at $0{ }^{\circ} \mathrm{C}$ for $1 \mathrm{~h}$ with transition gradients of $30^{\circ} \mathrm{C}$ per hour.

\subsubsection{Silver enhancement}

The reagents (Sigma Aldrich, $\mathrm{CH}$ ) were prepared in individual tubes as saturated solutions of hydroquinone, malic acid, and silver nitrate in anhydrous acetone at room temperature. Arabic gum was dispersed in anhydrous acetone and shaken for one hour at room temperature. The Arabic gum dispersion was used to protect the colloid by inhibiting the self-nucleation of silver.

After slowly cooling the saturated solutions to $0^{\circ} \mathrm{C}$ during one hour, equal parts of all saturated solutions and the Arabic gum suspension were mixed at $0{ }^{\circ} \mathrm{C}$. The mixture was centrifuged at $300 \mathrm{~g}$ for $5 \mathrm{~min}$ at $4{ }^{\circ} \mathrm{C}$ to remove any precipitates and was always freshly prepared before use.

After FSF the samples were washed three times with anhydrous acetone and the enhancement mixture was added to the reaction tubes for 30 minutes. Afterwards, the treated samples were washed again three times with anhydrous acetone before embedding in epoxy resin. All steps were performed at $0^{\circ} \mathrm{C}$ on ice water. The classical on-section silver enhancement of gold particles was performed with freshly made solutions after Danscher et al. (Danscher 1981) or alternatively Aurion Gold SE-EM (Aurion, NL) as described by the supplier.

\subsubsection{Embedding and preparation for TEM and EM image acquisition}

Samples in anhydrous acetone were embedded in Epon/Araldite (EA) essentially as described by Hohenberg et al. (Luft 1961; Hohenberg et al. 1994) by incubating the 
samples in $33 \%$ and $66 \%$ EA in acetone for $8 \mathrm{~h}$ each prior to transfer in $100 \%$ EA and polymerization at $60^{\circ} \mathrm{C}$ for 40 hours.

Ultrathin cross sections of cells of $50 \mathrm{~nm}$ were cut with a $45^{\circ}$ diamond knife (Diatome)

using an ultramicrotome (Reichert) and put on Formvar coated single slot grids (Ted Pella inc. USA).

Images were acquired with a Philips CM100 or a FEI Tecnai G2 Spirit (FEI, Eindhoven, The Netherlands) at an acceleration voltage of $80 \mathrm{kV}$ or $120 \mathrm{kV}$ with a Gatan Orius 1000 camera (Gatan Inc. USA). 


\section{Results}

\subsection{Trafficking route of HDLApoA-I in endothelial cells}

To get insight into the itinerary of HDL and ApoA-I in endothelial cells, we labeled them with Atto488, Atto594 or Atto655 fluorescent dyes for fluorescence microscopy (FLM) and with $1.4 \mathrm{~nm}$ nanogold complexes for electron microscopy (EM).

\subsubsection{ApoA-I and HDL are binding to endothelial cells}

FI-ApoA-I and fl-HDL were added to monolayers of ECs on coverslips and incubated at 4 ${ }^{\circ} \mathrm{C}$, briefly washed and fixed with formaldehyde before mounting. Both apoA-I and HDL were bound by ECs (figures $1 \mathrm{~A}$ and $1 \mathrm{C}$ ). Of note, the binding pattern of fl-HDL (Figure 1 A) shows a more evenly diffused pattern than fl-ApoA-I (Figure $1 \mathrm{C}$ ). Moreover, fiber-like structures are detectable in the presence of fl-ApoA-I (Figure $1 \mathrm{C}$ ) but not fl-HDL (figure 1A). FI-HDL binding to ECs was extensively competed by a 100 fold excess of un-labelled HDL (Figure $1 \mathrm{~B}$ ). By contrast binding of fl-ApoA-I was only little competed by excess of HDL (Figure $1 \mathrm{D})$.
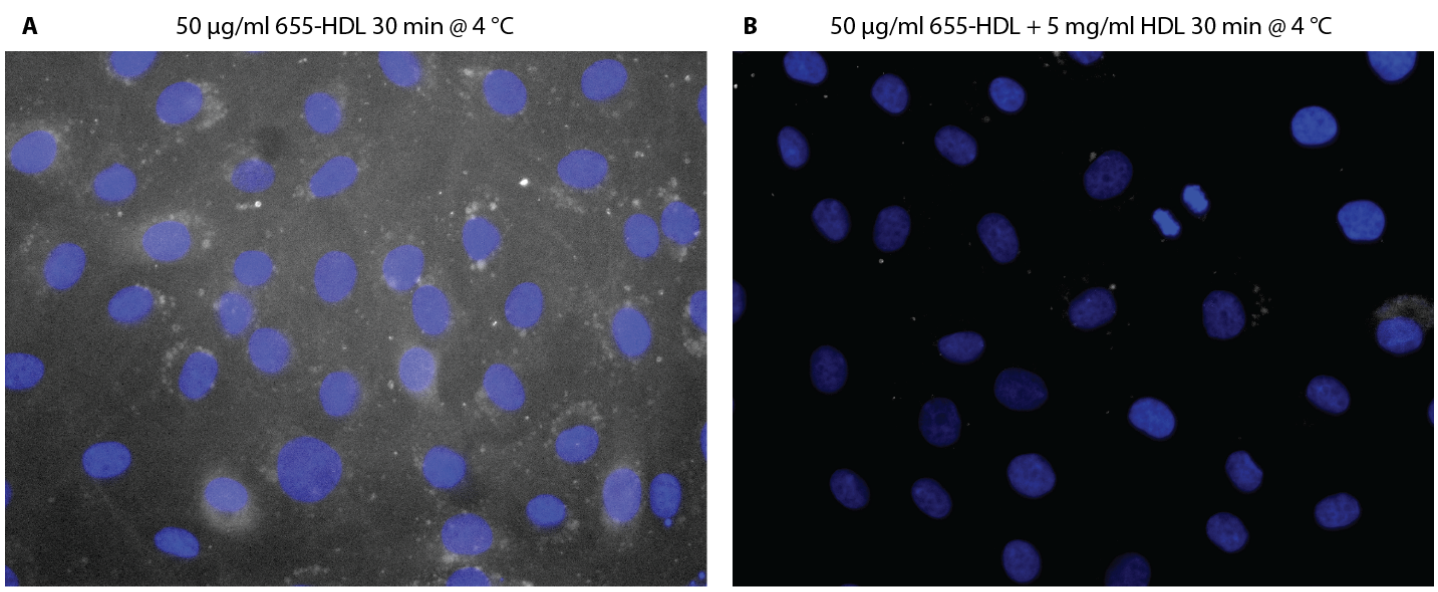

C

$50 \mu \mathrm{g} / \mathrm{ml} 488-\mathrm{ApoA}-\mathrm{I} 30 \mathrm{~min} @ 4^{\circ} \mathrm{C}$

D $\quad 50 \mu \mathrm{g} / \mathrm{ml} 488-A p o A-I+5 \mathrm{mg} / \mathrm{ml} \mathrm{HDL} 30 \mathrm{~min} @ 4{ }^{\circ} \mathrm{C}$
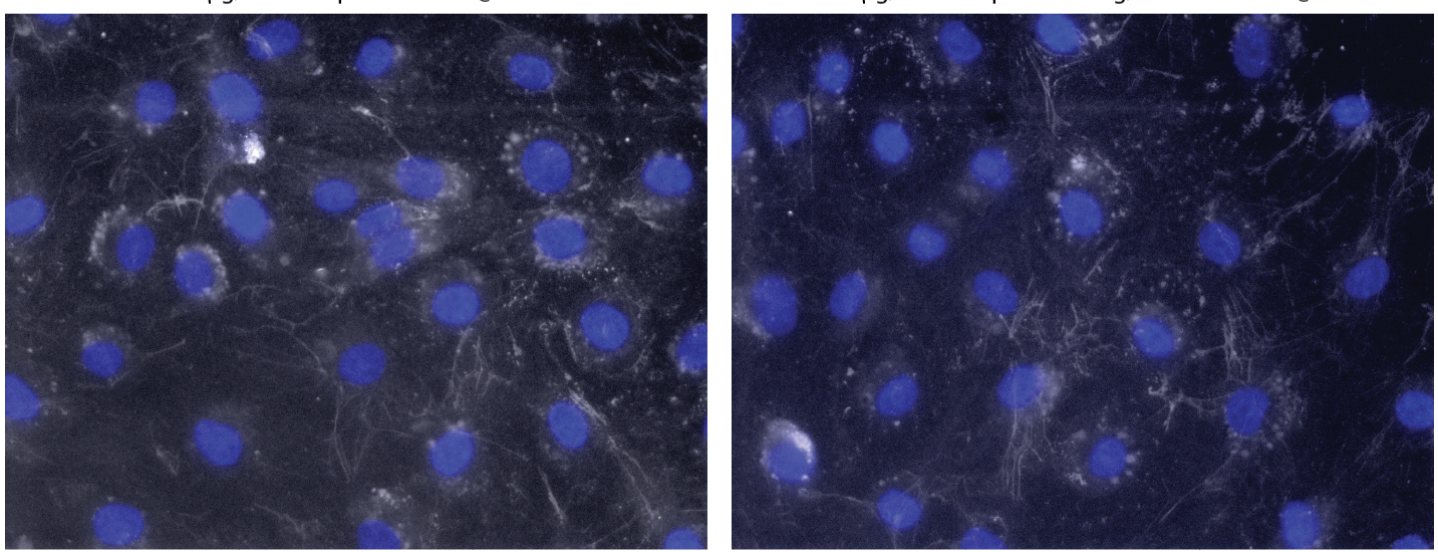

Figure 1: Binding of labeled HDL and ApoA-I competed with 100 x excess of not labeled HDL

A monolayer of ECs was pre-cooled for $30 \mathrm{~min}$ at $4^{\circ} \mathrm{C}$ following by a further $30 \mathrm{~min}$ incubation with 50 
$\mu \mathrm{g} / \mathrm{ml}$ 655-HDL (A) or $50 \mu \mathrm{g} / \mathrm{ml}$ 488-ApoA-I (C) in the absence (A, C) or presence of $5 \mathrm{mg} / \mathrm{ml} \mathrm{HDL} \mathrm{(B,} \mathrm{D).}$ The monolayers were then fixed with $3.75 \%$ formaldehyde for $40 \mathrm{~min}$ starting at $4{ }^{\circ} \mathrm{C}$ with gradual heat-up to room temperature. Cover slips were also incubated with DAPI for nuclear staining and investigated at fixed exposure.

To test for background effects and signal coming from free Atto-Dyes, we incubated ECs with free Atto655-Dye along with Atto655-HDL for 30 minutes. The free dye associates predominantly with nuclear and partially with cytoskeletal elements (Figure 2). This differs from the localization of fl-ApoA-I and fl-HDL indicating that the label attached to ApoA-I and HDL follow that of the particle and do not traffic as free label.
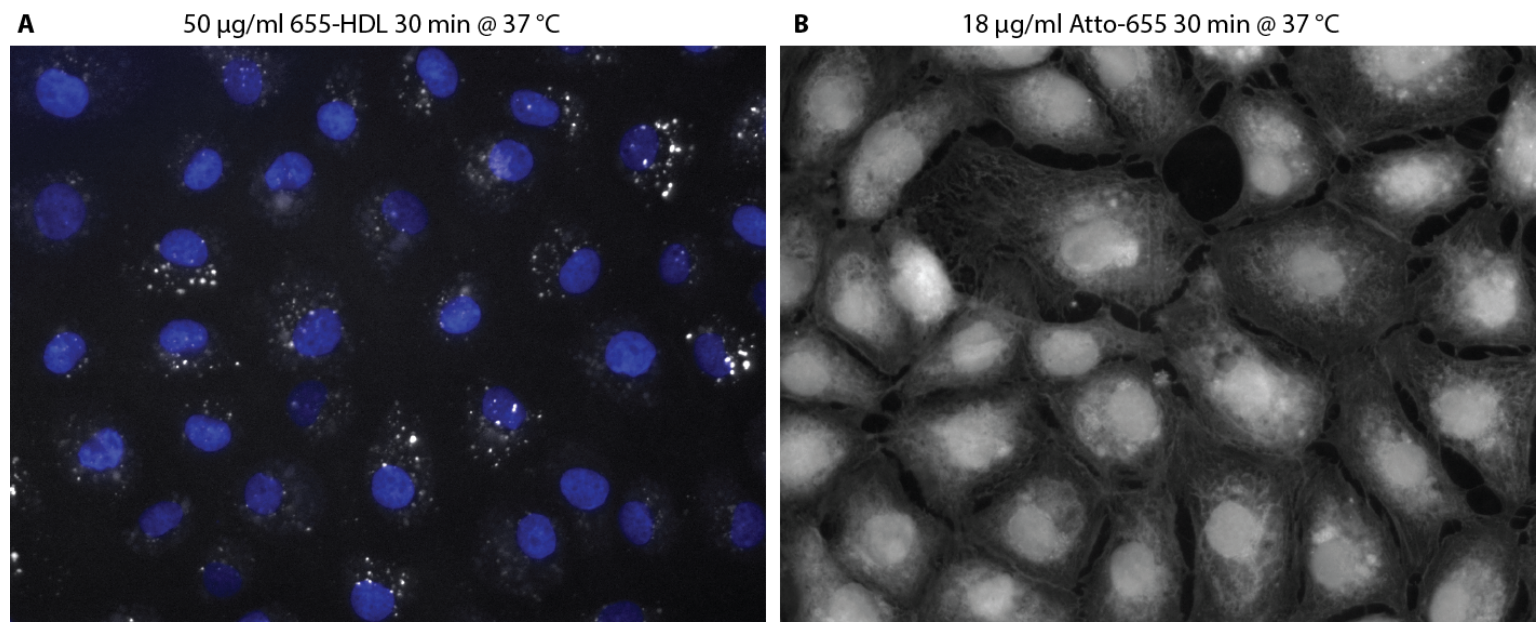

Figure 2: Comparison of fluorescence staining of endothelial cells by fl-HDL (A) free fluorescence dye (B)

A monolayer of ECs was incubated for $30 \mathrm{~min}$ at $37^{\circ}$ with $50 \mu \mathrm{g} / \mathrm{ml}$ 655-HDL (A) or $18 \mu \mathrm{g} / \mathrm{ml}$ free Atto655 dye (B), fixed with $3.75 \%$ formaldehyde and counter-stained with DAPI (A only) for nuclear staining. Note the different staining pattern of Atto-655 and 655-HDL.

\subsubsection{Uptake of ApoA-I and HDL}

$\mathrm{FI-HDL}$ was added to monolayers of EC on coverslips and incubated at $37^{\circ} \mathrm{C}$ for different timepoints after which the cells were briefly washed and fixed with PFA before mounting. HDL can be detected after about 5 minutes and the signal increases with the prolongation of incubation. At different timepoints, HDL is recovered in different compartments of the cells. The intracellular distribution of HDL after one hour is clearly different from the earlier shorter timepoints (Figure 3 A through D). 


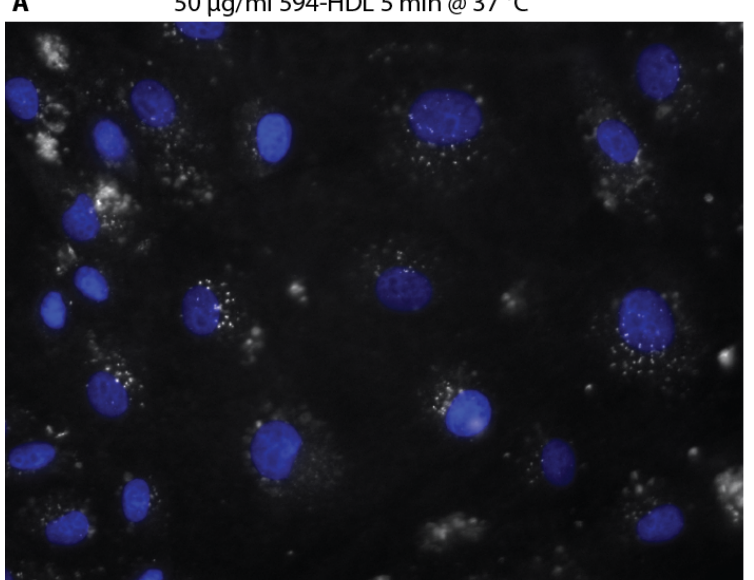

C

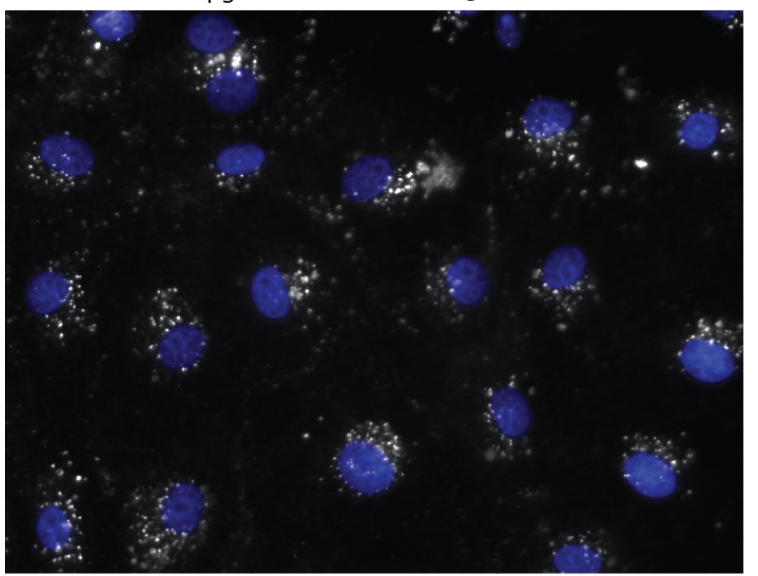

B

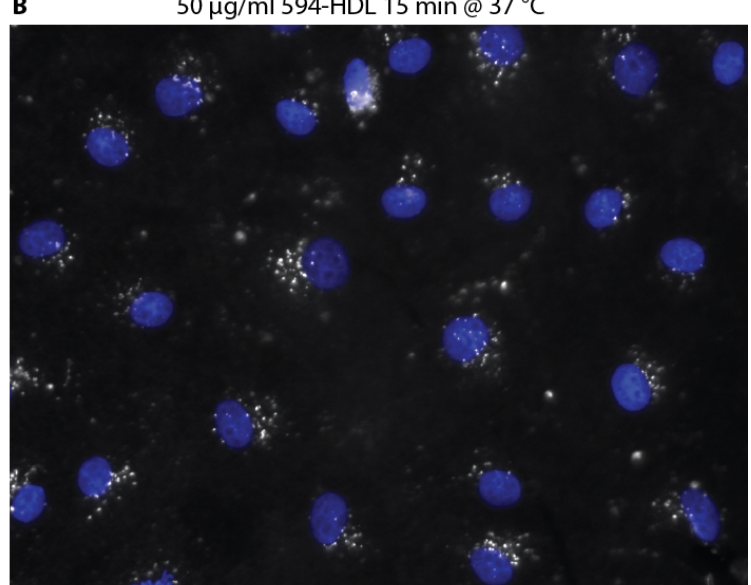

D

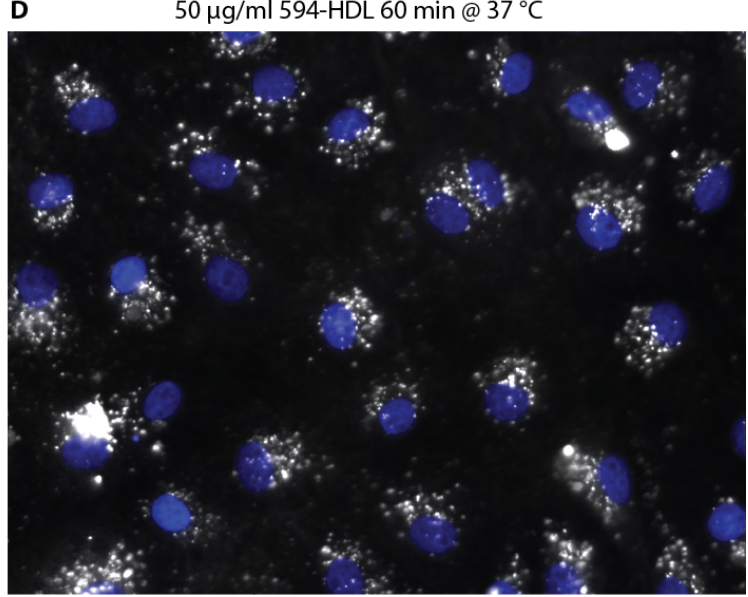

Figure 3: Time-dependent uptake of fl-HDL by EC monolayers. A monolayer of ECs was incubated for (A) $5 \mathrm{~min}$, (B) $15 \mathrm{~min}$, (C) $30 \mathrm{~min}$ and (D) $60 \mathrm{~min}$ at $37^{\circ}$ with $50 \mu \mathrm{g} / \mathrm{ml}$ 594-HDL, fixed with $3.75 \%$ formaldehyde and counter-stained with DAPI for nuclear staining. The longer fl-HDL is incubated with ECs, the more can be detected intracellular. 
When HDL and ApoA-I were incubated together with ECs for 30 minutes, they were found to colocalize perfectly, indicating a shared route of trafficking (Figure 4). Therefore all subsequent experiments were performed on HDL.
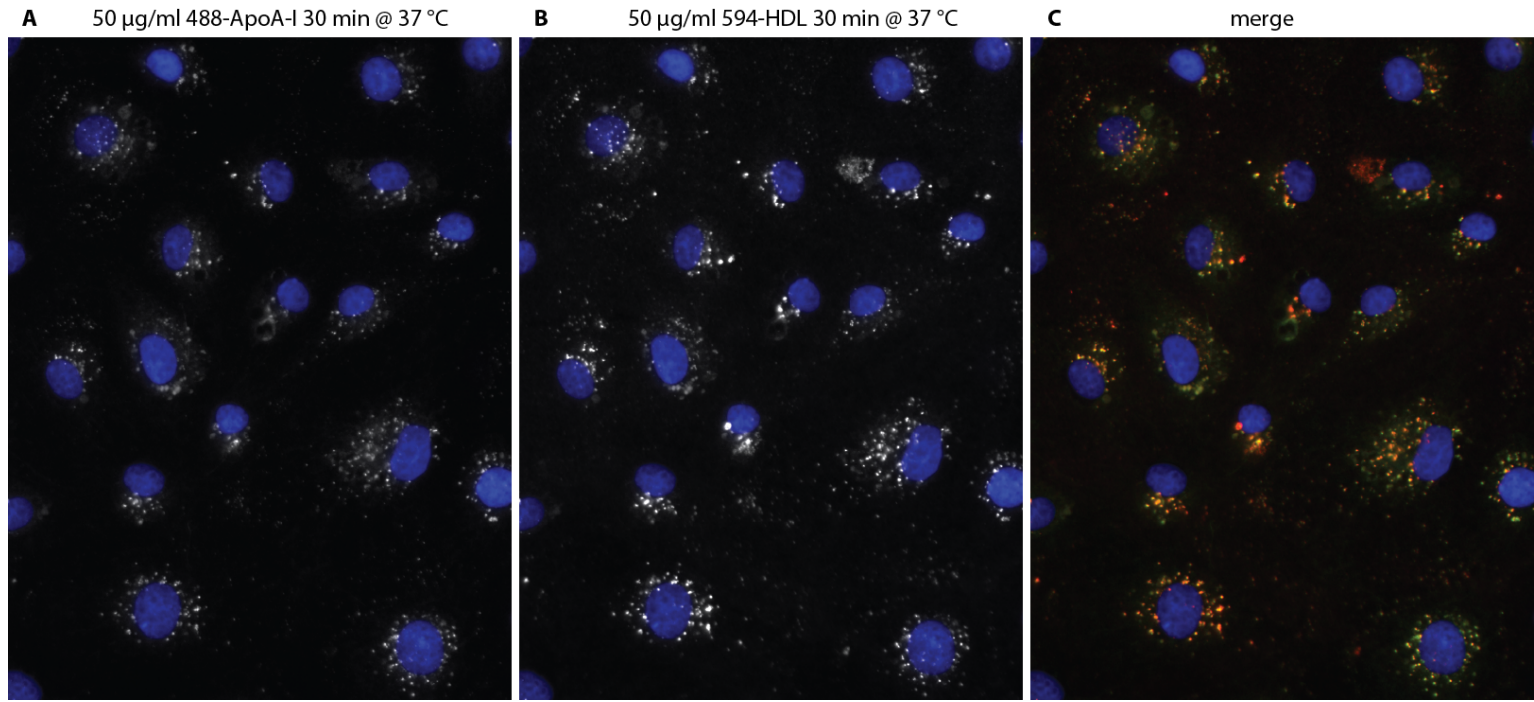

Figure 4: ApoA-I co-localizes perfectly with HDL inside ECs

A monolayer of ECs was incubated for $30 \mathrm{~min}$ at $37^{\circ}$ with $50 \mu \mathrm{g} / \mathrm{ml}$ of each $488-A$ poA-I and 594-HDL, fixed with $3.75 \%$ formaldehyde and counter-stained with DAPI for nuclear staining. In A, the 488ApoA-I signal is visualized, in B the one of 594-HDL. In C, the merge of A and B shows uniform colocalization of ApoA-I and HDL.

\subsubsection{Co-localization of ApoA-I and HDL with markers of endocytosis}

There are clathrin and caveolin dependent processes of endocytosis as well as endocytic pathways independent of clathrin and caveolin. We incubated fl-HDL for 30 minutes with ECs and subsequently stained the cells for clathrin or caveolin 1. Neither showed any colocalization with HDL (Figure $5 \mathrm{~A}$ and B). Since we saw almost no vesicles at very short time points, we reduced the temperature during the incubation with HDL and repeated the co-localization experiments. Also at $18{ }^{\circ} \mathrm{C}$ no co-localization of these endocytotic markers with HDL was seen (Figure $5 \mathrm{C}$ and $\mathrm{D}$ ). 
A

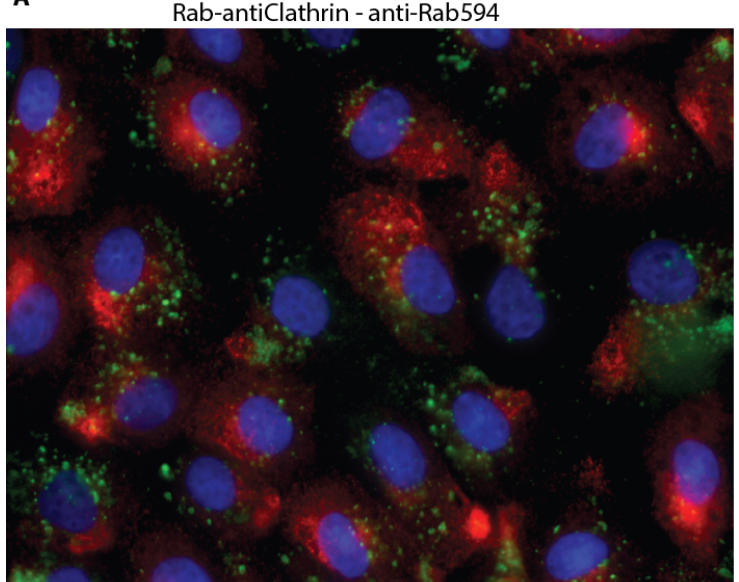

C

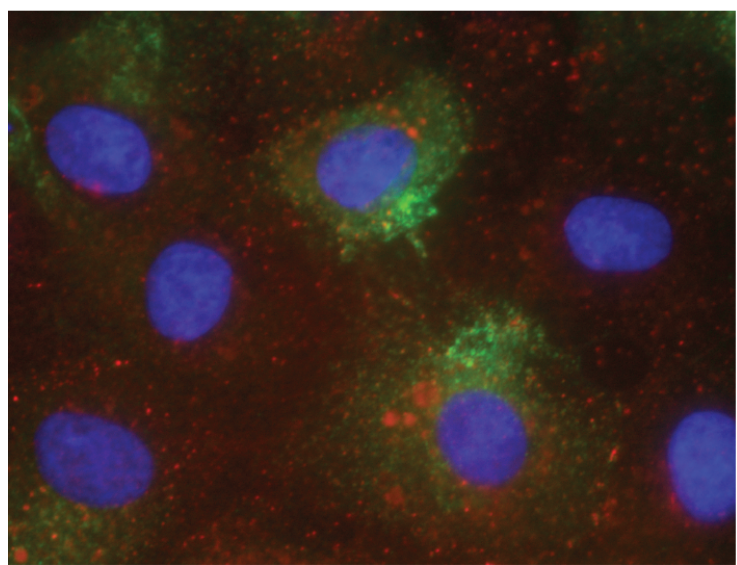

B

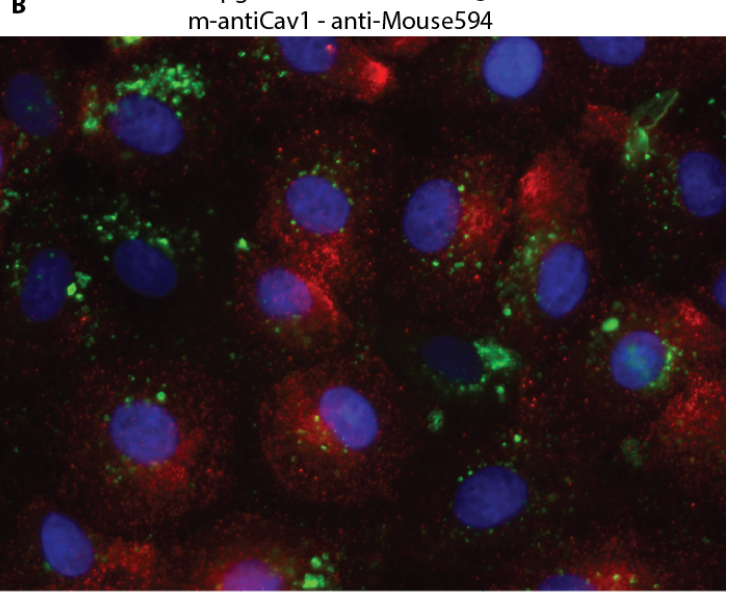

D

$50 \mu \mathrm{g} / \mathrm{ml} 594-\mathrm{HDL} 30 \mathrm{~min} @ 18^{\circ} \mathrm{C}$

m-antiCav1 - anti-Mouse488

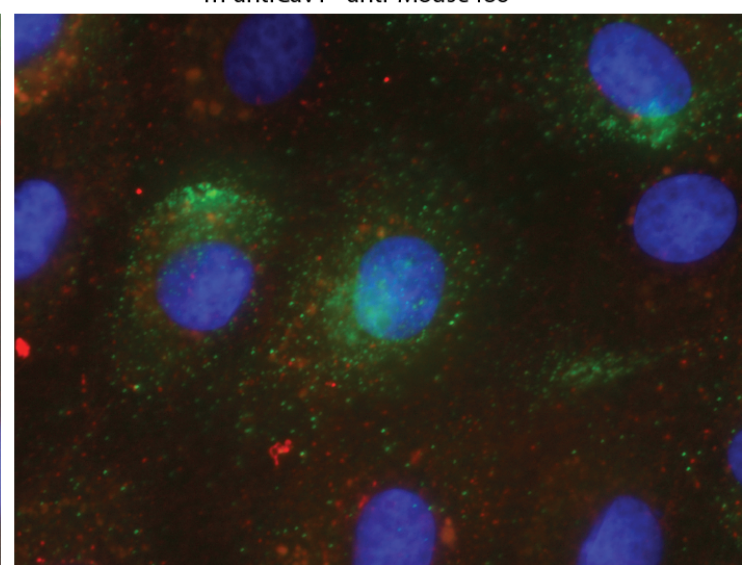

Figure 5: HDL colocalizes with neither clathrin nor cav1 at $37^{\circ} \mathrm{C}$ or $18^{\circ} \mathrm{C}$

Monolayers of ECs were incubated for $30 \mathrm{~min}$ at $37^{\circ}$ (A and B) or $18^{\circ} \mathrm{C}(\mathrm{C}$ and D) with $50 \mu \mathrm{g} / \mathrm{ml} \mathrm{fl-HDL,}$ fixed with $3.75 \%$ formaldehyde and stained with anti-Clathrin ( $A$ and $C$ ) or anti-Cav1 (B and D) in the corresponding secondary antibody (A and B - Alexa-594; C and D - Alexa 488) counter-stained with DAPI for nuclear staining. At neither $37^{\circ} \mathrm{C}$ nor $18^{\circ} \mathrm{C}$ HDL was found colocalized with clathrin or caveolin 1. 
Since Transferrin (Trf) is taken up by ECs via the Transferrin receptor (TrfR) in both a clathrin dependent and independent manner (Roberts \& Sandra 1994; Roberts et al. 1993; Tsuji et al. 2013; Kishimoto \& Tavassoli 1987; Fishman et al. 1987) to supply of themselves well as the tissues below the endothelium with iron, we tested for a convergence between the pathways of HDL and Trf in ECs. When FL-HDL and fluorescently labeled Trf were added to ECs with 1-2 minutes difference and incubated for 30 minutes, partial overlap with the two fluorescence signals was detected indicating crossroads in the vesicular transport of HDL and Trf in ECs (Figure 6).
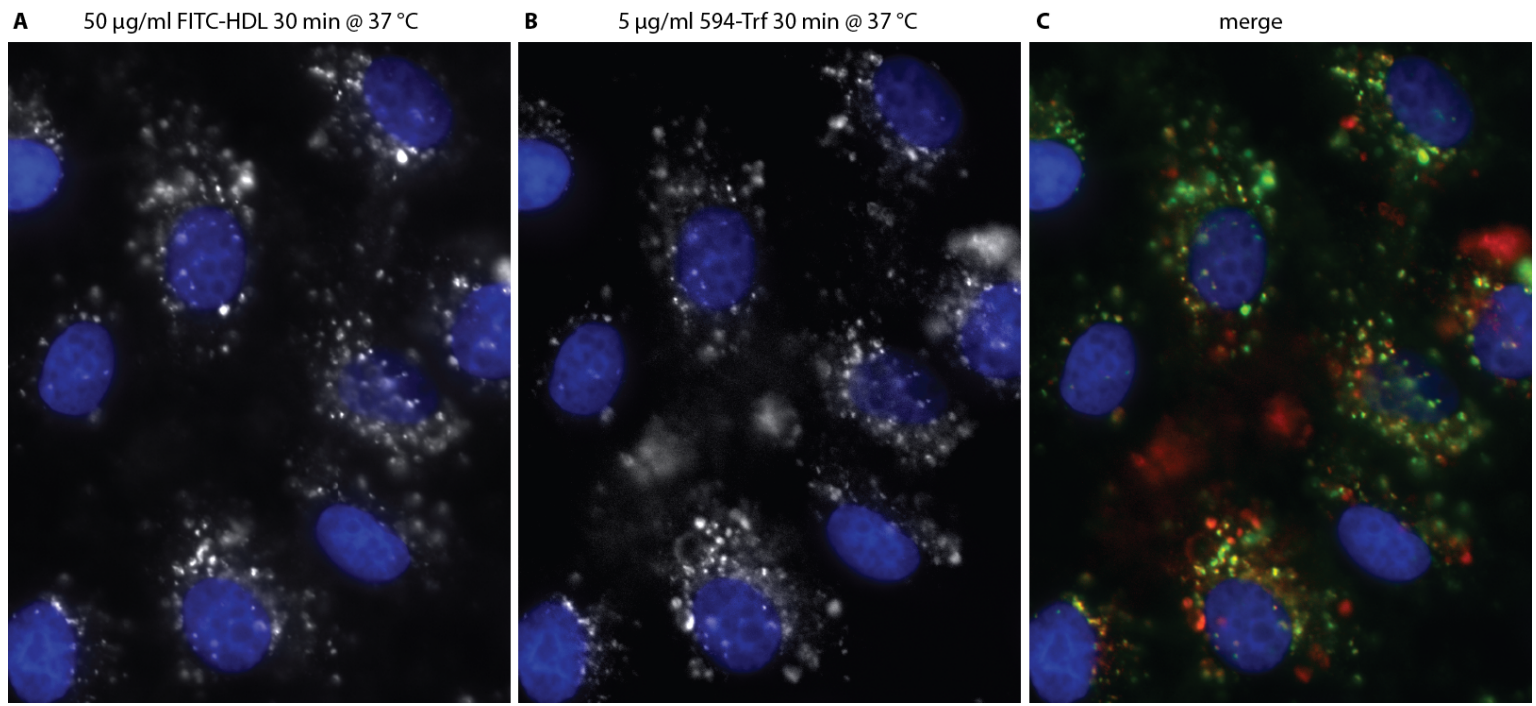

Figure 6: partial co-localization of HDL with Transferrin

A monolayer of ECs was incubated for $30 \mathrm{~min}$ at $37^{\circ}$ with $50 \mu \mathrm{g} / \mathrm{ml} \mathrm{FITC-HDL}$ and $5 \mu \mathrm{g} / \mathrm{ml} \mathrm{594-Trf,} \mathrm{fixed}$ with $3.75 \%$ formaldehyde and counter-stained with DAPI for nuclear staining. In A, the FITC-HDL signal is visualized, in B the one of 594-Transferrin. In C a merge from A and B is showing partial the co-localization between HDL and Transferrin. 
Albumin is transcytosed through the ECs via caveolae and dependent of both caveolin 1 and the gp60 receptor (Vogel et al. 2001; Geoffroy \& Becker 1984). We compared its itinerary with the one of HDL. When incubated for 30 minutes, fl-albumin was partially colocalized with fl-HDL (Figure 7).
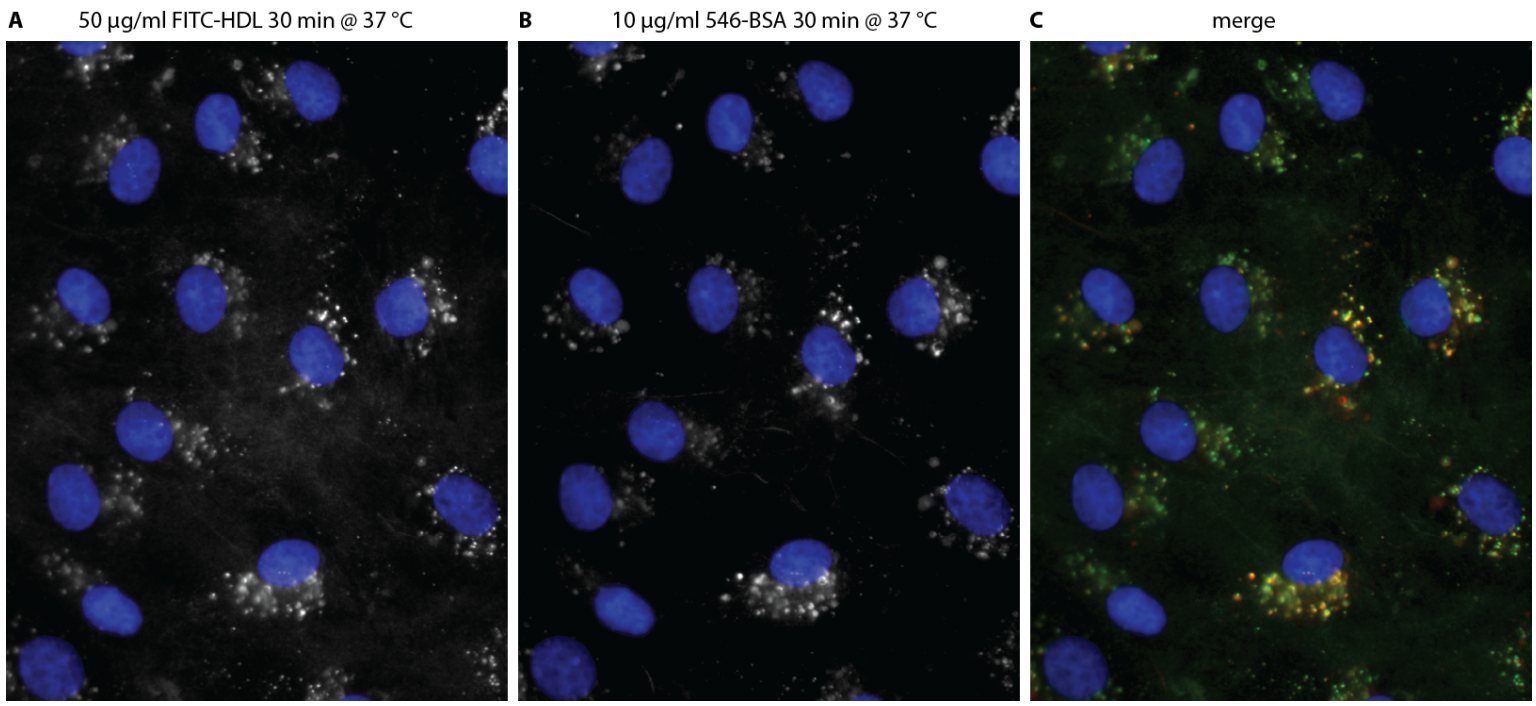

Figure 7: HDL partially co-localizes with Bovine Serum Albumin (BSA)

A monolayer of ECs was incubated for $30 \mathrm{~min}$ at $37^{\circ}$ with $50 \mu \mathrm{g} / \mathrm{ml} \mathrm{FITC-HDL}$ and $10 \mu \mathrm{g} / \mathrm{ml} 546$ Albumin, fixed with $3.75 \%$ formaldehyde and counter-stained with DAPI for nuclear staining. In A, the FITC-HDL signal is visualized, in B the one of 546-BSA. In C a merge from A and B is showing the partial co-localization between HDL and Transferrin.

To test for HDL uptake by fluid phase, we treated ECs with Amiloride and EIPA, two inhibitors for $\mathrm{Na} / \mathrm{H}$ channels needed for fluid phase trafficking. In either condition $\mathrm{FI}-\mathrm{HDL}$ up take was almost normal indicating that HDL uptake is not driven by fluid phase (Figure 8 A-C). To corroborate this finding, ECs were coincubated with fl-HDL together with fluorescently labeled $40 \mathrm{kDa}$ Dextran, a marker for fluid phase uptake. There was no colocalization visible (Figure 8 D-F). 


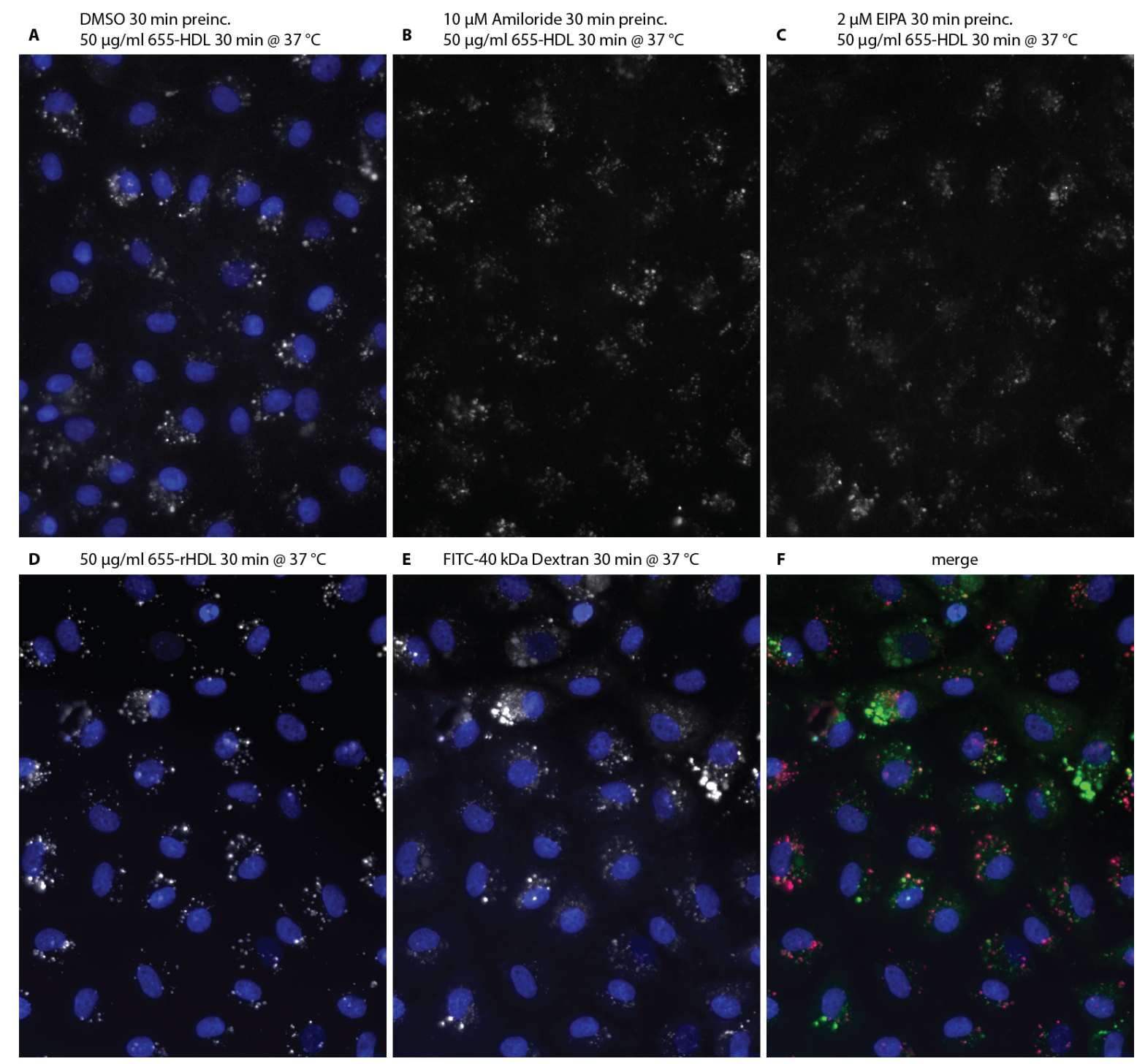

Figure 8: HDL uptake cannot be blocked by Amiloride or EIPA and it does not colocalize with 40 kDa Dextran

A-C: A monolayer of ECs was preincubated for 30 min with either $10 \mu \mathrm{M}$ Amiloride or $2 \mu \mathrm{M}$ EIPA before $50 \mu \mathrm{g} / \mathrm{ml}$ 655-HDL was added and incubated for another $30 \mathrm{~min}$, fixed with $3.75 \%$ formaldehyde and counter-stained with DAPI for nuclear staining.

D-F: A monolayer of ECs was incubated with $50 \mu \mathrm{gml}$ 655-rHDL together with FITC-40kDa Dextran for $30 \mathrm{~min}$, fixed with $3.75 \%$ formaldehyde and counter-stained with DAPI for nuclear staining

To test for the involvement of the lipid kinases of the PI3/4K family, which were recently identified to play a role in clathrin independent endocytosis (Basquin \& Sauvonnet 2013), we used pharmacological inhibition by wortmannin, a general inhibitor for PI3/4K kinases. Pretreatment of ECs with $2 \mu \mathrm{M}$ wortmannin for 20 minutes resulted in reduced HDL uptake and changed its vesicular distribution. The HDL containing vesicles were blown up (Figure 9 A vs B).

When dynamin was blocked by incubation of cells with $80 \mu \mathrm{M}$ dynasore for 20 minutes at $37^{\circ} \mathrm{C}$, ECs took up less fl-HDL. Even more strikingly, HDL positive vesicles were no longer 
localized on one side of the nucleus but randomly distributed around the nucleus. In the presence of dynasore at $18{ }^{\circ} \mathrm{C}$ which decreases membrane fluidity as well as the fission and fusion of vesicles, fl-HDL appeared as a patchy pattern over the whole monolayer of ECs in (Figure 9).

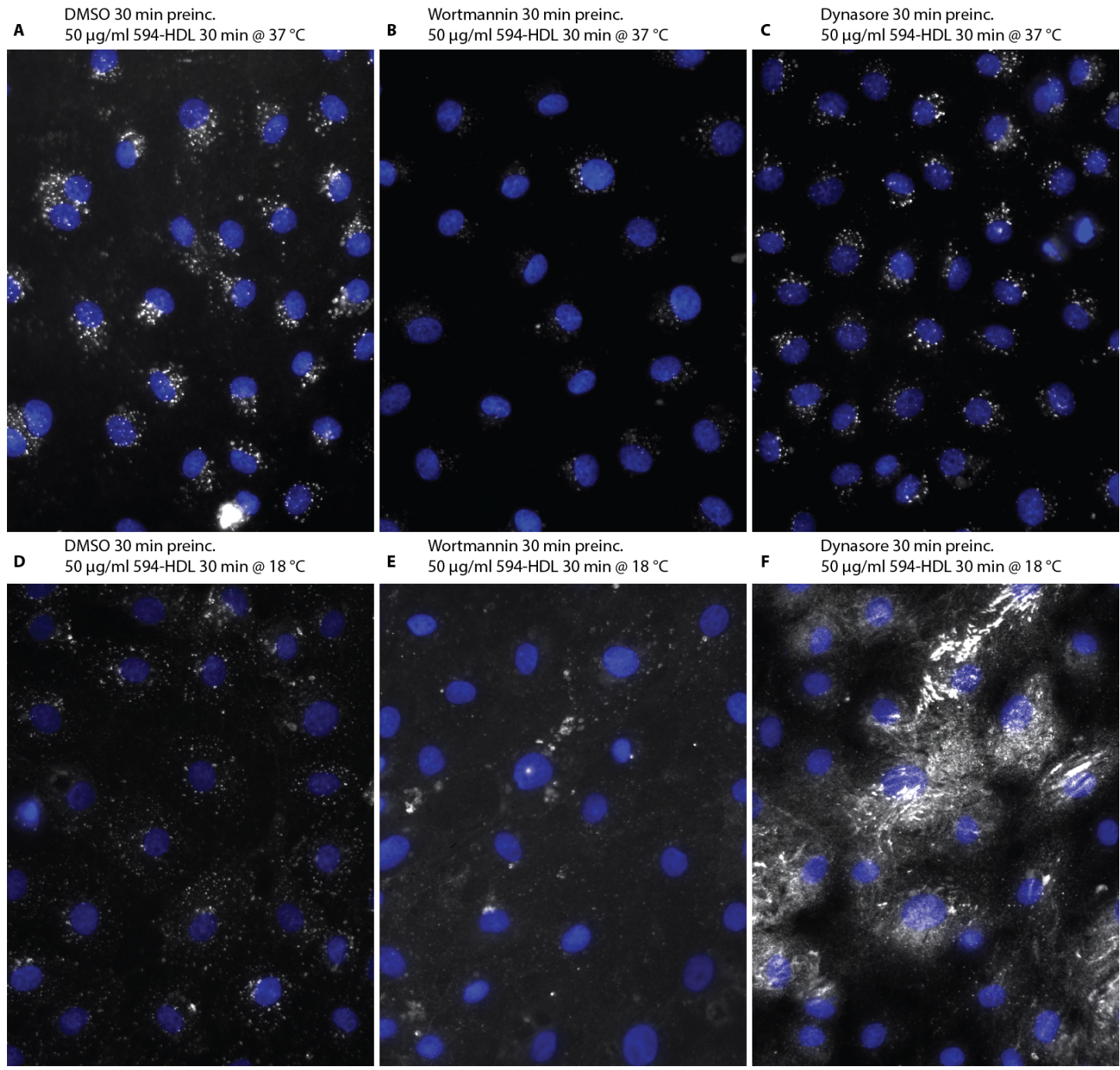

Figure 9: HDL uptake is altered by Wortmannin and Dynasore

A monolayer of ECs was preincubated at $37^{\circ} \mathrm{C}$ (panel A-C) or $18^{\circ} \mathrm{C}$ (panel D-F) for 30 min with either $0.2 \mathrm{mM}$ Wortmannin ( $B$ and $E$ ) or $80 \mu \mathrm{M}$ Dynasore (C and F).

$50 \mu \mathrm{g} / \mathrm{ml}$ 596-HDL was added (A-F) and incubated for another $30 \mathrm{~min}$, fixed with $3.75 \%$ formaldehyde and counter-stained with DAPI for nuclear staining.

To follow the cell surface protein steady state internalization and highlight the whole endocytotic pathway of ECs, we labelled all N-acetyl-glucosamine (GlycNAc) residues on the cell surface of ECs with the fluorescently labeled lectin wheat-germ agglutinin (flWGA). 
After adding fl-HDL to the fl-WGA treated cells, complete co-localization was observed in the first 10 minutes which weakened during the subsequent 20 minutes and disappeared after one hour (Figure 10).

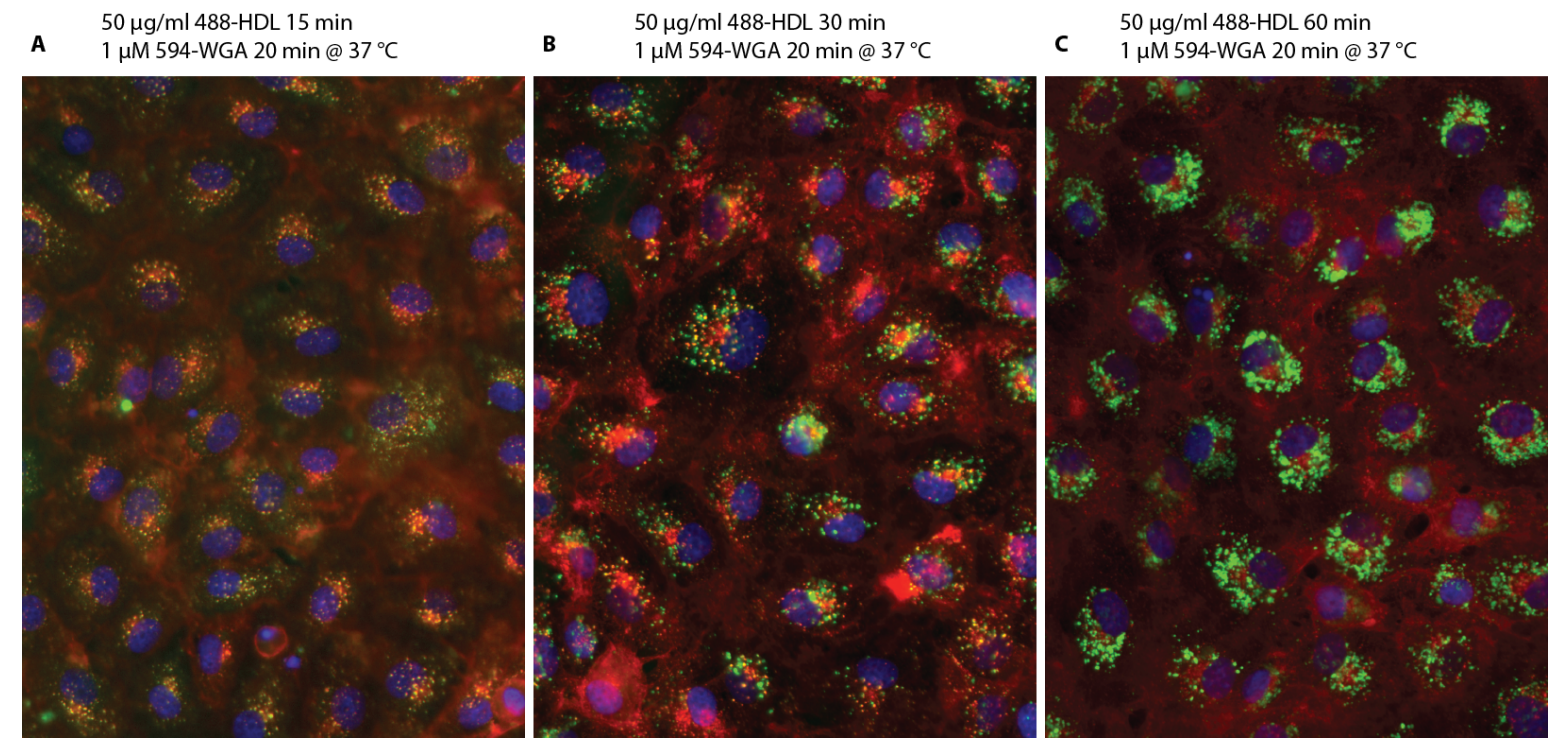

Figure 10: HDL colocalizes with WGA in 10-30 min but not after that time

A monolayer of ECs was incubated with $1 \mu \mathrm{M}$ 594-WGA for $20 \mathrm{~min}$ and $50 \mu \mathrm{g} / \mathrm{ml}$ 488-HDL for $15 \mathrm{~min}$ $(A), 30 \mathrm{~min}(B)$ and $60 \mathrm{~min}(\mathrm{C})$, cells were fixed then with $3.75 \%$ formaldehyde and counter stained with DAPI for nuclear staining.

Endothelial cells also take up acetylated LDL (AcLDL) via scavenger receptors. To test whether HDL shares this pathway, we incubated fl-AcLDL and fl-HDL with ECs and found almost no colocalisation inside the cells (Figure 11).
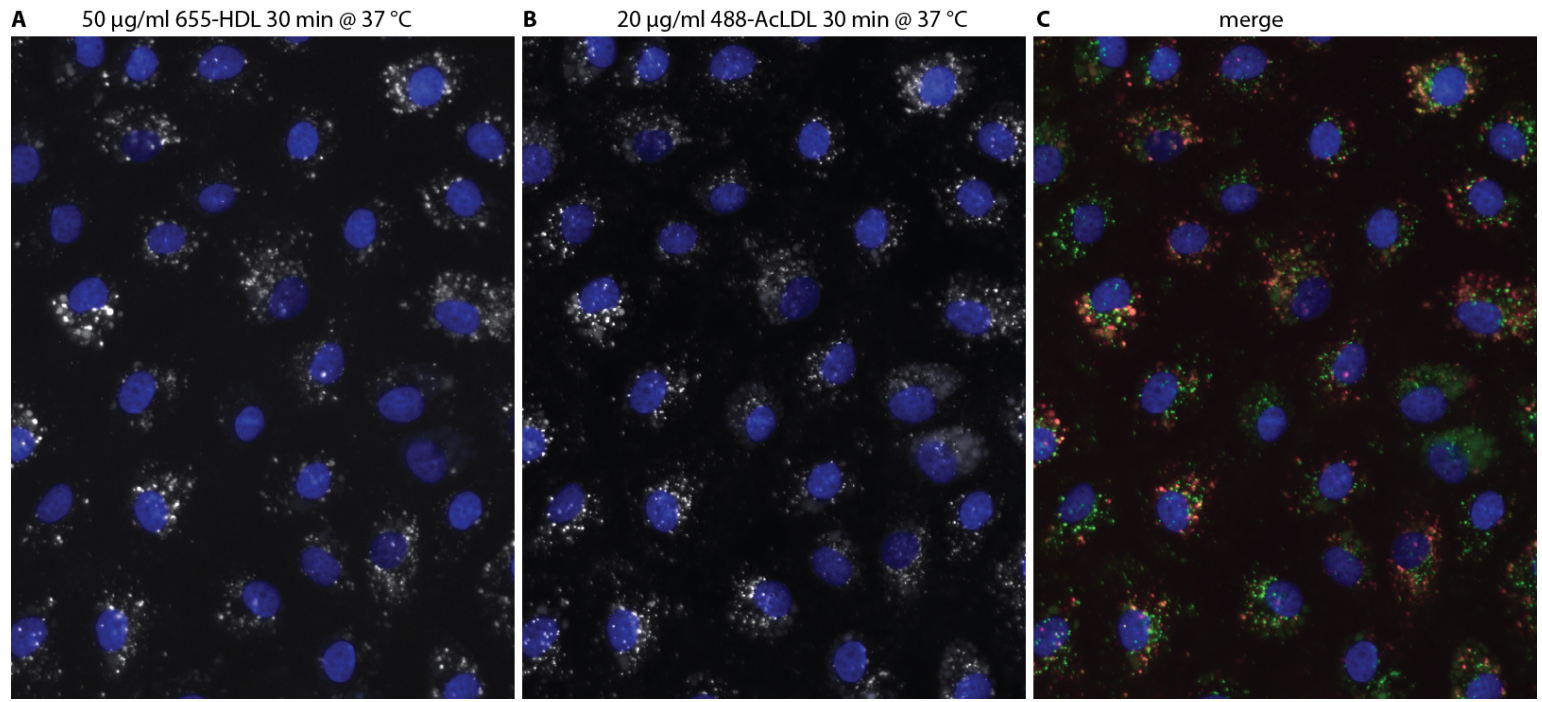

Figure 11: AcLDL does not colocalize with HDL

A monolayer of ECs was incubated for $30 \mathrm{~min}$ at $37^{\circ}$ with $50 \mu \mathrm{g} / \mathrm{ml} \mathrm{655-HDL}$ and $20 \mu \mathrm{g} / \mathrm{ml} \mathrm{488-AcLDL}$, fixed with $3.75 \%$ formaldehyde and counter-stained with DAPI for nuclear staining. In A, the 655-HDL signal is visualized, in $B$ the one of 488-AcLDL. In $C$ a merge from $A$ and $B$ is showing almost no colocalization between HDL and AcLDL. 


\subsubsection{HDL is trafficking through different compartments over a period of 4 hours}

During incubations for different time intervals ranging from 5 minutes to 16 hours, the cellular localization of HDL changes significantly. At early time points HDL was hardly detectable. We observed that preincubation of ECs with unlabeled HDL enhanced the binding of HDL (see Figure 26). We exploited this phenomenon for visualizing the binding of HDL. After stimulation of ECs with $50 \mu \mathrm{g} / \mathrm{ml} \mathrm{HDL}$ for 30 minutes and subsequent incubation of ECs with fl-HDL, this fl-HDL can be visualized in small-punctuated patterns. After prolonged incubations for up to 120 minutes HDL was reshuffled into bigger vesicles at the same location (Figure $12 \mathrm{E}$ and F). After 2-3 hours, the HDL is further moved to another compartment, and after $16 \mathrm{~h}$ we observed $\mathrm{HDL}$ in bigger vesicles (Figure $12 \mathrm{G}-\mathrm{I}$ ). 

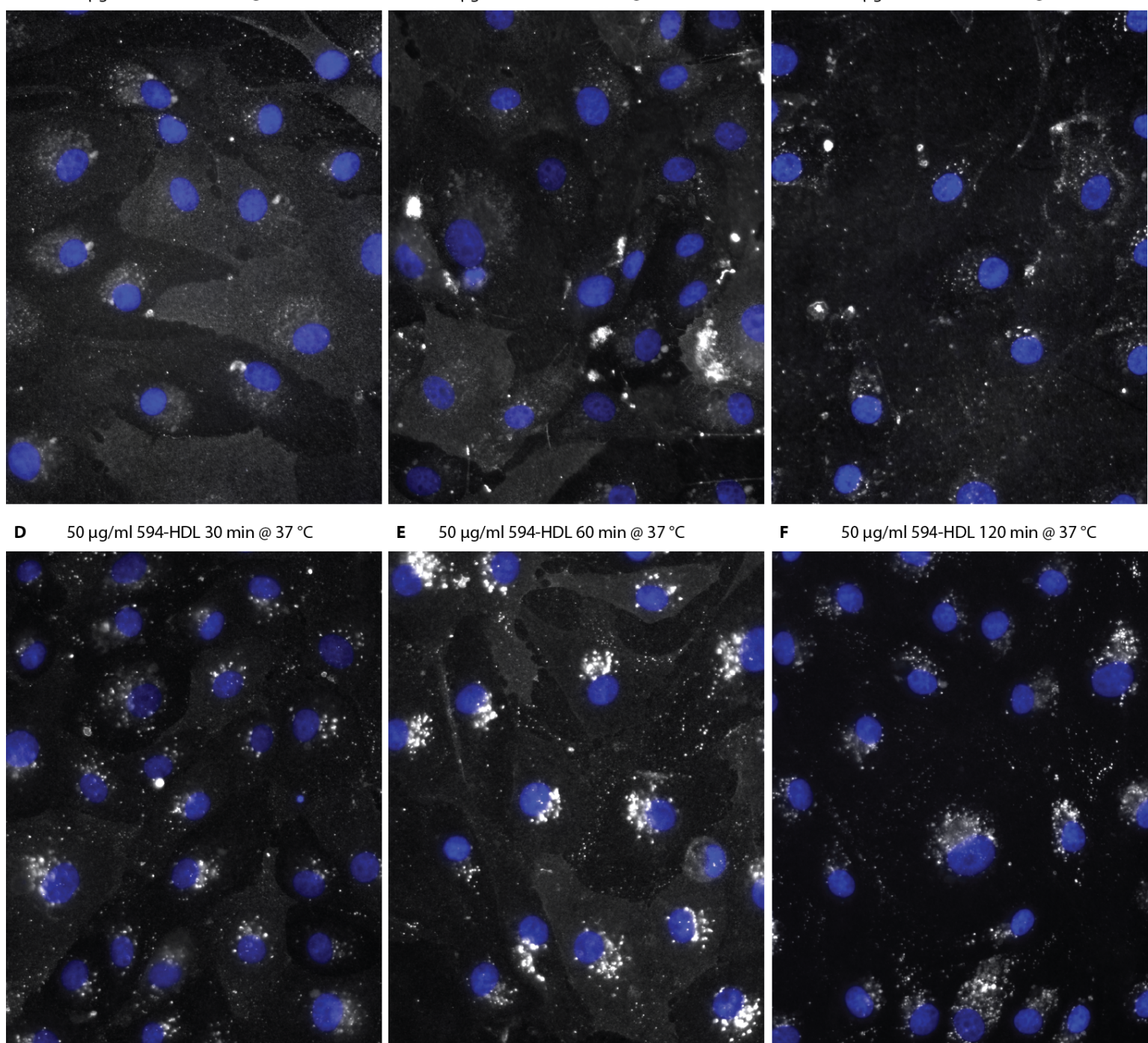

E $\quad 50 \mu \mathrm{g} / \mathrm{ml} 594-\mathrm{HDL} 60 \min @ 37^{\circ} \mathrm{C}$

F $\quad 50 \mu \mathrm{g} / \mathrm{ml} 594-\mathrm{HDL} 120 \mathrm{~min} @ 37^{\circ} \mathrm{C}$

$\mathbf{G}$

$50 \mu \mathrm{g} / \mathrm{ml}$ 594-HDL $180 \mathrm{~min} @ 37^{\circ} \mathrm{C}$
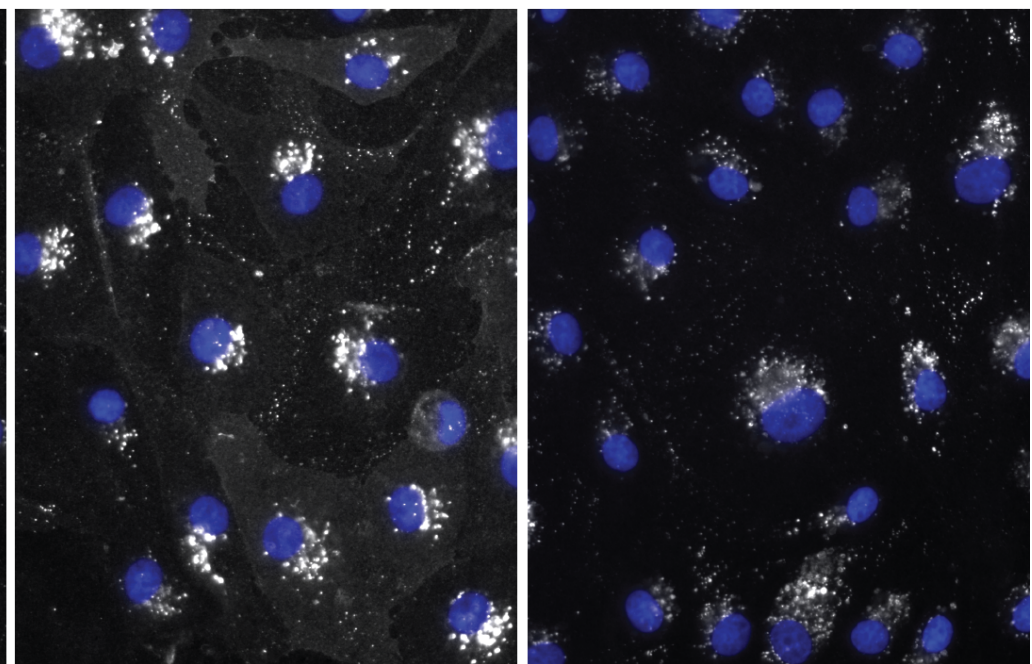

H $\quad 50 \mu \mathrm{g} / \mathrm{ml} 594-\mathrm{HDL} 240 \mathrm{~min} @ 37^{\circ} \mathrm{C}$

I $50 \mu \mathrm{g} / \mathrm{ml} 594-\mathrm{HDL} 16 \mathrm{~h} @ 37^{\circ} \mathrm{C}$
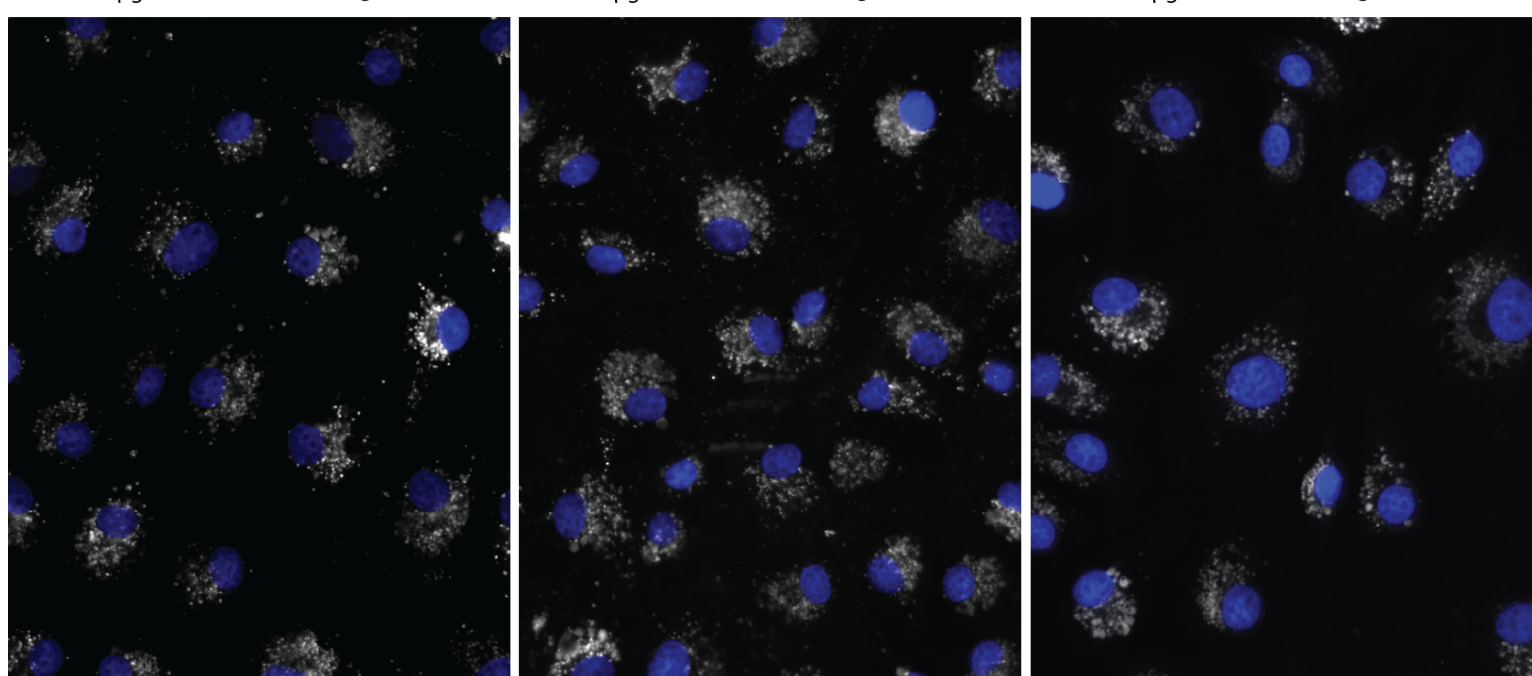

Figure 12: HDL uptake over 5 minutes up to 16 hours. ECs were pre-stimulated with HDL to increase HDL uptake . A monolayer of ECs was incubated for $5 \mathrm{~min}$ (A), $10 \mathrm{~min}$ (B), $15 \mathrm{~min}$ (C), $30 \mathrm{~min}$ (D), 60 $\min (E), 120 \mathrm{~min}(F), 180 \mathrm{~min}(\mathrm{G}), 240 \mathrm{~min}(\mathrm{H})$ and $16 \mathrm{~h}$ (I) as indicated with $50 \mu \mathrm{g} / \mathrm{ml}$ 596-HDL, fixed with $3.75 \%$ formaldehyde and counter-stained with DAPI for nuclear staining. 


\subsubsection{HDL is passing the endothelial monolayer faster than it accumulates inside the vesicles identified}

To visualize the internalization of HDL at real time, FI-HDL was added to ECs while scanning at maximum speed on a confocal microscope the xyz volume of a EC and it's surrounding. After two minutes already some fl-HDL was passing through the monolayer and retrieved in the subendothelial space. After only 15 minutes it could be observed in internal vesicles (Figure 13).

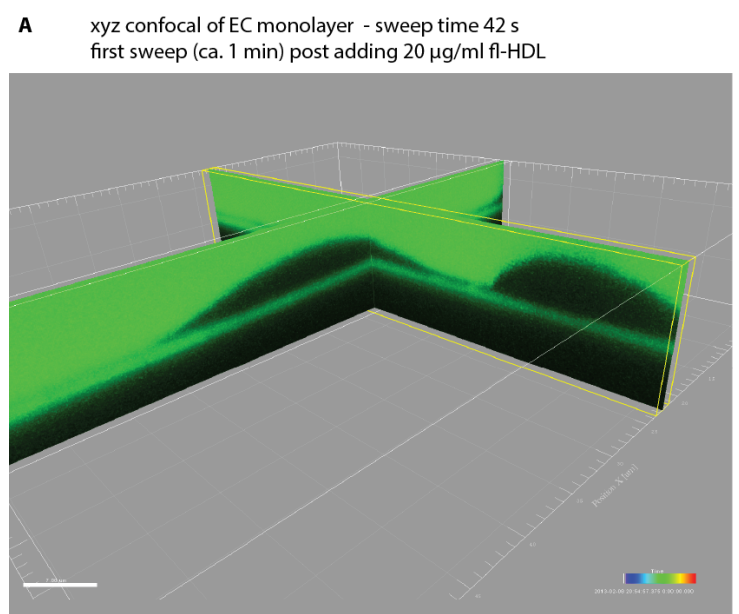

B $\quad x y z$ confocal of EC monolayer - sweep time 42 s 20th sweep (ca. $15 \mathrm{~min}$ ) post adding $20 \mu \mathrm{g} / \mathrm{ml}$ fl-HDL

Figure 13: HDL passes through the EC monolayer in less than 2 minutes, much before any vesicles can be detected intracellularly

Monolayers of ECs were grown on transwell inserts which were then put on a drop of medium on a petri dish with optical glass bottom and scanned from below at a inverse confocal microscope. After the first volume scan, the 488-HDL was given into the transwell and scanning was continued. A shows the first scan, $B$ the $20^{\text {th }}$ scan after 15 minutes of adding $488-\mathrm{HDL}$ to the cell layer

\subsubsection{Colocalization of HDL with organelles}

LDL is taken up by all cells via the LDL receptor or related gene family members(e.g. LRP). The majority is targeted to the lysosomes for satisfying the cellular need of cholesterol and free fatty acids. Only a small proportion is transcytosed through ECs as intact particles (Nistor \& Simionescu 1986). To test if HDL is also transported to lysosomes for degradation and cholesterol uptake, we used Lysotracker DND 99 (Life Technology), a pH dependent red fluorescent dye to visualize lysosomes and late endosomes in cells, which we incubated with green labeled HDL. As shown in Figure 14, there is very little if at all co-localization of lysotracker signals with HDL indicating that, at the timepoints investigated, HDL is not transported to lysosomes (Figure 14). 
A

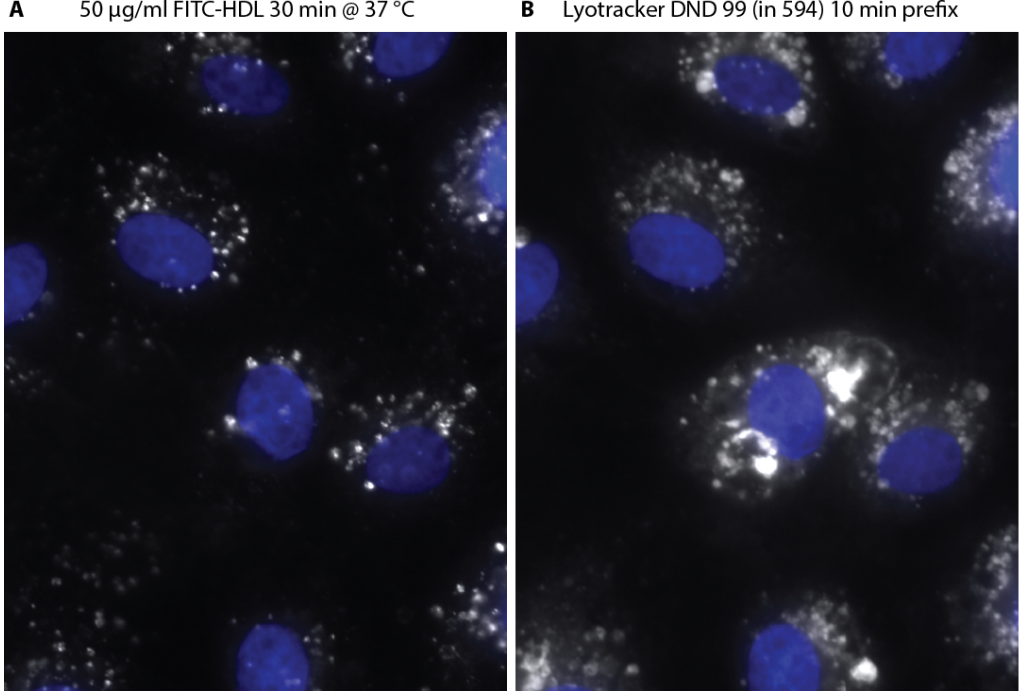

merge

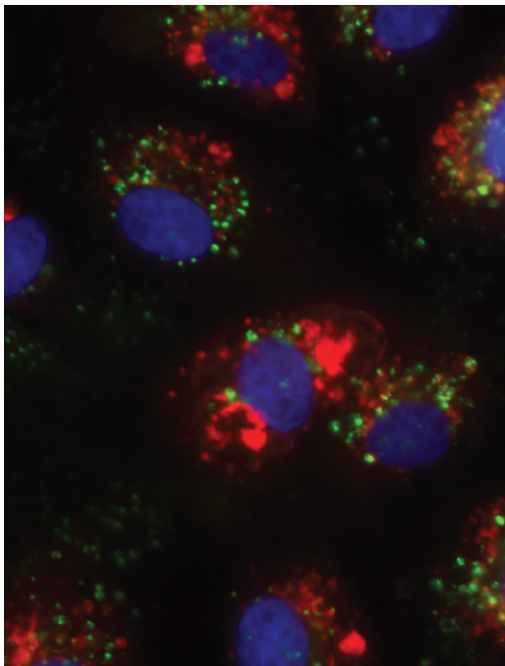

Figure 14: HDL does not colocalize with Lysotracker DND 99

A monolayer of ECs was incubated for $30 \mathrm{~min}$ at $37^{\circ}$ with $50 \mu \mathrm{g} / \mathrm{ml} \mathrm{FITC-HDL}$ and during the last 10 min additionally with $1 \mu \mathrm{M}$ Lysotracker DND, fixed with $3.75 \%$ formaldehyde and counter-stained with DAPI for nuclear staining. 
There is a distinct caveolar endocytotic pathway known to target the golgi or endoplasmatic reticulum (ER) (Le 2003). HDL positive vesicles were found accumulating around one side of the nucleus so that we speculated that HDL is transported into the golgi or ER. We added fl-HDL for 30 minutes to ECs. After fixing the cells and labellig the ER with anti-Calnexin antibodies (Figure $15 \mathrm{~A}, \mathrm{~B}, \mathrm{C}$ ) and the golgi with anti-golgi58-protein (Figure $15 \mathrm{D}, \mathrm{E}, \mathrm{F})$ neither organelles were colocalized with HDL but the HDL positive vesicles were in close proximity to the Golgi.

$50 \mu \mathrm{g} / \mathrm{ml} 594-\mathrm{HDL} 30 \mathrm{~min} @ 37^{\circ} \mathrm{C}$

B

anti-Calnexin / AntiGoat Alexa-488

C merge
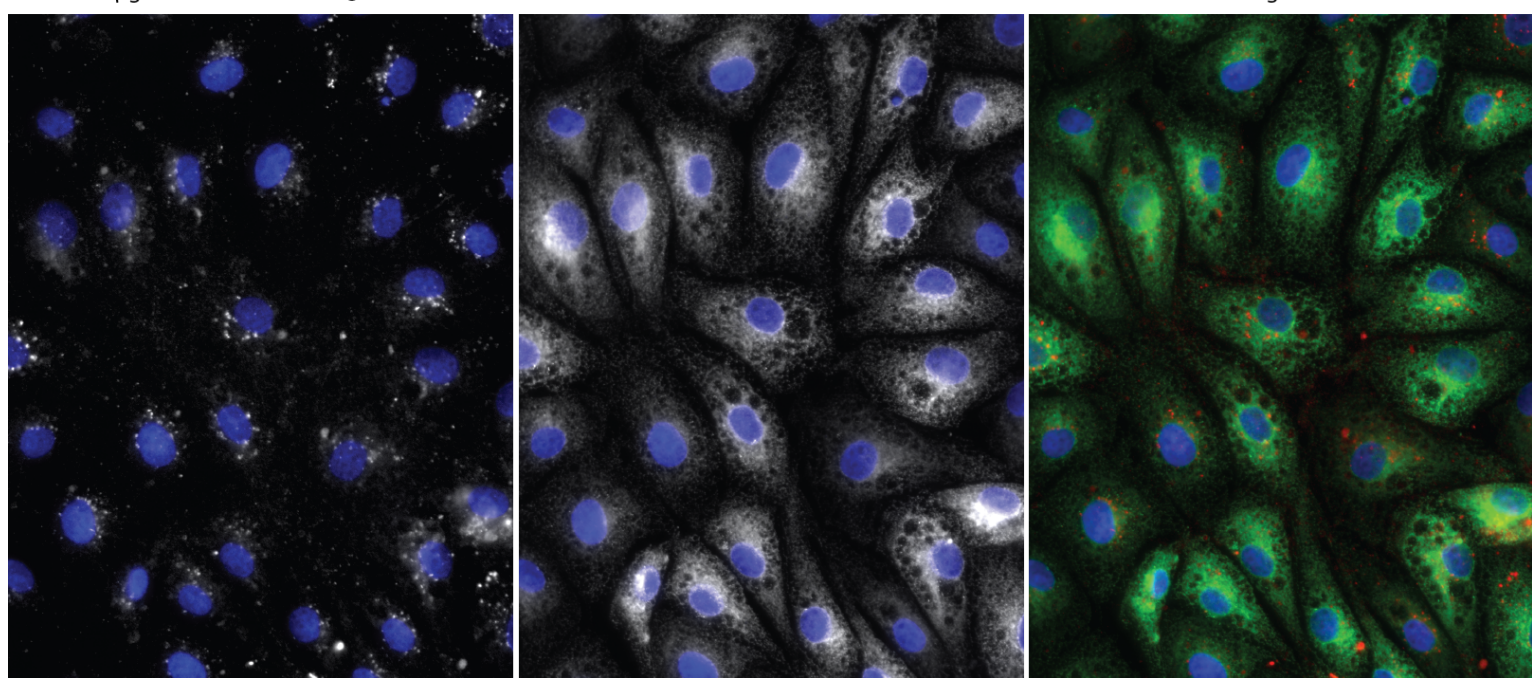

A $\quad 50 \mu \mathrm{g} / \mathrm{ml} 594-\mathrm{HDL} 30 \mathrm{~min} @ 37^{\circ} \mathrm{C}$

B anti-Golgi58kProtein / AntiGoat Alexa-488

C

merge

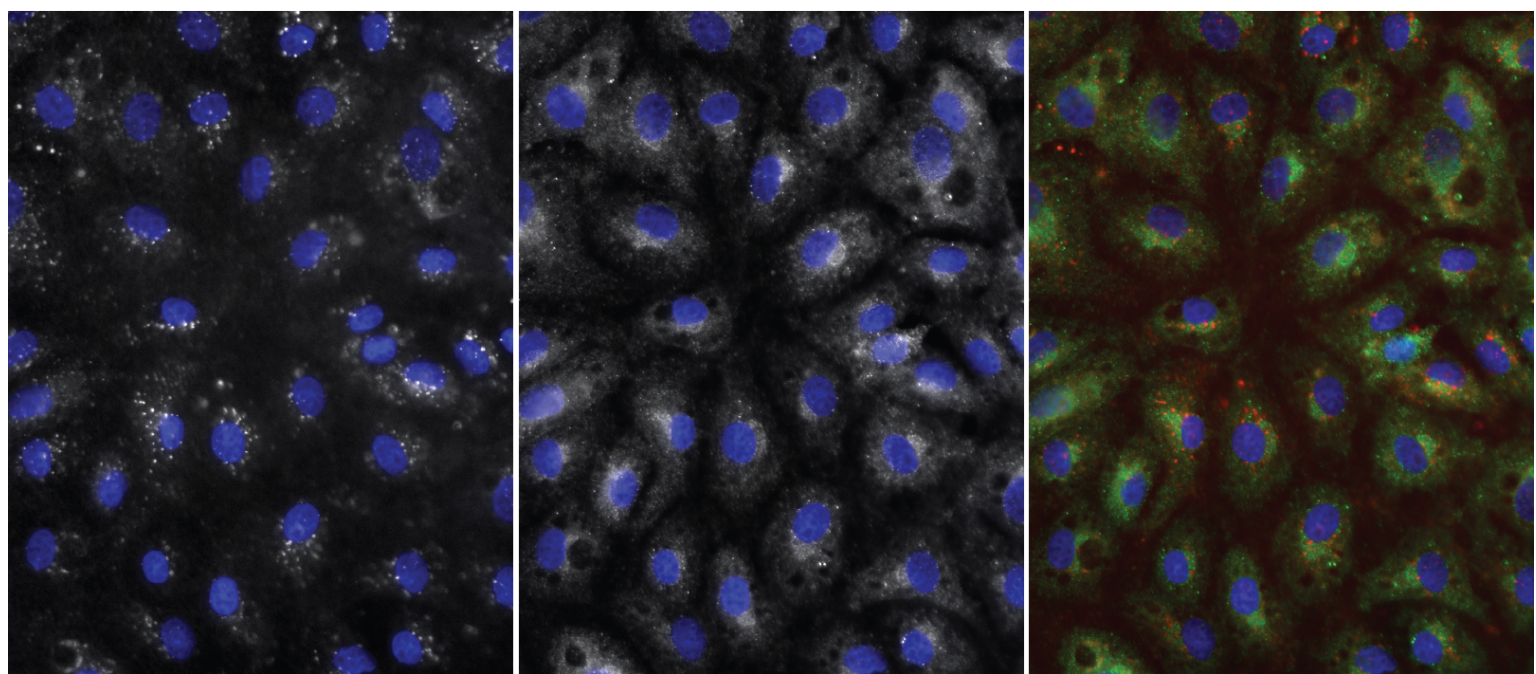

Figure 15: HDL fails to co-localize with Golgi or ER but clusters around the golgi positive vesicles Monolayers of ECs were incubated for $30 \mathrm{~min}$ at $37^{\circ}$ with $50 \mu \mathrm{g} / \mathrm{ml} \mathrm{fl}-\mathrm{HDL}$, fixed with $3.75 \%$ formaldehyde and stained with anti-Calnexin (B) or anti-Golgi58kProtein (E) and the corresponding secondary antibodies labeled with Alexa-488. DAPI was used for nuclear staining. HDL was colocalized with neither the ER (merge in C) nor the Golgi (merge in F).

As we observed HDL uptake by ECs, we tested colocalization of HDL with early or late endosomes (Rab5 or Rab7), recycling endosomes (Rab11a), and endosome-trans golgi 
network trafficking (Rab9 and Syntaxin6). ECs were incubated with fl-HDL for 30 minutes and after fixing, the cells were stained against the proteins described above. Unfortunately none of the vesicle markers we used appeared to co-localize with HDL indicating that HDL passes quickly through endosomes if at all to end up in other vesicles that are Rab5 and/or Rab7 negative (Figure 16). Negative co-localization with Rab 11a (Figure 17) and Syntaxin 6 and Rab9 (Figure 18) indicate neither back transport to the plasma membrane nor transport to the trans golgi network.

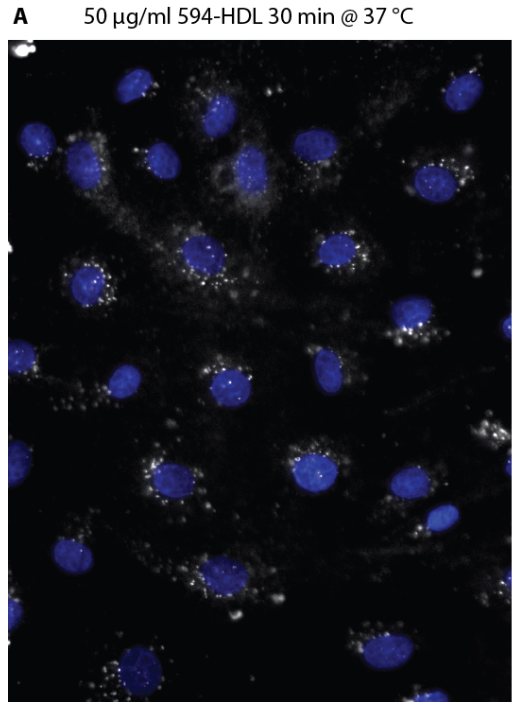

B anti-Rab5 / AntiRabbit Alexa-488

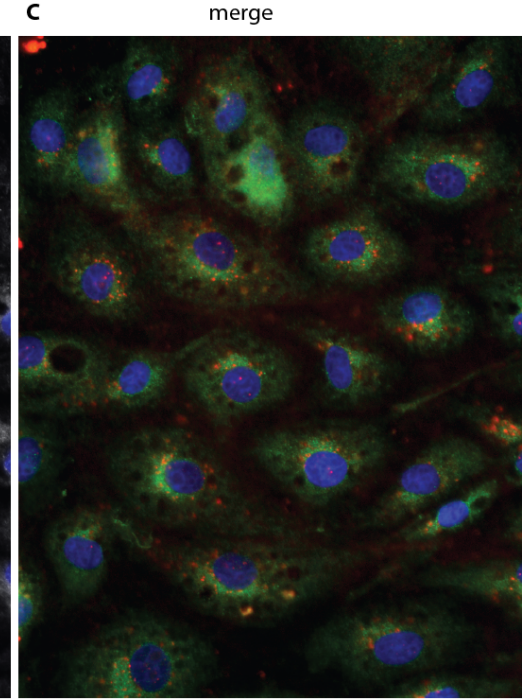

D $\quad 50 \mu \mathrm{g} / \mathrm{ml} 594-\mathrm{HDL} 30 \mathrm{~min} @ 37^{\circ} \mathrm{C}$ E
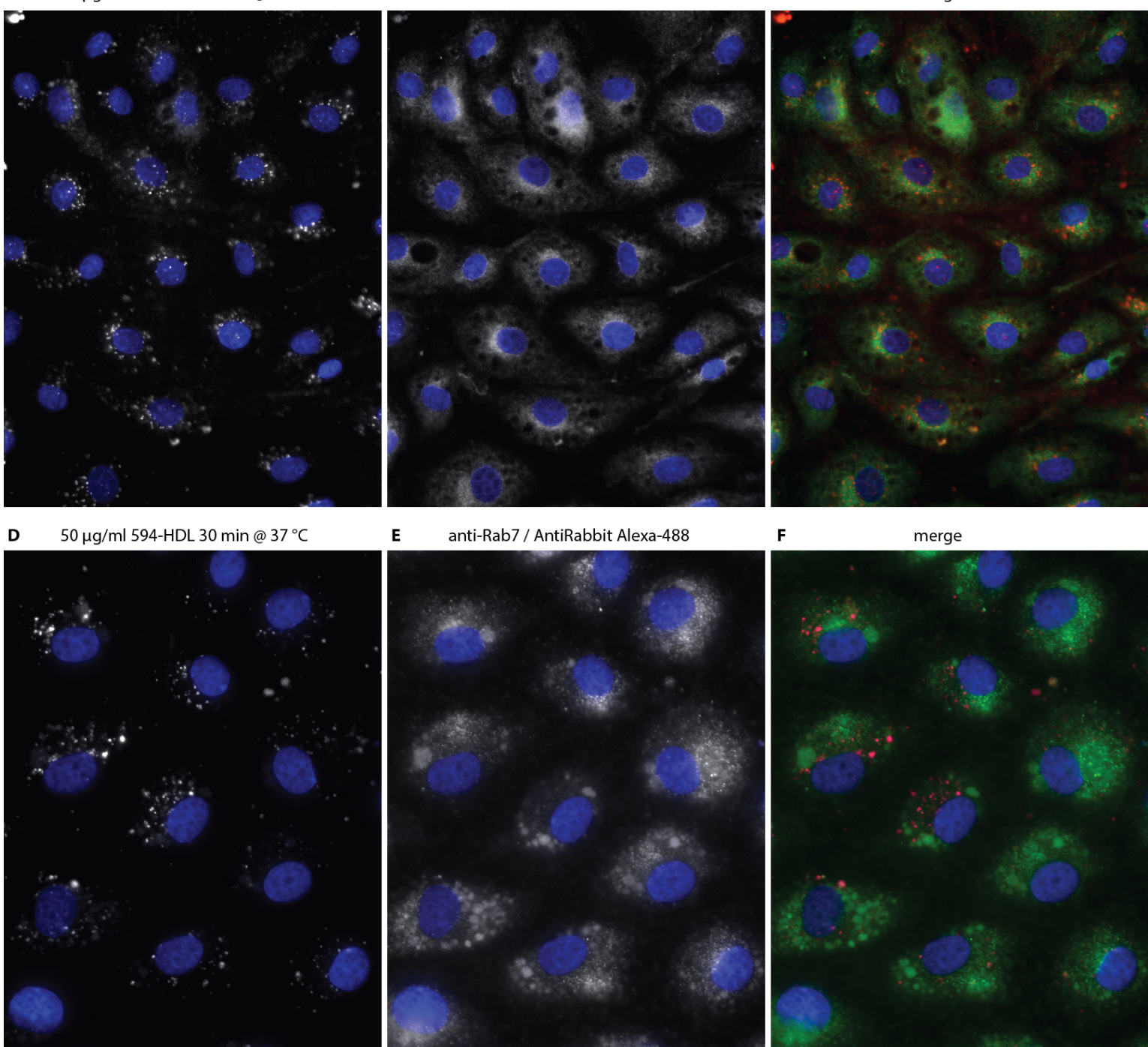

Figure 16: HDL does not colocalize with early (Rab5) and late (Rab7) endosomes Monolayers of ECs were incubated for $30 \mathrm{~min}$ at $37^{\circ}$ with $50 \mu \mathrm{g} / \mathrm{ml} \mathrm{fl-HDL}$, fixed with $3.75 \%$ formaldehyde and stained with anti-Rab5 (B) or anti-Rab7 (E). The secondary antibodies were labeled with Alexa-488. DAPI was used for nuclear staining. Neither the early endosomes (Rab5 - merge in C) nor late endosomes (Rab7 - merge in F) colocalize with fl-HDL 
$50 \mu \mathrm{g} / \mathrm{ml}$ 594-HDL $30 \min @ 37^{\circ} \mathrm{C}$ B anti-Rab1 1a / AntiRabbit Alexa-488 C

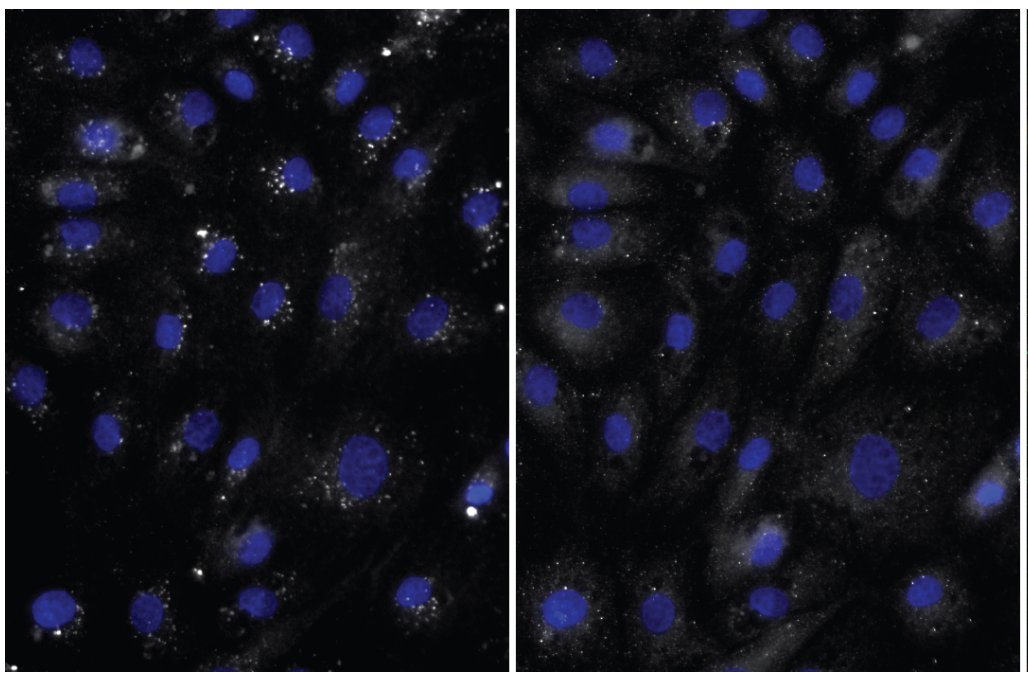
merge

Figure 17: HDL is not recycled in a Rab11a dependent manner Monolayers of ECs were incubated for $30 \mathrm{~min}$ at $37^{\circ}$ with $50 \mu \mathrm{g} / \mathrm{ml} \mathrm{fl-HDL}$, fixed with $3.75 \%$ formaldehyde and stained with anti-Rab11a (B) and a secondary antibody labeled with Alexa-488. DAPI wa sused for nuclear staining. The recycling endosomes (Rab11a) do not co-localize with fl-HDL (merge in panel $\mathrm{C}$ ). 

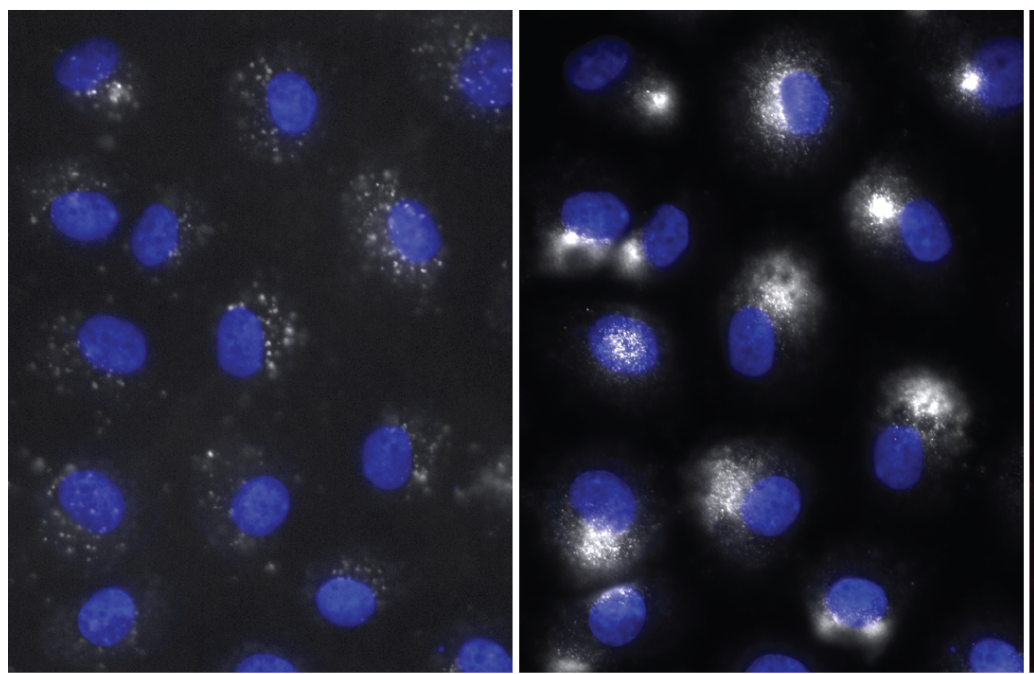

D $50 \mu \mathrm{g} / \mathrm{ml} 594-\mathrm{HDL} 30 \mathrm{~min} @ 37^{\circ} \mathrm{C}$ E anti-Syntaxin6 / AntiRabbit Alexa-488
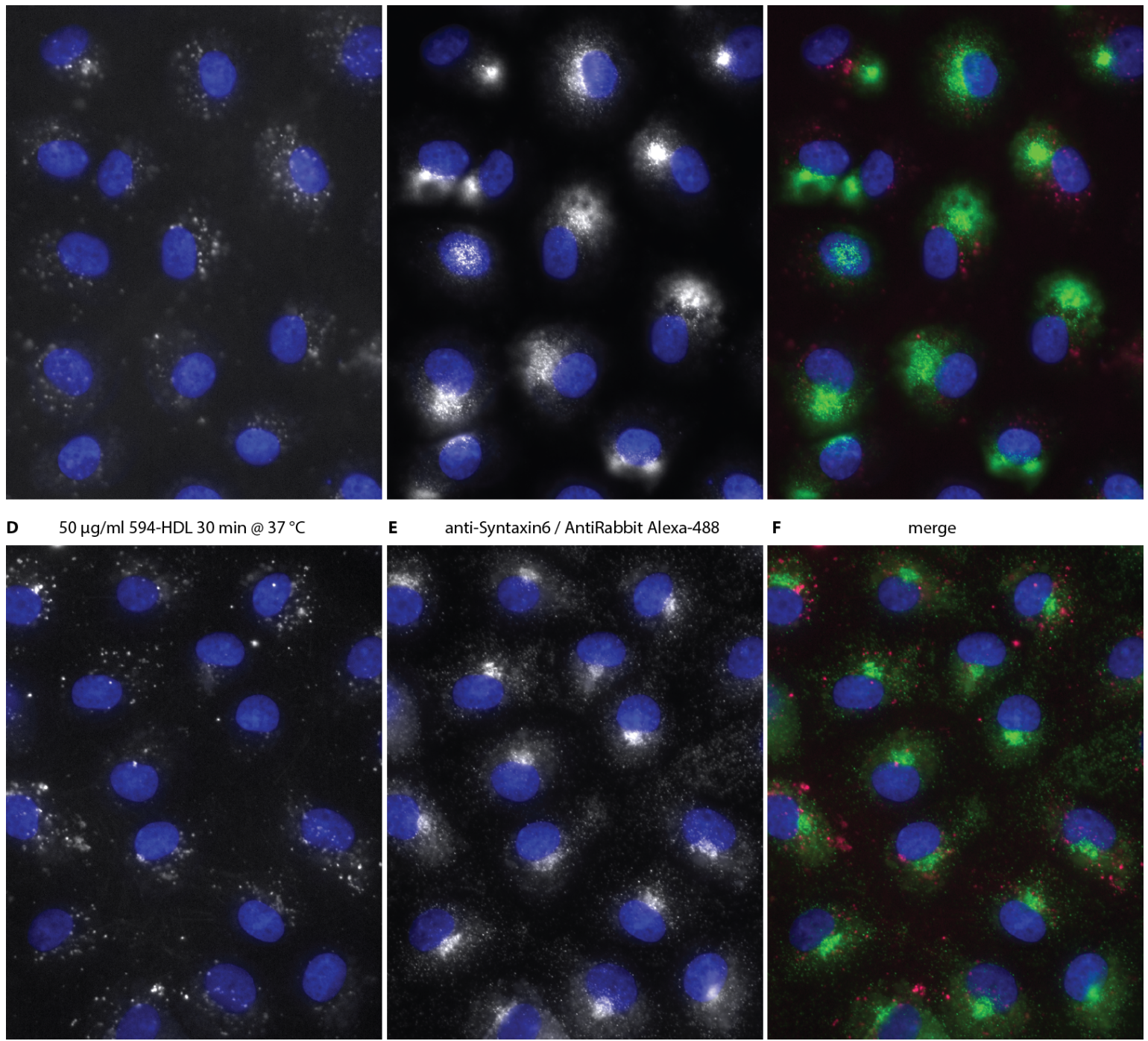

Figure 18: HDL does not colocalize with Rab9 or Syntaxin 6

Monolayers of ECs were incubated for $30 \mathrm{~min}$ at $37^{\circ}$ with $50 \mu \mathrm{g} / \mathrm{ml} \mathrm{fl}-\mathrm{HDL}$, fixed with $3.75 \%$ formaldehyde and stained with anti-Rab9 (B) or anti-Syntaxin6 (E). The corresponding secondary antibodies were labeled with Alexa-488. DAPI was used for nuclear staining. Neither Rab9 nor Syntaxin 6 colocalize with HDL (merges in C and F). 


\subsubsection{Role of the cytoskeleton on HDL trafficking}

Cytoskeleton disruption with colchicine and cytochalasin D in ECs resulted in reduced HDL uptake. After tubulin disruption by colchicine, HDL remained in small intracellular peripheral vesicles (Figure 19).
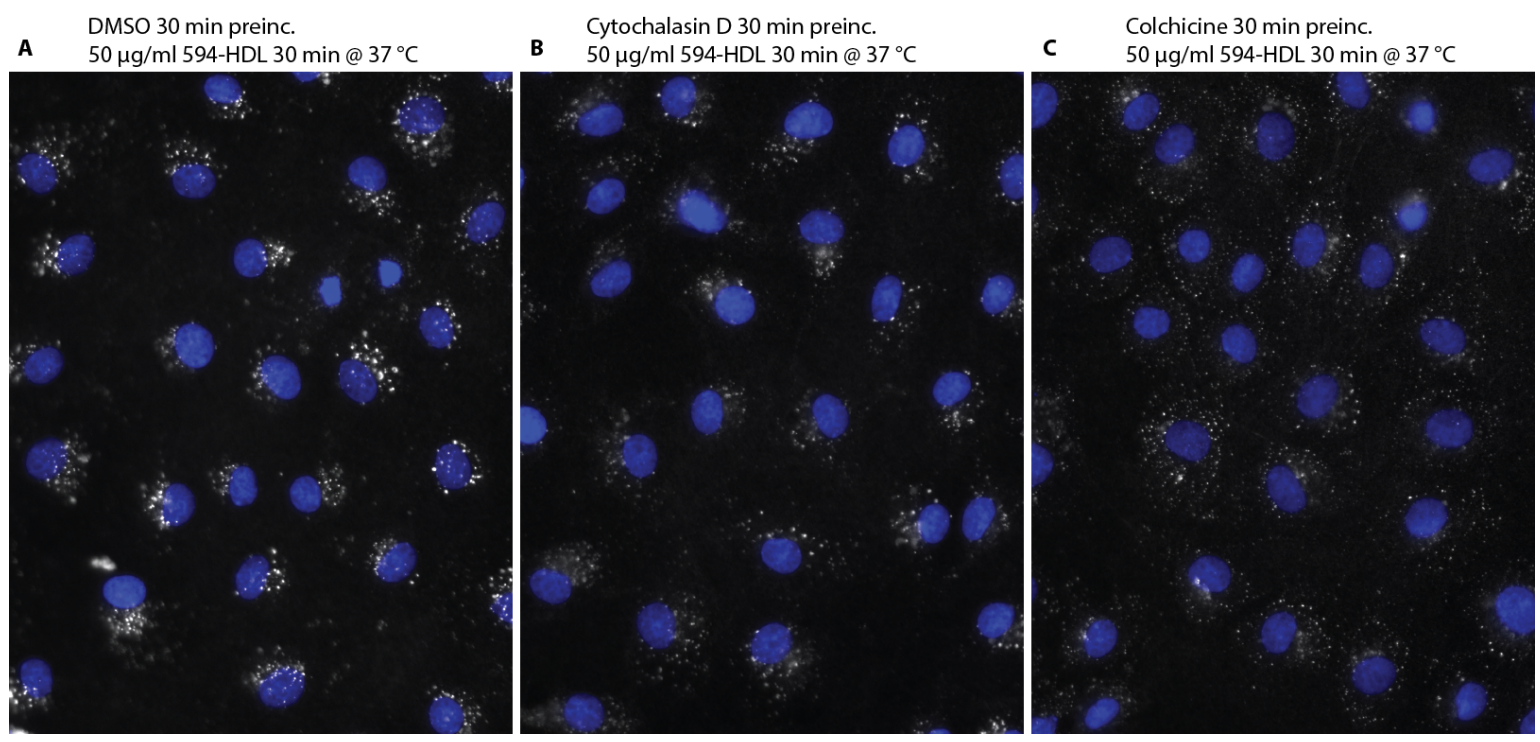

Figure 19: HDL uptake and trafficking is affected by blocking tubulin and F-actin

A monolayer of ECs was preincubated for $30 \mathrm{~min}$ with either (B) $5 \mu \mathrm{M}$ Cytochalasin D or (C) $1 \mu \mathrm{M}$ Colchicine before $50 \mu \mathrm{g} / \mathrm{ml}$ 596-HDL was added and incubated for another $30 \mathrm{~min}$, fixed with $3.75 \%$ formaldehyde and counter-stained with DAPI for nuclear staining.

\subsection{Volume enhancement of $1.4 \mathrm{~nm}$ Nanogold-HDL for visualization in EM}

Since all approaches to colocalize HDL with some known structures of the cells failed, we investigated th elocalization of HDL by EM. As glutaraldehyde fixations are slow and a lipid containing particle may not be fixed fast enough to represent the real state and localization of HDL, we used state of the art high pressure freezing (HPF) and freeze substitution fixation (FSF) for sample preparation. To avoid artefacts by too big or noncovalently bound electron microscope compatible label, we used $1.4 \mathrm{~nm}$ nanogold to label HDL. As nanogold is too small to be detected directly in EM, it had to be enhanced.

Unfortunately classical enhancement methods were not sensitive enough to detect HPFFSF nanogold, so we developed our own volume silver enhancement after FSF to detect nanogold HDL. 


\subsubsection{Increased detection sensitivity of volume silver enhancement of $1.4 \mathrm{~nm}$ nanogold}

HDL after HPF and FSF compared to classical on-section silver enhancement

To study HDL trafficking in endothelial cells, we labeled HDL with $1.4 \mathrm{~nm}$ nanogold and added it to a monolayer of EC followed by HPF for preservation for electron microscopy. On the one hand we performed the on-section silver enhancement of nanogold providing very low signal intensity (Figure $20 \mathrm{~A}$ and $1 \mathrm{~B}$ ), on the other hand, the volume silver enhancement after HPF and FSF in solution (Figure $20 \mathrm{C}$ and 1D).

As expected, much more nanogold was accessible for the enhancement reaction using the volume enhancement protocol. Significantly more events were detected than with onsection enhancement (Figure $20 \mathrm{C}$ and 1D compared to $26 \mathrm{~A}$ and 1B). On-section enhancement mainly provided single events on multi vesicular bodies. In contrast, using the volume enhancement protocol we were able to find many events, covering also other types of vesicles and also being more consistently appearing throughout the section. In addition, these pictures resembled more closely to the data obtained by fluorescence microscopy, which under similar conditions yielded more than just one or two vesicles visible in a virtual section through the cell.

Importantly, the volume silver enhancement showed less background (electron dense areas) derived from the enhancement and resulted in more clearly visible ultrastructure.

1

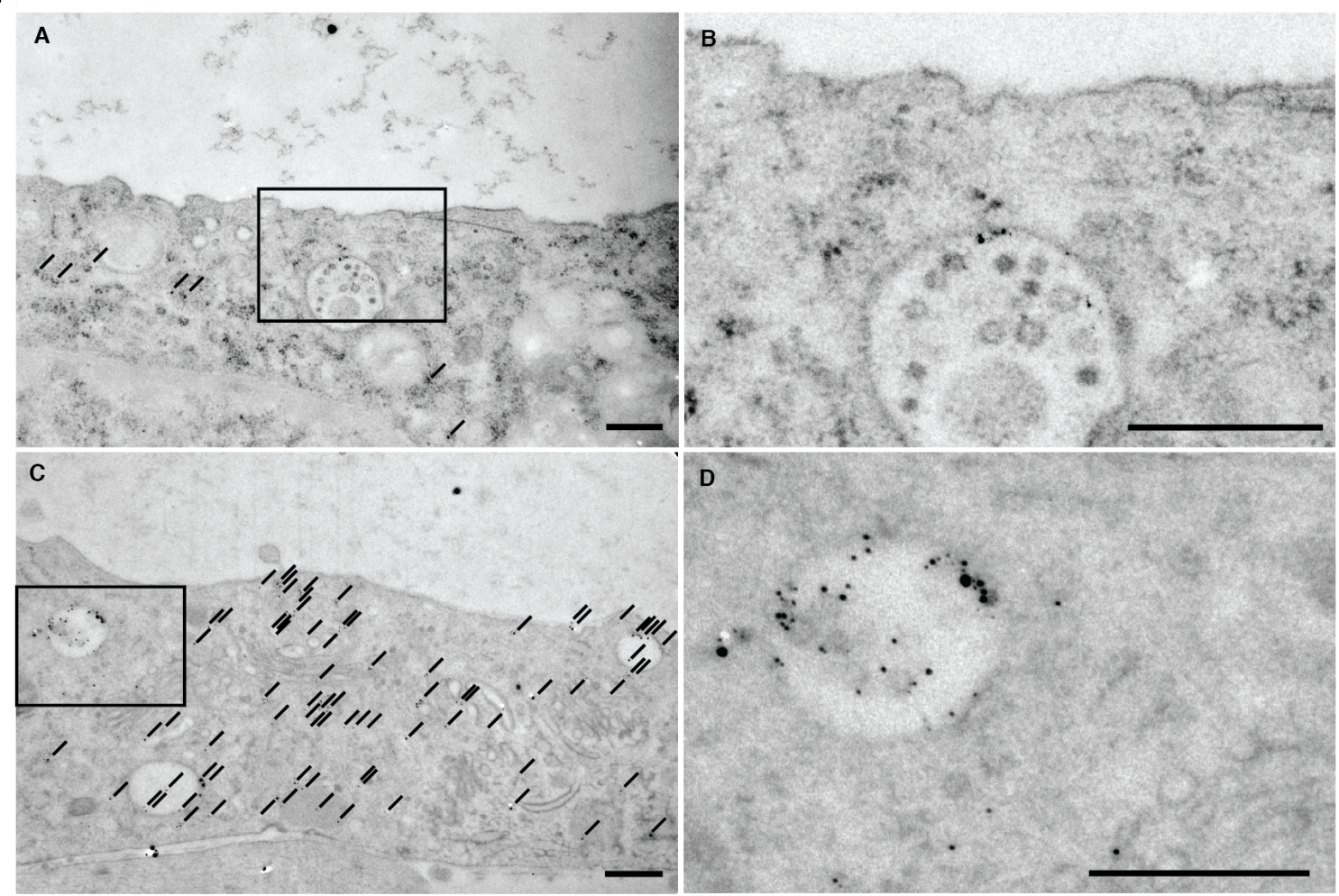

Figure 20: Endothelial cells were incubated for one hour with $1.4 \mathrm{~nm}$ Au-HDL at $37^{\circ} \mathrm{C}$, washed, then high pressure frozen, fixed during freeze substitution with OsO4. A and $\mathrm{B}$, samples were processed for TEM and silver enhancement was performed on ultrathin sections. In $C$ and $D$ volume silver 
enhancement was performed directly after freeze substitution. Dashes in low magnification (A and C) help visualize the distribution of the particles. Bar $=500 \mathrm{~nm}$

\subsection{2 $1.4 \mathrm{~nm}$ nanogold $L D L$ and $1.4 \mathrm{~nm}$ nanogold Albumin}

To verify that our method generated results comparable to other classical methods, we also visualized LDL (Anderson et al. 1976; Brown \& Goldstein 1979) and albumin (Vogel et al. 2001; Geoffroy \& Becker 1984) which are known to be endocytosed by the LDLreceptor and the GP60 cell surface protein, respectively, into endothelial cells. Both ligands were also coupled to $1.4 \mathrm{~nm}$ nanogold as the tracer and tested using the volume silver enhancement protocol. Both ligands were detected in endothelial cells after 30 minutes. Au-BSA was detected to a higher extend on the surface of EC (Figure $21 \mathrm{~A}$ and $27 \mathrm{~B}$ ) compared to Au-LDL (Figure $21 \mathrm{C}$ and $27 \mathrm{D}$ ) or Au-HDL (Figure $20 \mathrm{C}$ and D).

2
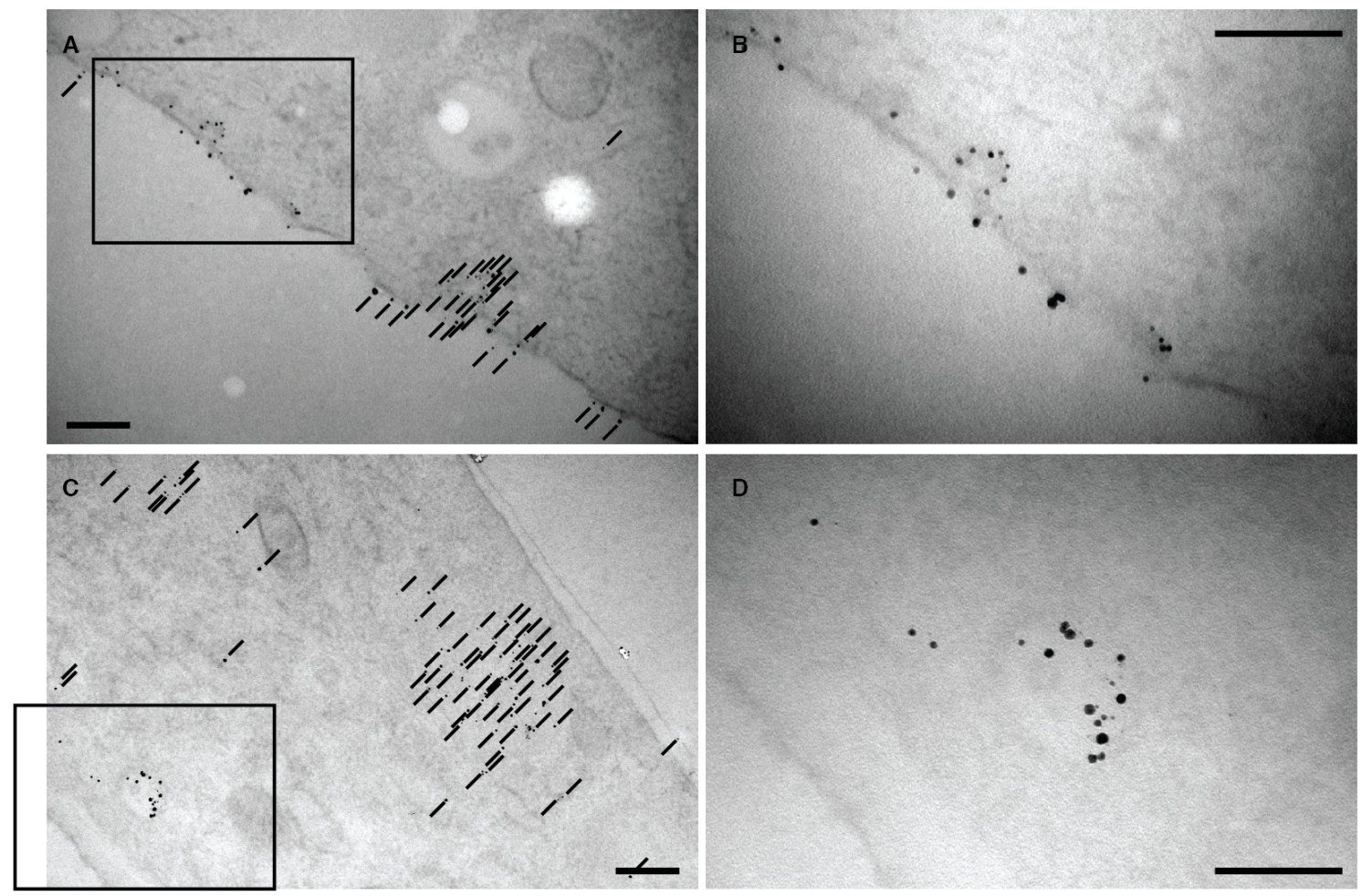

Figure 21: Endothelial cells were incubated for one hour with $1.4 \mathrm{~nm}$ Au-BSA (A and B) and 1.4 nm AuLDL (C and D), at $37^{\circ} \mathrm{C}$, washed, high pressure frozen, fixed during freeze substitution with 0 sO4 and volume silver enhancement was performed as described. Dashes help visualize the distribution of the particles. Bar $=200 \mathrm{~nm}$

\subsubsection{High background on badly frozen samples, very low on well-frozen samples}

To verify the specificity of the volume silver enhancement and to determine the background generated by the improved method, the enhancement on HPF, FSF treated 
cells was performed with native (not labeled) HDL. In Figure 22A and B hardly any silver is visible.

Sometimes HPF generated badly frozen monolayers of cells on which the volume enhancement resulted in silver particles evenly distributed throughout the biological material (Figure 22 C and D). Such samples cannot be used for analysis but were easily detectable because of the even distribution and the ice damaged ultrastructures (Figure 22 D).

3
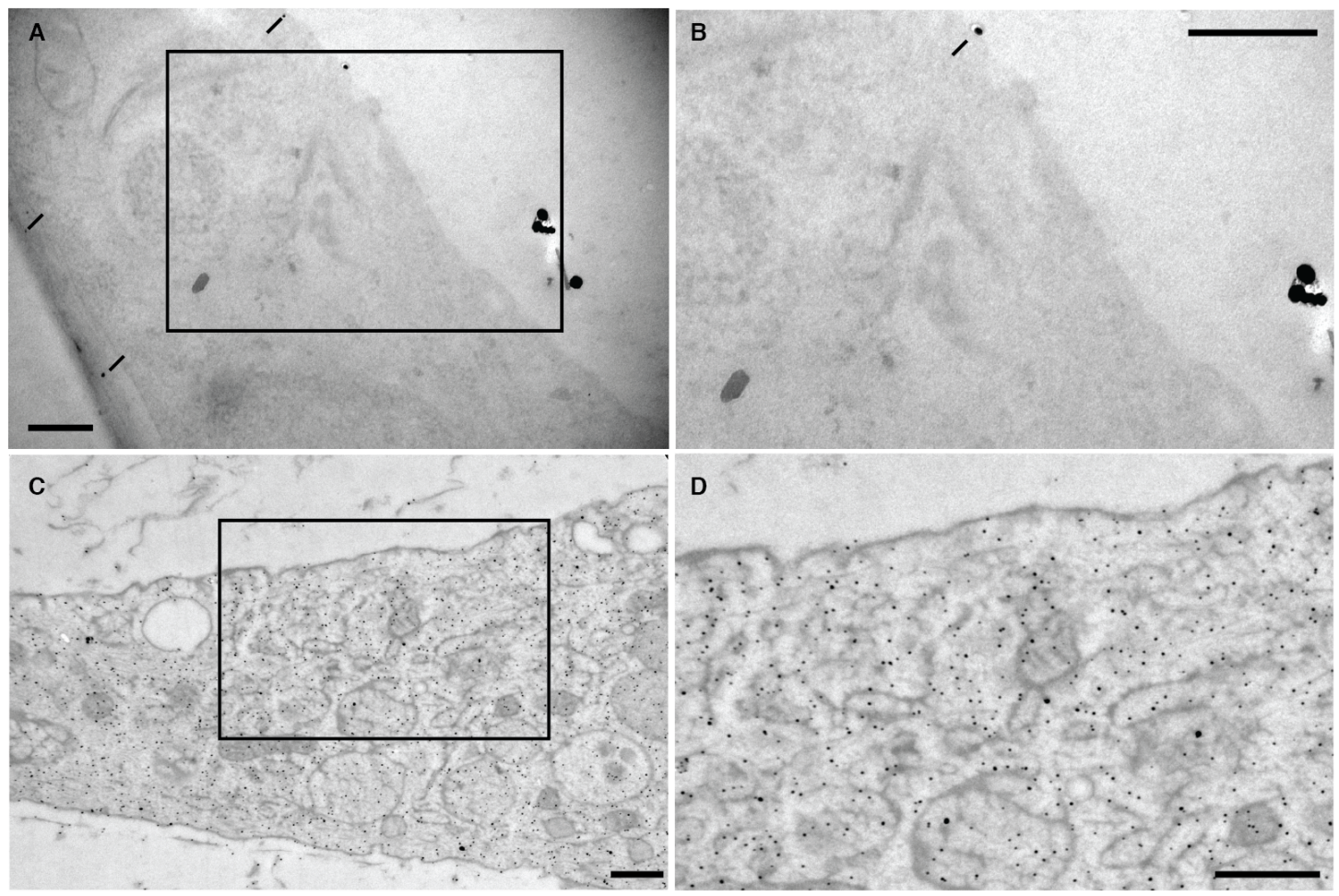

Figure 22: Determination of specificity and background: To determine the specificity and background of the volume enhancement protocol, endothelial cells were HPF/FSF after incubation with native (without 1.4-Au label) HDL and then volume enhanced. It shows very low background and autonucleation on HPF samples with good ultrastructure conservation (A and $B)$.

Possible pitfalls: HPF/FSF processed endothelial cells after incubation with $1.4 \mathrm{~nm} \mathrm{Au-HDL}$ on transwell membranes were volume enhanced. Uniform distribution of silver particles was seen on sections, where the HPF freezing was suboptimal and a lot of ice damage happened (C and D).

Bar 500 nm 


\subsection{Cellular localization of ABCA1, ABCG1, SR-BI and EL in endothelial cells and in bovine endothelium}

To analyse the cellular distribution of ABCA1, ABCG1, SR-BI and EL, which were previously found by our lab to be involved in the binding and transport of ApoA-I or HDL, we performed indirect immunofluorescence stainings with commercially available antibodies to localize ABCA1, ABCG1, SR-BI and EL in cell culture grown EC monolayers (Figure 23) and cryocuts of bovine aorta tissue. The tissue was cryocut and immunostained to detect the candidates in native endothelia (Figure 24).

ABCA1, ABCG1 and SR-BI were found mostly intracellularly within intracellular vesicles rather than on the surface. Only $A B C A 1$ and SR-BI were found at very low intensities at the surface (Figure $23 \mathrm{~A}$ and $\mathrm{C}$ ). EL, although active extracellularly, was only immunodetected in vesicles (Figure $23 \mathrm{D}$ ).

It turned out to be difficult to prepare cryocuts of aorta with intact endothelium. It was very fragile and easily displaced from the intima and eventually lost. Vasa vasorum were much easier to immunostain and analyse (Figure 24). 
A

antiABCA1 Novus 400-105 / AntiRabbit Alexa-488

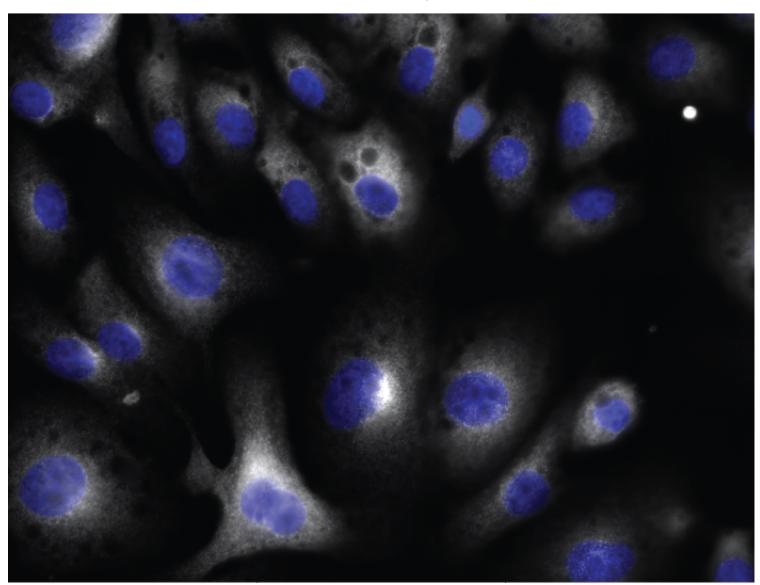

C antiSRB1 Abcam ab3 / AntiRabbit Alexa-488

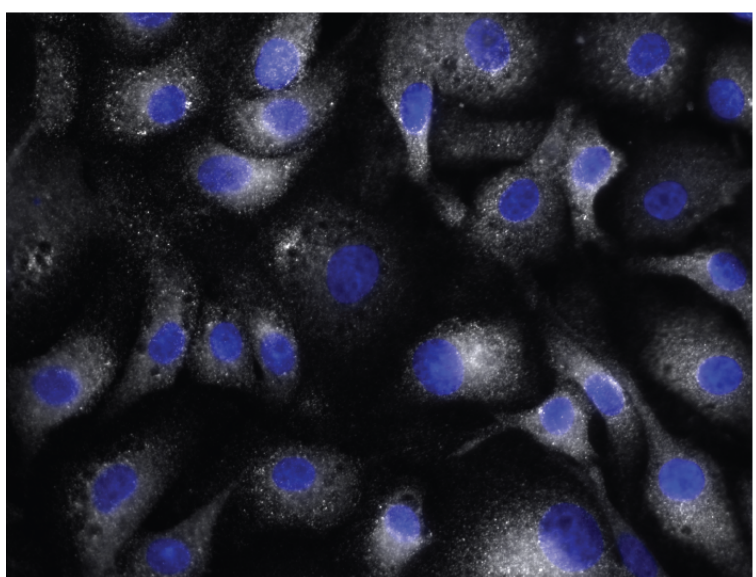

B

antiABCG1 H65 / AntiRabbit Alexa-488

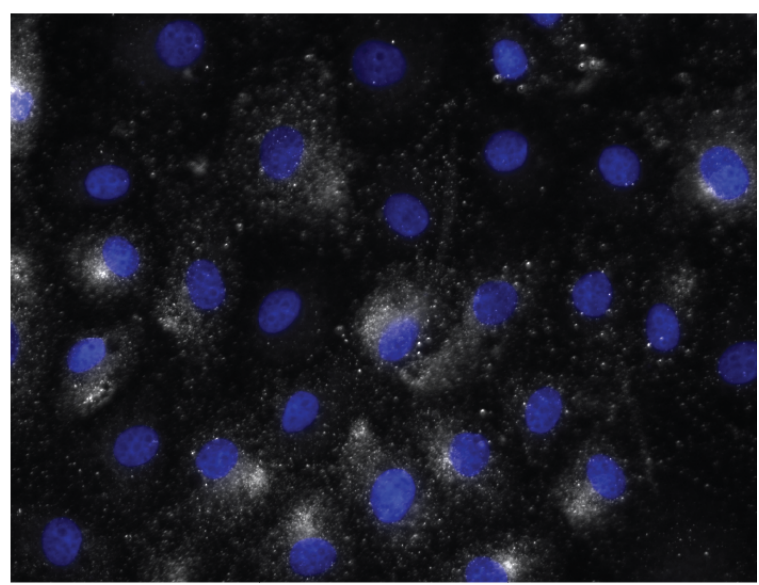

D antiLIPG / AntiRabbit Alexa-594 - 30 min 488-HDL

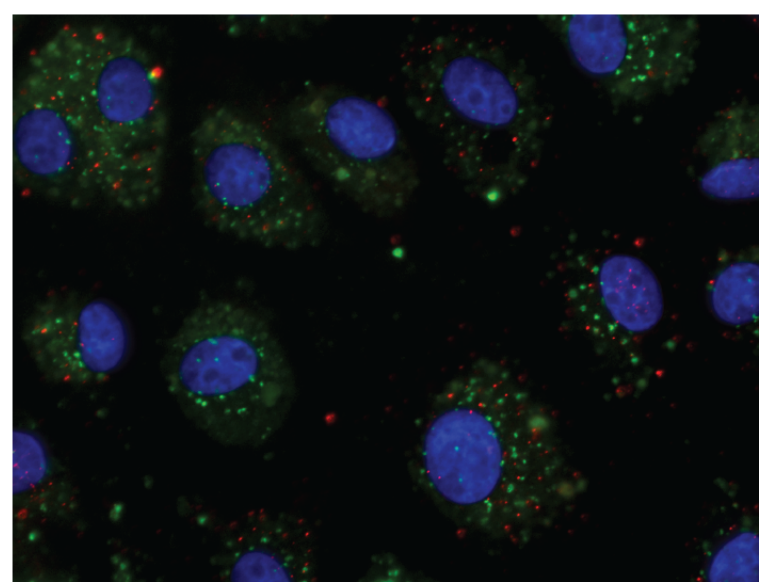

Figure 23: Immunostaining of ABCA1, ABCG1, SR-BI, and EL in ECs Monolayers of ECs were fixed with $3.75 \%$ Formaldehyde, blocked with $5 \%$ Donkey serum and incubated with the antibodies against ABCA1, ABCG1, SR-BI or EL (LIPG) and then with secondary alexa-coupled antibodies. In D, monolayers were incubated for $30 \mathrm{~min}$ with $50 \mu \mathrm{g} / \mathrm{ml}$ 488-HDL prior to fixation for co-localization studies. After indirect immunostaining, a DAPI staining was performed for nuclear localization. 
A

antiSRB1 Abcam ab3 / AntiRabbit Alexa-594 antiZO1 / AntiMouse Alexa-488

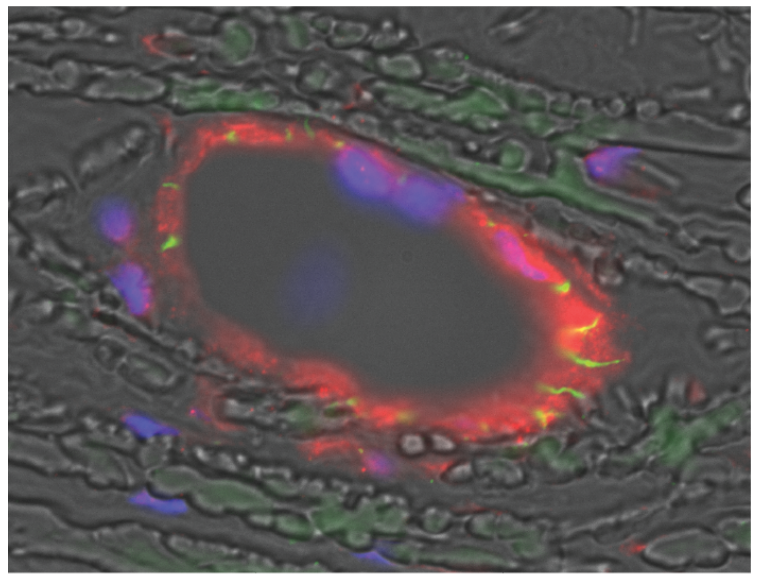

C antiABCA1 Abcam ab18180/ AntiMouse Alexa-488

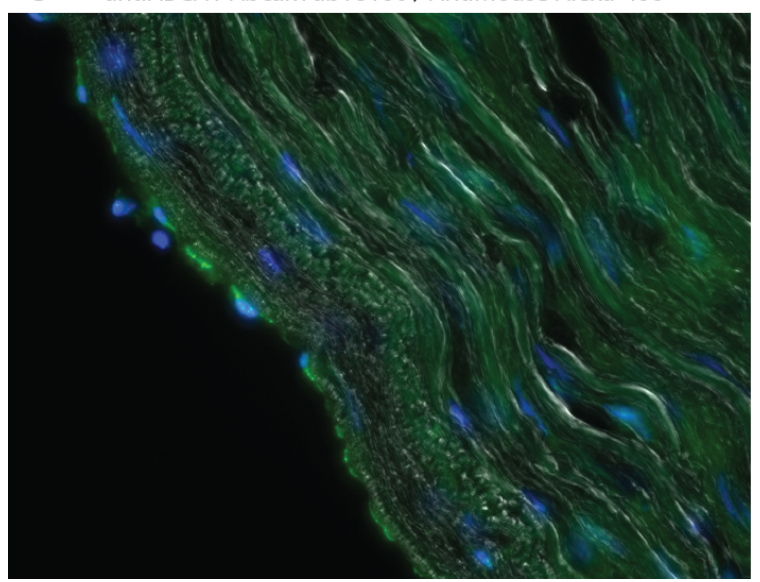

B antiABCG1 H65 / AntiRabbit Alexa-594

antiZO1 / AntiMouse Alexa-488

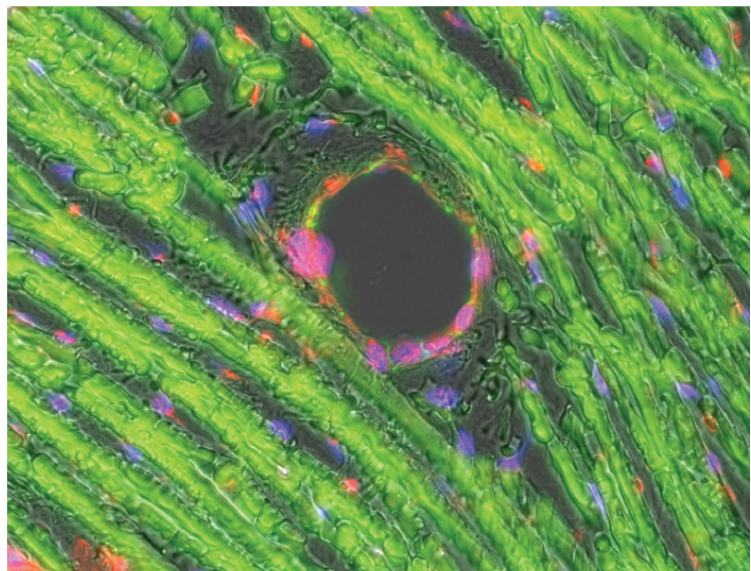

antiLIPG / AntiRabbit Alexa-488

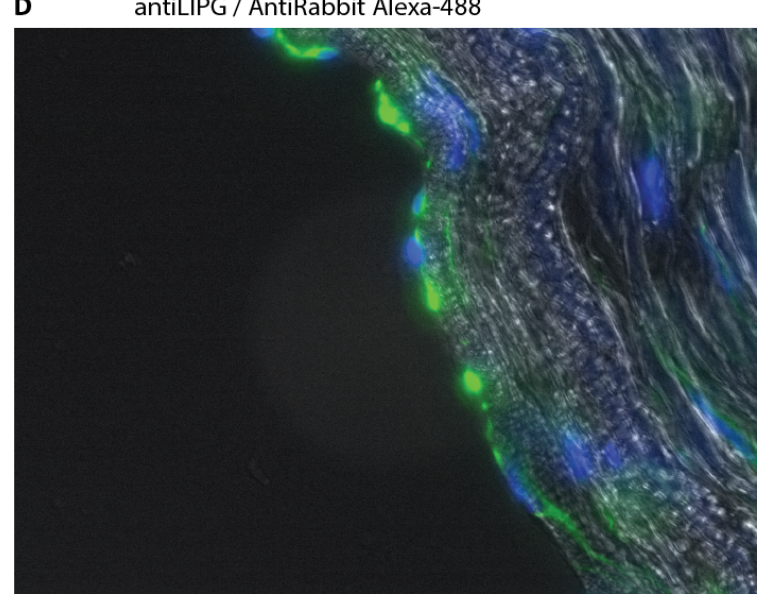

Figure 24: Immunostaining for ABCA1, ABCG1, SR-BI and EL in the endothelium of aortic vasa vasorum (A and $B)$ and aorta (C and $D)$

Bovine aortas were obtained freshly from the slaughter house. Cubes of $5 \times 5 \mathrm{~mm}$ including the endothelium were frozen in OCT upon which they were cryocut at 7-14 um thickness. The cuts were thawn and fixed with $3.75 \%$ formaldehyde and then indirectly immunostained

\subsection{Modulation of trafficking of HDL/ApoA-I by SR-BI and HDL itself}

In biochemical studies binding of 125I-HDL to ECs was clearly seen reduced after knockdowns of SR-BI and EL (Rohrer et al. 2009b). However, we failed to co-localize HDL with ABCA1, ABCG1, SR-BI, or EL in ECs. The interaction however could be too brief with too few contacts for immunocolocalization.

To analyse if inhibition of SR-BI interferes with the endothelial uptake of HDL, we incubated ECs with an anti-SR-BI antibody. After 30 minutes pre-incubation with the antibody, fl-HDL was added to the ECs and another 30 minutes later cells were fixed and visualy inspected. ECs preincubated with anti-SR-B antibody revealed reduced HDL uptake (Figure $25 \mathrm{~A}$ and $\mathrm{B}$ ). 
Alternatively the cells were pretreated with BLT1, a lipid transport inhibitor for SR-BI, for 30 minutes to be then incubated with fl-HDL for additional 30 minutes. This BLT1 treatment led to even more pronounced reduction in HDL uptake (Figure $25 \mathrm{C}$ and $\mathrm{D}$ ).
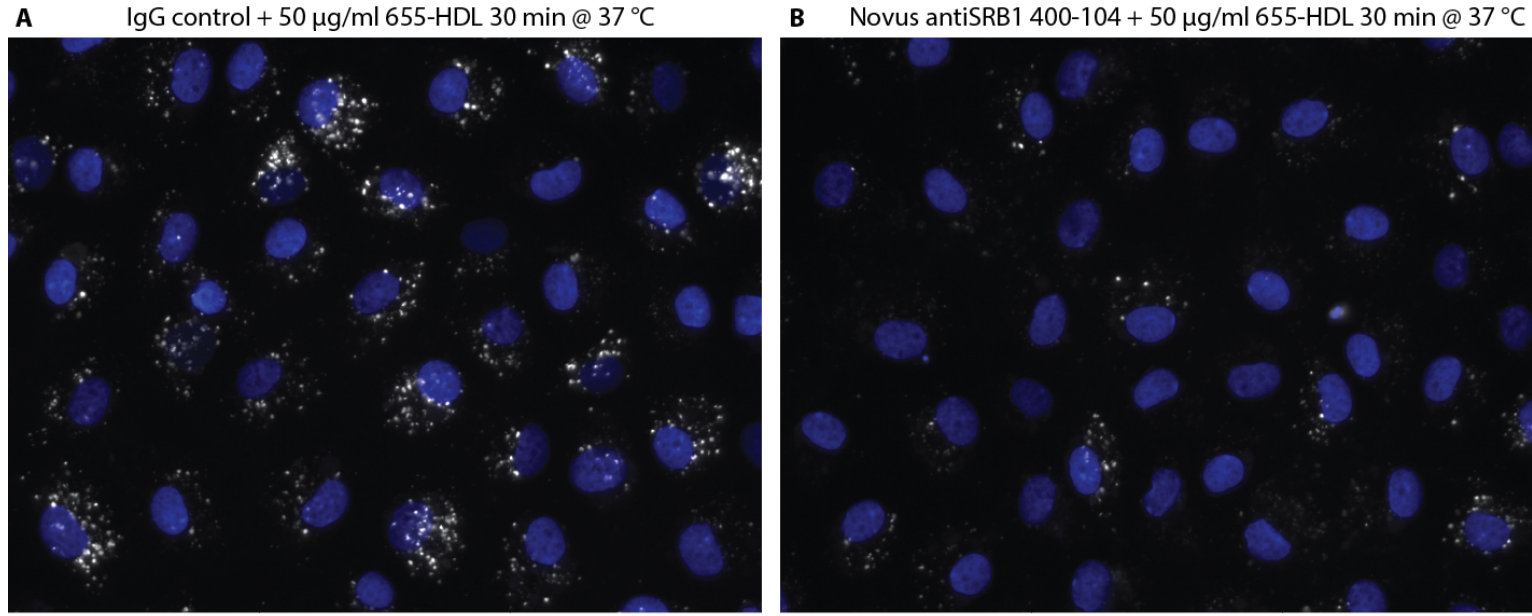

C DMSO preinc. $20 \mathrm{~min}, 50 \mu \mathrm{g} / \mathrm{ml} 594-\mathrm{HDL} 30 \mathrm{~min} @ 37^{\circ} \mathrm{C}$

D BTL1 preinc. $20 \mathrm{~min}, 50 \mu \mathrm{g} / \mathrm{ml} 594-\mathrm{HDL} 30 \mathrm{~min} @ 37^{\circ} \mathrm{C}$
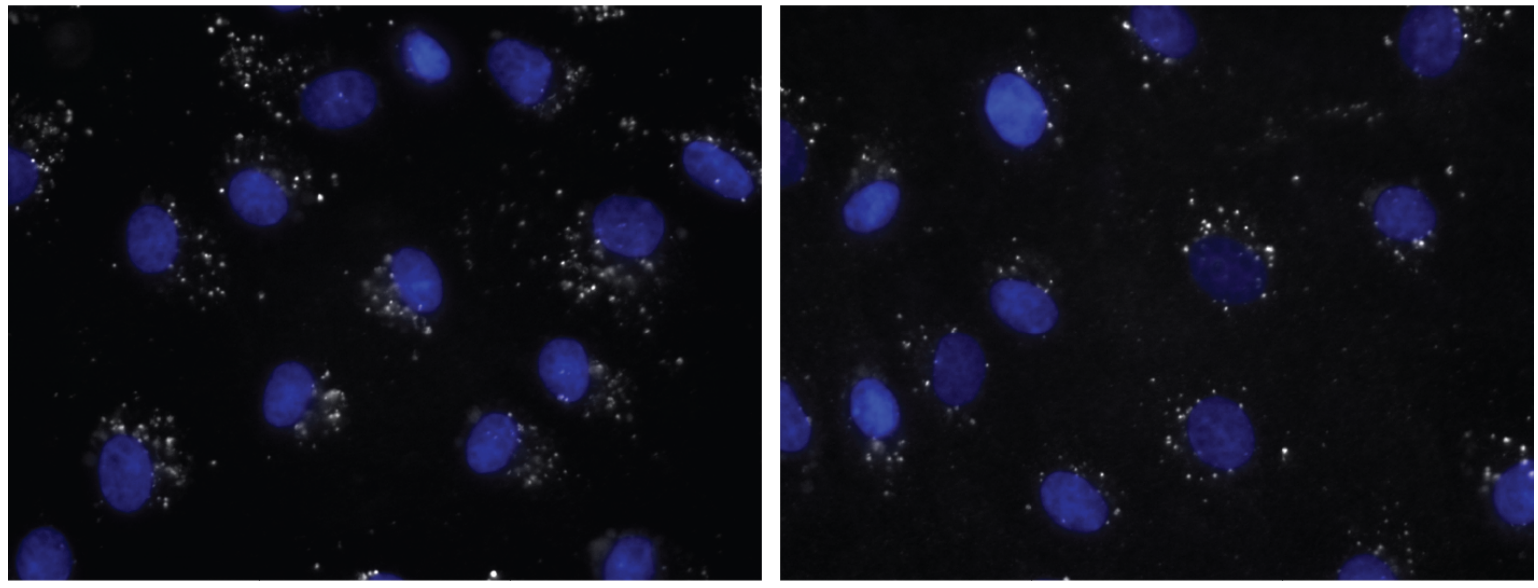

Figure 25: preincubation with antiSR-BI or BLT1 reduce HDL uptake

Monolayers of ECs were preincubated with either a blocking antibody (B) or isotype control (A) or BLT1 (D) at $10 \mu \mathrm{M}$ for 20 minutes. Then $50 \mu \mathrm{g} / \mathrm{ml}$ 594-HDL was added to the cells and further incubated for $30 \mathrm{~min}(A-D)$, the cells were fixed with $3.75 \%$ formaldehyde, counter stained with DAPI. 
When ECs were incubated with unlabeled HDL for 30 minutes before incubation with flHDL, the uptake of fl-HDL was enhanced (Figure 26).

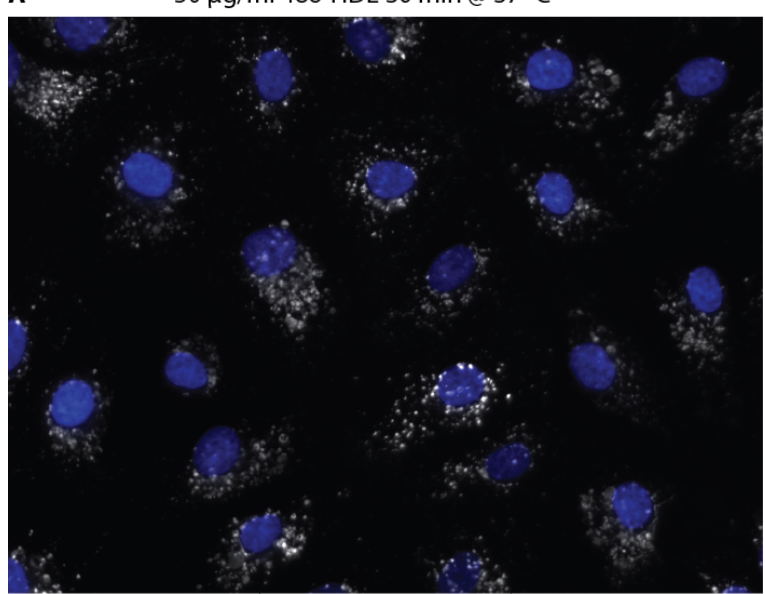

B $\quad 100 \mu \mathrm{g} / \mathrm{ml} \mathrm{HDL} 30 \mathrm{~min}, 50 \mu \mathrm{g} / \mathrm{ml}$ 488-HDL $30 \min @ 37^{\circ} \mathrm{C}$

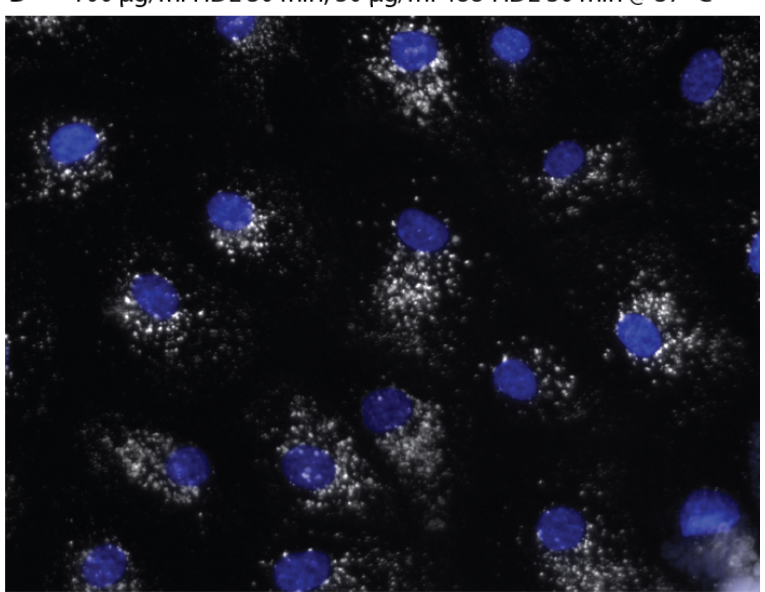

Figure 26: HDL preincubation increases uptake of HDL

Monolayers of ECs were incubated with $100 \mu \mathrm{g} / \mathrm{ml}$ unlabeled HDL (B) prior to 30 minutes incubation with $50 \mu \mathrm{g} / \mathrm{ml}$ fl-HDL (A and B). The cells were fixed with $3.75 \%$ formaldehyde and counter stained with DAPI for nuclear staining.

\subsubsection{Phosphoprotein-Profiles in ECs after exposure to HDL or ApoA-I}

We investigated HDL induced signaling in ECs by analyzing the phosphoprotein-profile with the phospho-kinase membrane arrays from R\&D systems covering 43 kinases and two signaling proteins. After 30 minutes incubation of ECs with 3 different HDL preparations, we identified 9 consistently up-regulated and 6 consistently down-regulated phosphosites (Figure 27). In addition there were 10 sites, which were discrepantly regulated upon exposure to the different HDLs. Phosphosites downregulated by HDLs are WNK1 T60, HCK Y411 FAK Y397 PRAS40 T246, STAT3 Y705 and HSP27 S78/82. Phosphosites upregulated by HDLs include PLC-Y1 Y783, Akt T308, STAT2 Y689, p38a T180Y182, STAT6 Y641, eNOS S1177, p53 S46, STAT5b Y699 and c-Jun S63.

For comparison we also investigated ApoA-I induced signaling in ECs by analyzing the same phosphoprotein-profile with the phospho-kinase membrane. After 30 minutes incubation of ECs with delipidated ApoA-I preparations, we identified 5 consistently upregulated and 6 consistently down-regulated phosphosites.

Phosphosites downregulated by ApoA-I are Stat3 S727, p53 S392, HSP60, WNK1 T60, PLCg1 Y783 and HSP27 S78/S82. Phosphosites upregulated by ApoA-I are akt T308, cJun S63, p70 s6k T421/S424, PDGF Rb Y751 and p38a T180/Y182. 


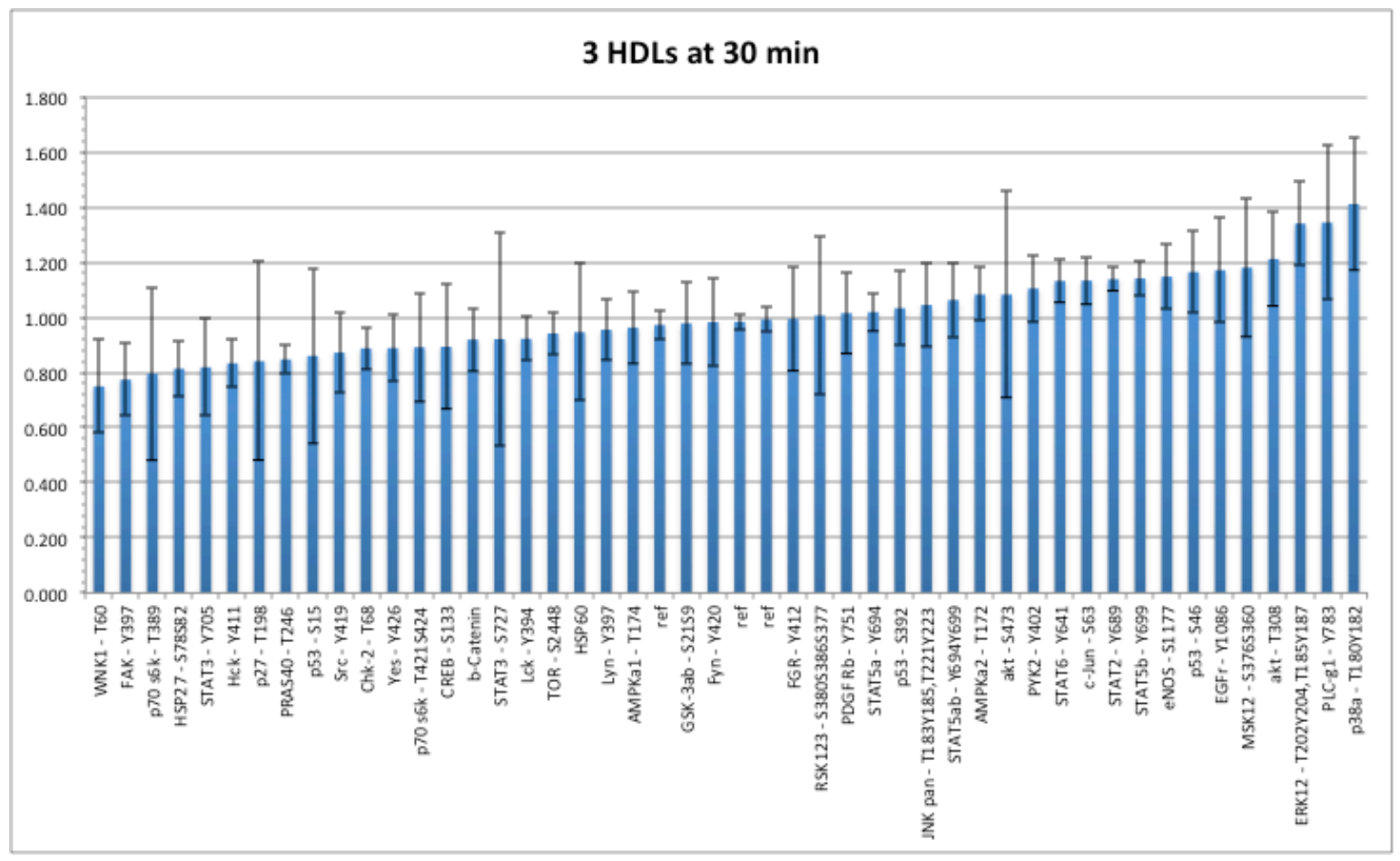

Figure 27: Changes in the degree of phosphorylation of kinases and signaling proteins in response to 30 min incubation of ECs with HDL. Data are means + standard deviations of three independent experiments

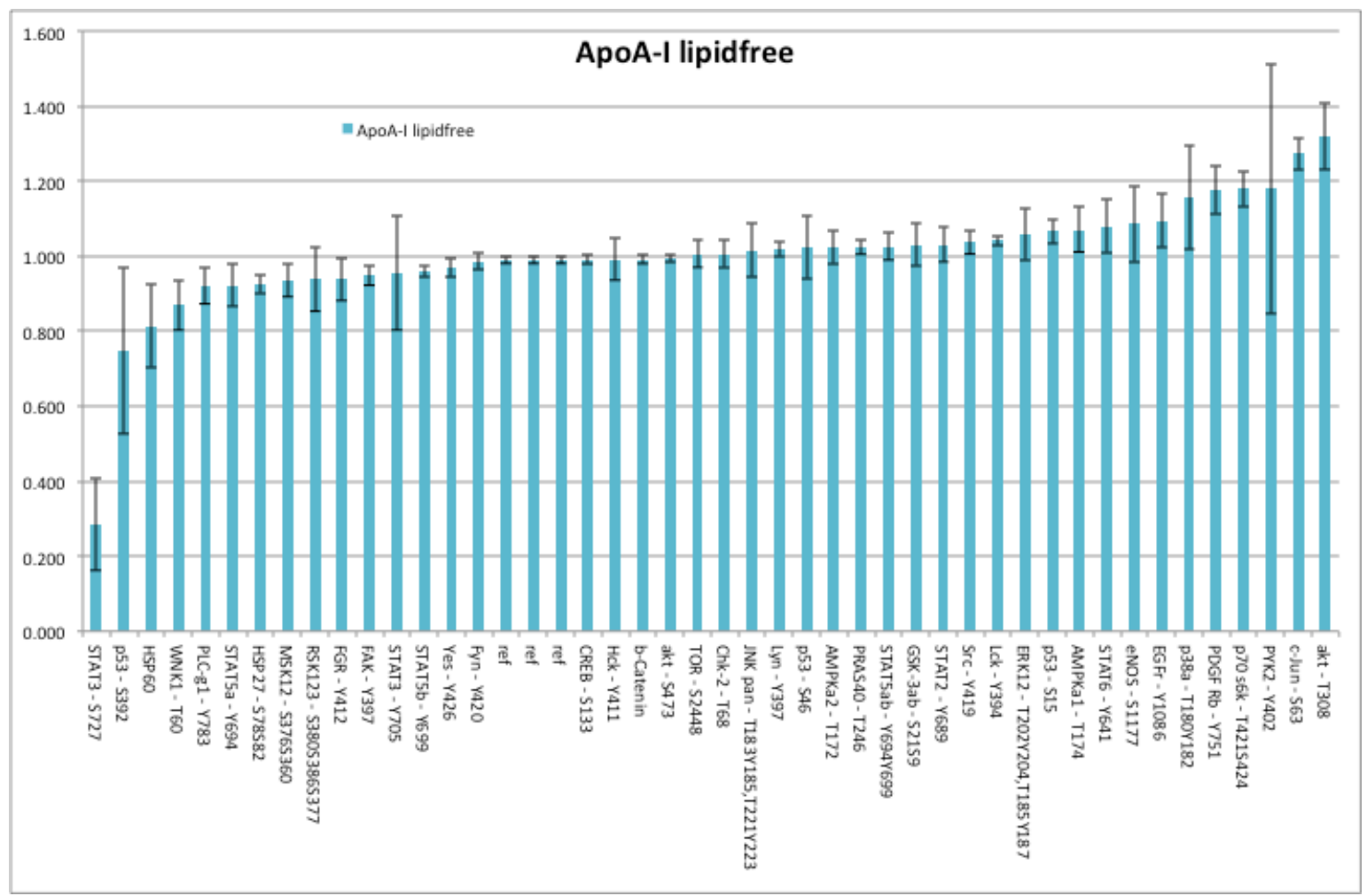

Figure 28 : Changes in the degree of phosphorylation of kinases and signaling proteins in response to $30 \mathrm{~min}$ incubation of ECs with $100 \mu \mathrm{g} / \mathrm{ml}$ lipid free apoA-I. Data are means + standard deviations of three independent experiments 


\begin{tabular}{|c|c|c|}
\hline Phosphosites & $\begin{array}{l}\text { HDL-induced changes in } \\
\text { phosphorylation (fold) }\end{array}$ & $\begin{array}{l}\text { ApoA-I induced changes } \\
\text { in phosphorylation (fold) }\end{array}$ \\
\hline WNK1 - T60 & $0.749 \pm 0.170$ & $0.869 \pm 0.066$ \\
\hline FAK - Y397 & $0.774 \pm 0.131$ & n.s. \\
\hline HSP27 - S78S82 & $0.814+0.101$ & $0.925+0.027$ \\
\hline STAT3 - Y705 & $0.819 \pm 0.177$ & n.s. \\
\hline HCK - Y411 & $0.833 \pm 0.088$ & n.s. \\
\hline PRAS40 - T246 & $0.847 \pm 0.051$ & n.s. \\
\hline STAT3 - S727 & n.s. & $0.285+0.123$ \\
\hline P53 - S392 & n.s. & $0.749 \pm 0.222$ \\
\hline HSP60 & n.s. & $0.813 \pm 0.112$ \\
\hline PDGF Rb - Y751 & n.s. & $1.177+0.066$ \\
\hline P70 s6k - T421 / S424 & n.s. & $1.179 \pm 0.048$ \\
\hline c-Jun - S63 & $1.133 \pm 0.086$ & $1.274 \pm 0.043$ \\
\hline STAT6 - Y641 & $1.132+0.078$ & n.s. \\
\hline STAT2 - Y689 & $1.139 \pm 0.042$ & n.s. \\
\hline STAT5b - Y699 & $1.141 \pm 0.064$ & n.s. \\
\hline eNOS - S1177 & $1.148+0.119$ & n.s. \\
\hline Akt - T308 & $1.212 \pm 0.171$ & $1.320 \pm 0.089$ \\
\hline PLC-g1 - Y783 & $1.344+0.281$ & $0.921 \pm 0.048$ \\
\hline p38a - T180Y182 & $1.411 \pm 0.240$ & $1.156+0.138$ \\
\hline
\end{tabular}




\section{Discussion}

To elucidate the itinerary of ApoA-I and HDL through endothelial cells (ECs), we investigated the cellular localization of ApoA-I and HDL. HDL as well as ApoA-I are taken up by ECs, and ApoA-I and HDL co-localize indicating the same route of trafficking. We compared the trafficking of ApoA-I and HDL with Transferrin and Albumin, which were used as tracers for clathrin- and caveolin-mediated endocytosis, respectively. Both pathways showed partial colocalization indicating a non-classical pathway for HDL trafficking. Further experiments showed that HDL is targeted neither to lysosomes nor to the Golgi nor to the endoplasmatic reticulum. Only a small amount can be detected in early endosomes (Rab5) and endosome to trans-golgi network (Rab9), but not at all with late endosomes (Rab7), the recycling endosomes (Rab11a) or vesicles involved in transGolgi network sorting (Syntaxin6). EM ultrastructure showed HDL to be located mainly in multivesicular bodies. We performed pharmacological inhibitions and found that HDL uptake depends on intact cytoskeleton but not on fluid phase uptake. HDL was found to stimulate its own uptake into ECs. We identified several HDL and/or ApoA-I induced changes in the phosphorylation of signaling molecules, which however still remain to be linked to HDL endocytosis.

\subsection{Novel methodological developments}

As we did not figure out the identity of HDL containing vesicles by light microscopy, we decided to use electron microscopy to visualize them and get a glimpse on their ultrastructure. $1.4 \mathrm{~nm}$ nanogold and undecagold (Nanoprobes USA) as well as AuroraGold-linked lipids (Avanti USA) are excellent tools for studying the cellular trafficking of proteins, small molecules, nanoparticles, lipid droplets, micelles, lipoproteins and lipid carrying proteins by electron microscopy. Because of their limited visibility by electron microscopy, they have not been extensively used. Rather, alternative methods like DAB photo oxidation through fluorescent labels (Dantuma et al. 1998) or larger labels like colloidal gold were used which however compromise spatial resolution and potentially interfere with the trafficking of the protein of interest.

On-section silver enhancement of HDL in endothelial cells after HPF, FSF, and embedding in EA proved to be a suboptimal method for the detection of $1.4 \mathrm{~nm}$ nanogold, since the signal was extremely weak compared to fluorescent data. Morphew et al. (Morphew et al. 2008) were the first to establish a method to visualize nanogold particles 
with an enhancement method during FSF allowing three dimensional EM studies of small tracers. However, the drawback of their volume enhancement method is the multitude of handling steps and the long enhancement time at two different temperatures.

This led us develop the described short protocol for volume silver enhancement after FSF, which reduces the enhancement to effectively 30 minutes compared to 18 hours outlined in Morphews protocol (Figure 29).

4

Enhancment 3D short after FSF Enhancement 2D on section Enhancment 3D during FSF

\begin{tabular}{|l|}
\hline Biological Experiment \\
\hline High Pressure Freezing \\
\hline
\end{tabular}

Break possible - storage of samples in LN2

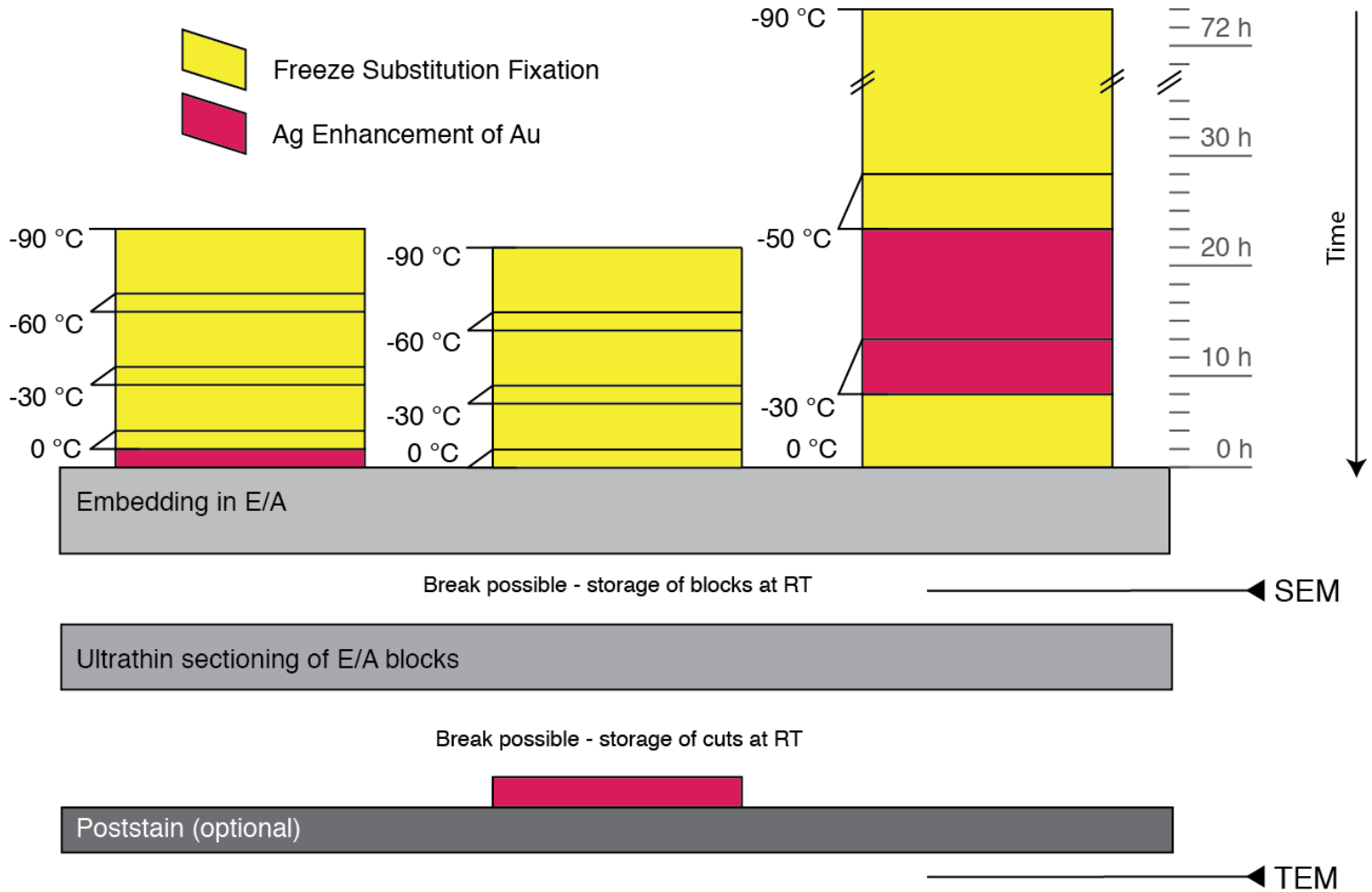

Figure 29: Fast volume enhancement after FSF

The method is based on the classical silver enhancement approaches and Arabic gum was added as a protection colloid. With the Arabic gum present, the auto-nucleation and background signals were kept low on high pressure frozen samples of good quality. In badly frozen samples, silver nucleation was detected throughout the sample. The even distribution refers to distortion of the ultrastructure due to ice crystals generated during the freezing process. 
In conclusion, we here present a novel sensitive and fast method for the visualization of lipid containing nanogold labeled particles in cells by TEM, which is compatible with HPF and FSF. This method opens new possibilities for the electron microscopic or tomographic analysis of nanogold labelled ligands within cells. It offers advantages in situations where lipid trafficking and lipid involvement is crucial.

\subsection{What is the trafficking route of HDL and ApoA-I in endothelial cells?}

To unravel the trafficking route of $\mathrm{HDL}$ and ApoA-I through ECs, we tried to co-localize HDL with vesicle and organelle markers as well as other proteins trafficking through ECs. We also explored effects of pharmacological inhibition on the trafficking of HDL through ECs.

\subsubsection{HDL co-localizes with lipid-free ApoA-I}

After 30 minutes HDL colocalizes perfectly with ApoA-I (Figure 4) when both are incubated with a monolayer of ECs either together or sequentially with a difference of some minutes. This is in agreement with the model previously established by our lab based on biochemical trafficking experiments using wild type and mutant ApoA-I (Ohnsorg et al. 2011). An ApoA-I mutant, which does not elicit ABCA1 dependent lipid efflux and therefore does not form HDL discs was not internalized by ECs. However after prior artificial lipidation, HDL discs containing the mutant ApoA-I were internalized. We therefore suggested that lipid-free ApoA-I is lipidated by ABCA1 to be internalized by the same route that artificial discoidal or native spherical HDL uses. Based on this, we continued with our experiments with HDL as the object in study, as it behaves identical to ApoA-I.

\subsubsection{Time dependent trafficking of HDL through ECs}

Upon incubation for different time intervals, the fluorescent HDL changed its distribution within ECs (Figure 12). Initially few very weak signals appeared in the periphery of ECs as small vesicles. After 10 minutes the fluorescent HDL containg vesicles started clustering around the golgi at one side of the nucleus. This distribution is maintained from $30 \mathrm{~min}$ to about 3 hours. Thereafter the distribution becomes more peripheral. After 16 hours, more fluorescent HDL was detected on one side of the nucleus than in the periphery. At this 
later time points the vesicles also appeared to be bigger than at shorter time points. Thus during a period ranging from 5 minutes to 16 hours, HDL resides in at least 3 different compartments of ECs. The nature of these HDL containing compartments needs to be defined.

Endocytosis of GlycNAc labeled membrane proteins with fl-WGA was slower than HDL uptake (Figure 10). During the first 10 minutes we observed co-localization of HDL with WGA. During the following 20-30 minutes HDL and WGA accumulated in different golgisurrounding vesicles. From here, HDL was continuing its journey only after hours. Unfortunately we were not able to identify the compartment where HDL remained for hours by fluorescence microscopy since none of our organelle markers showed any colocalization with HDL Therefore we switched to electron microscopy to analyse the vesicles, which contain HDL between 20 min and $4 \mathrm{~h}$ after uptake. The Au-HDL was mainly localized in multi vesicular bodies (MVB) where it was associated with the main membrane as well as the inner vesicles. Since MVBs are the main sorting stations of vesicular traffic, we assume that the HDL seen in fluorescence microscopy close to the golgi functions as a buffer or intermediate storage compartment for HDL transcytosis.

\subsubsection{Evidence for very fast transcytosis}

To analyse HDL transcytosis in temporal resolution, live microscopy experiments on cells cultured in transwells were performed. Surprisingly, while scanning at full speed the signals appeared both intracellularly in the ECs and below the ECs at the basolateral side. One to two volume sweeps (corresponding to 82 and164 seconds, respectively), after adding $\mathrm{fl}-\mathrm{HDL}$ to the upper compartment of transwell plates containing a monolayer of ECs, signal could be detected below the EC layer (Figure 13). Only 10-15 minutes later vesicles lightened up inside ECs. Unfortunately, while being very good for light sectioning, the available confocal microscope was not fast and sensitive enough to detect fast weak signals of peripheral vesicles between zero and 82 seconds. However, the monolayer was still visibly intact and no signal could be detected in the junctions. Two alternative models can explain our findings:

1. HDL may be trafficked through ECS by two parallel routes, one very fast leading to resecretion of $\mathrm{HDL}$ and one much slower leading to the accumulation of HDL within MVBs. 2. HDL is trafficked through one route and HDL accumulates in MVB's if endocytosis is faster than exocytosis. To distinguish which model is true, we need access to fast live $3 d$ microscopy and interfere with sorting processes inside the cell. 


\subsubsection{Role of clathrin. caveolae and fluid phase for HDL uptake by}

Both Albumin and Transferrin are internalized and resecreted by endothelial cells to supply sub-endothelial cells with their cargo, notably fatty acids and iron, respectively. HDL was partially co-localized with both Transferrin (Trf) and Albumin (Alb) (Figure 6 and Figure 7) indicating that their itinerary is overlapping with that of HDL. However the lack of complete co-localization indicates that they are not following the identical route. Albumin uptake depends on caveolin 1 and involves gp60 as the receptor (Geoffroy \& Becker 1984; Vogel et al. 2001). Transferrin was reported to pass the endothelium by both clathrin dependent and independent pathways (Kishimoto \& Tavassoli 1987; Fishman et al. 1987; Roberts et al. 1993; Roberts \& Sandra 1994; Tsuji et al. 2013). Transferrin interacts with the transferrin receptor for either endocytosis pathway.

To test if HDL is internalized by clathrin or caveolin coated vesicles, we checked for colocalization. At neither $37^{\circ} \mathrm{C}$ nor $18^{\circ} \mathrm{C}$ we observed any co-localization of $\mathrm{HDL}$ with clathrin and Caveolin 1 (Figure $5 \mathrm{C}$ and D). In conjunction with the lack of complete colocalization between HDL, albumin and transferrin this indicates that HDL is internalized by ECs through a non-clathrin- and non-caveolin-dependent endocytic pathway.

We suspected that HDL is taken up by fluid phase. The underlying pinocytosis does not require any defined receptor-ligand-interaction but is a bulk transport regulated independently of dynamin 2, clathrin and caveolin in epithelial cells (Cao et al. 2007). For example viruses are known to be internalized by pinocytosis (Mercer \& Helenius 2009; Mercer \& Helenius 2012). Interestingly, blocking of $\mathrm{Na} / \mathrm{H}$-channels essential for any fluid phase transport by Amiloride and/or EIPA even at high concentrations did not change HDL uptake (Figure $8 \mathrm{~A}-\mathrm{C}$ ). In addition we tried to co-localize fl-HDL with fluorescently labelled $40 \mathrm{kDa}$ Dextran, which is taken up by cells through fluid phase endocytosis. We did not observe any co-localization of HDL and fl-Dextran (Figure $8 \mathrm{D}-\mathrm{E}$ ). Taken together, these findings indicate that HDL is not taken up by fluid phase.

\subsubsection{HDL does not go to lysosomes}

Previous studies have shown that HDL is $10-20$ fold less effectively degraded than LDL when incubated with endothelial cells (Tauber, Goldminz, Vlodavsky, et al. 1981). When cells need cholesterol or lipids, they can either synthetize it themselves, or increase uptake of lipoproteins. LDL is taken up by the LDL-receptor or LDL-Receptor like Protein family proteins (LRPs) and then transported to the lysosomes for degradation and delivery of lipids to other organelles. Only a part of LDL internalized by ECs is transported to lysosomes and degraded together with its receptor (Vasile et al. 1983). There are some 
indications that a considerable part of LDL is transcytosed by ECs through caveolin 1 containing vesicles (Bian et al. 2014). In fact, LDL found in the subendothelial space had to cross the endothelium. However this process is not well known. It is well possible that LDL crosses ECs by pathways avoiding the lysosomes similar to Trf and Alb and HDL. But for

Biochemical turnover studies from our lab indicate that there is almost no degradation of HDL proteins in ECs (Rohrer et al. 2009b). In agreement with this and excluding any significant transport of HDL into lysosomes, we found no co-localization of fl-HDL with Lysotracker DND 99 (Figure 14). This non-lysosomal targeting is also indicated by the lack of any co-localization of HDL with Rab7, a marker for late endosomes (Figure 16) through which all classic traffic to lysosomes is channeled.

The residence of a considerable proportion of HDL within ECs over a rather long period of time (Figure 12) without being degraded and secreted (Figure 13) indicates that HDL exerts functions while located intracellularly. Of special note HDL exerts many protective functions in endothelial cells. They are usually explained by extracellular interactions of HDL with ECs for example via cholesterol efflux or signaling events on the EC cell surface (Mineo \& Shaul 2013; Annema \& von Eckardstein 2013). But it will be interesting whether some depend on HDL internalization.

\subsubsection{No co-localization with organelles and main sorting vesicular pathways}

As after 30 minutes intracellular fl-HDL clusters close to one side of the nucleus, we suspected that it is transcytosed through the transgolgi network (TGN). However, staining the cells incubated with fl-HDL for Golgi58kDa protein and calnexin as markers for golgi and endoplasmatic reticulum (ER), respectively, revealed no co-localization (Figure 15). Neither did we see any co-localization with rab9 and syntaxin6 (Figure 18), both being involved in the trafficking to the TGN and golgi (Bock et al. 1997; $\mathrm{Ng}$ et al. 2012). This indicates, that HDL is localized in vesicles in close proximity to TGN, golgi or ER-golgi intermediate compartment (ERGIC) (Appenzeller-Herzog \& Hauri 2006) but it is not directly crossing these metabolically active organelles of ECs.

To further study the intinerary of HDL in ECs, we explored its co-localization with Rab5, the protein found on most endocytic endosomes, and Rab7, a marker for late endosomes. HDL failed to co-localize with either Rab5 or Rab7 after 30 minutes. Within shorter intervals, HDL positive vesicles were too faint for co-localization. This suggests that HDL passes the endosomes very quickly or in low amounts to accumulate in vesicles, which are rab5 and rab7 negative (Figure 16). 
Rab11a is a marker for recycling vesicles transporting membrane and material coming from the apical surface back to the apical membrane. The Rab11a staining pattern was completely different from that of internalized fl-HDL (Figure 17), so that it is very unlikely that HDL travels through the recycling route. This is also in agreement with the transendothelial transport that we observed by biochemical experiments (Rohrer et al. 2009b).

\subsubsection{HDL uptake and sorting depends on the cytoskeleton and dynamin}

The cytoskeleton is essential for any vesicular trafficking within the cell. Vesicles can be moved either by actin tails or kinesin-dynein driven movement across microtubule (DePina \& Langford 1999). To analyse their impact on HDL uptake, we destabilized f-actin formation and blocked the generation of new actin fibers by cytochalasin $D$ and disturbed microtubuli by colchicine. Both drugs affected the quantitative uptake of HDL slightly. However and unlike the interference with actin, the destruction of microtubules led to a gross change in the cellular distribution of HDL positive vesicles, which accumulated in peripheral rather than perinuclear compartments (Figure 19). It appears that the destruction of microtubule networks blocks the accumulation of HDL in MVB. This indicates, that HDL has to pass through endosomic vesicles before reaching MVBs. Dynamin aids the formation of vesicles by invagination from membranes by providing machinery for pinching off the newly formed vesicle from the original membrane. We tested the involvement of dynamin by blocking it pharmacologically with dynasore (Macia et al. 2006), an inhibitor of dynamin activity and dynamin dependent vesicle formation. In our experiments dynasore treatment slightly reduced HDL uptake. Strikingly, however, dynamin shifted the distribution of HDL into smaller vesicles. This suggests that some essential sorting steps are blocked by dynasore or that the cell architecture in general was disturbed by the treatment (Figure 9). At $18{ }^{\circ} \mathrm{C}$ dynamin blockage by Dynasore led to the patchy accumulation of small vesicles close to the cell surface with much higher fluorescence signal than even the $37^{\circ} \mathrm{C}$ internalized fl-HDLs and than we would expect to see. It could be that dynasore together with the temperature-lowered fluidity of membranes halts HDL internalization at one certain state and thereby favors the cellular accumulation of HDL.

The PI3/4 Kinase inhibitor Wortmannin was another drug, which had significant effect on HDL uptake and distribution, ,. The uptake of HDL in the presence of Wortmannin was partially blocked (Figure 9) indicating that PI3/4K signaling was influencing the uptake of $\mathrm{HDL}$ or that $\mathrm{HDL}$ required a certain membrane distribution of $\mathrm{PI} 3 \mathrm{P}, \mathrm{PI}(3,4) \mathrm{P} 2$ and $\mathrm{PI}(3,4,5) \mathrm{P} 3$. It is well possible that downstream signaling of PI3K via Akt and TOR 
signaling regulate $\mathrm{HDL}$ transport. Notably Akt is known to mediate many protective functions in ECs and to be activated by HDL, for example to activate eNOS and surpress VCAM1 cell surface expression (Mineo et al. 2003). The interaction of SR-BI with HDL which we previously found to modulate HDL transcytosis is known to signal via SR-BIPDZK-(?)-PI3K-Akt (Saddar et al. 2010) To analyse this hypothesis in a more targeted approach, it will be essential to investigate if HDL regulates its own uptake by ECs via $\mathrm{PI3K} /$ Akt signaling.

\subsection{What is the cellular localization of ABCA1, ABCG1, SR-BI and EL in endothelial cells?}

Indirect immunostainings of monolayers of ECs (Figure 23) and cryocuts of bovine aorta tissue (Figure 24) showed ABCA1, ABCG1, SR-BI and EL located intracellularly in vesicles but surprisingly not on the cell surface. Possibly there are low amounts of some of these proteins on the cell surface because reducing the expression levels of SR-BI, EL and ABCG1 by siRNA reduced ${ }^{125} \mathrm{I}-\mathrm{HDL}$ binding (Robert et al. 2013; Rohrer et al. 2009b). It is well possible that the amount of these proteins on the surface was too low for detection by indirect immunostaining. Alternatively these proteins participate in HDL binding indirectly by modulating another receptor. This may indicate that these interaction sites on ECs either are very few or recycle very rapidly upon binding of HDL between the plasma membrane and intracellular compartments. Alternatively, we did not choose the right HDL receptor candidates. For example CD36 and cubilin/megalin, endothelial lipase and SR-BI splice variants need further detection beyond immunostainings. Transfection with fluorescent fusion proteins may influence the localization and function of a protein in study but they give crucial information in live microscopy on the steady state as well as fast events upon possible binding of HDL on the cell surface.

ABCA1 as well as F1-ATPase are interacting with lipid free ApoA-I, which is internalized only after lipidation.

Hardly any SR-BI was detected on the surface of ECs, in contrast to hepatocytes, where substantial amounts of SR-BI are expressed (Fenske et al. 2009). It is possible that one of its splice variants, for example SR-B1.2, is responsible for HDL-binding and internalisation. SR-B1.2 contains a clathrin interaction signal but in contrast to SRB1.1 the clathrin signal is replacing the PDZK signaling domain (Eckhardt et al. 2006) SR-B1.1 is known to be expressed in ECs and to mediate cytoprotective effects of HDL via PDZK1. 
By contrast SR-BI1.2 is not known to be expressed by ECs. Further elucidation of the exact role of SR-BI and its isoforms in ECs will be essential to better understand HDL trafficking.

ABCG1 can probably be excluded for being a direct receptor for HDL as it has been shown in other cell types to act as a intracellular sterol transporter (Tarling \& Edwards 2011). We also failed to find ABCG1 on the surface of ECs by immunofluorescence. Also in our biochemical studies using radiolabelled 125i-HDL (Rohrer et al. 2009b) ABCG1 knockdown limited HDL uptake to a greater extent than its binding. This may suggest ABCG1 regulates endocytosis via sterol distribution inside ECs.

The ECs express an extensive glycokalyx, which can be several $\mu \mathrm{m}$ thick (Ebong et al. 2011). The glycocalix can hinder endocytosis of extracellular molecules by prefiltering material before it gets into contact with the EC plasma membrane (Arkill et al. 2011; Arkill et al. 2012). However, it can also facilitate uptake by direct or indirect binding of the molecule to be internalized. A prominent example for facilitated uptake by direct binding is the association of LDL to proteoglycans, which enhances the uptake of LDL by the LDL receptor pathway. HDL is not directly bound by proteoglycans (Rinninger et al. 1998). However, EL is bound by proteoglycans which in turn tethers HDL on ECs (Strauss et al. 2002; Jahangiri et al. 2005). In fact heparinase digestion as well as both inhibition and siRNA silencing of EL decreased both binding and transport of HDL through the ECs (Robert et al. 2013). Conversably binding and transport were increased by overexpression of wild type EL. Interestingly a catalytically inactive EL increased binding but not internalization and transport.

\subsection{How is the trafficking of HDL and ApoA-I modulated?}

Although our microscopy experiment showed no staining SR-BI on the surface, the presence of a blocking antibody against SR-BI or the SR-BI inhibitor BLT1 reduced the uptake of HDL into ECs (Figure 25). This is in agreement with our unpublished biochemical data showing reduced binding and uptake of HDL in the presence of BLT1 or siRNA or blocking antibodies against SR-BI.

The lack of SR-BI localization by indirect immunofluorescence on the cell surface may be because only small amounts of SR-BI are involved in the trafficking of HDL or that the recycling and recruitment of SR-BI to the plasma membrane is fast and tightly regulated so that only few SR-BI molecules remain on the surface. After all, SR-BI is a cholesterol sensor and involved in lipid exchange (Saddar et al. 2013). Therefore ECs may prevent 
themselves to receive or loose lipids to their environment, especially to the luminal side, in an uncontrolled way.

Interestingly BLT1 was less potent than anti-SR-BI antibodies in inhibiting HDL uptake by ECs (Figure 25). One reason could be that the blockage of lipid transport by BLT1 is indirectly affecting SR-BI conformation and thereby influences the binding to HDL. Alternatively lipid transport via SR-BI is modulating the SR-BI independent uptake of HDL by another as yet unidentified receptor.

With respect to the latter explanation it is noteworthy that pretreatment of ECs with competing amounts of HDL increased fl-HDL uptake significantly (Figure 26). Therefore and because both HDL and apoA-I are known to induce different signal transduction cascades in ECs, we systematically assessed the signaling elicited by HDL or lipid free ApoA-I in ECs. We used a phospho-kinase membrane array, to assess the phosphorylation of 43 kinases and two signaling molecules in ECs, which were incubated for 30 minutes with three different preparations of each HDL and apoA-I Nine and six phosphosites were significantly up- and downregulated, respectively, by all HDL preparations. In addition several phosophosites were incongruently regulated upon exposure to the three different HDL preparations resulting in high standard deviations if the data is taken together (Figure 27).

ApoA-I up- and downregulated five and six phosphosites, respectively (Figure 28). Compared to HDL, the response to apoA-I was much less variable. The more variable and heterogenous response to HDL probably reflects the greater heterogeneity of HDL particles, which are known to function as platforms for many different hydrophobic molecules and to be prone to interindividual structural and functional variation (Annema \& von Eckardstein 2013). Especially the inflammatory status of an individual is known to result in HDL changes and exert in "dysfunctional HDL". 


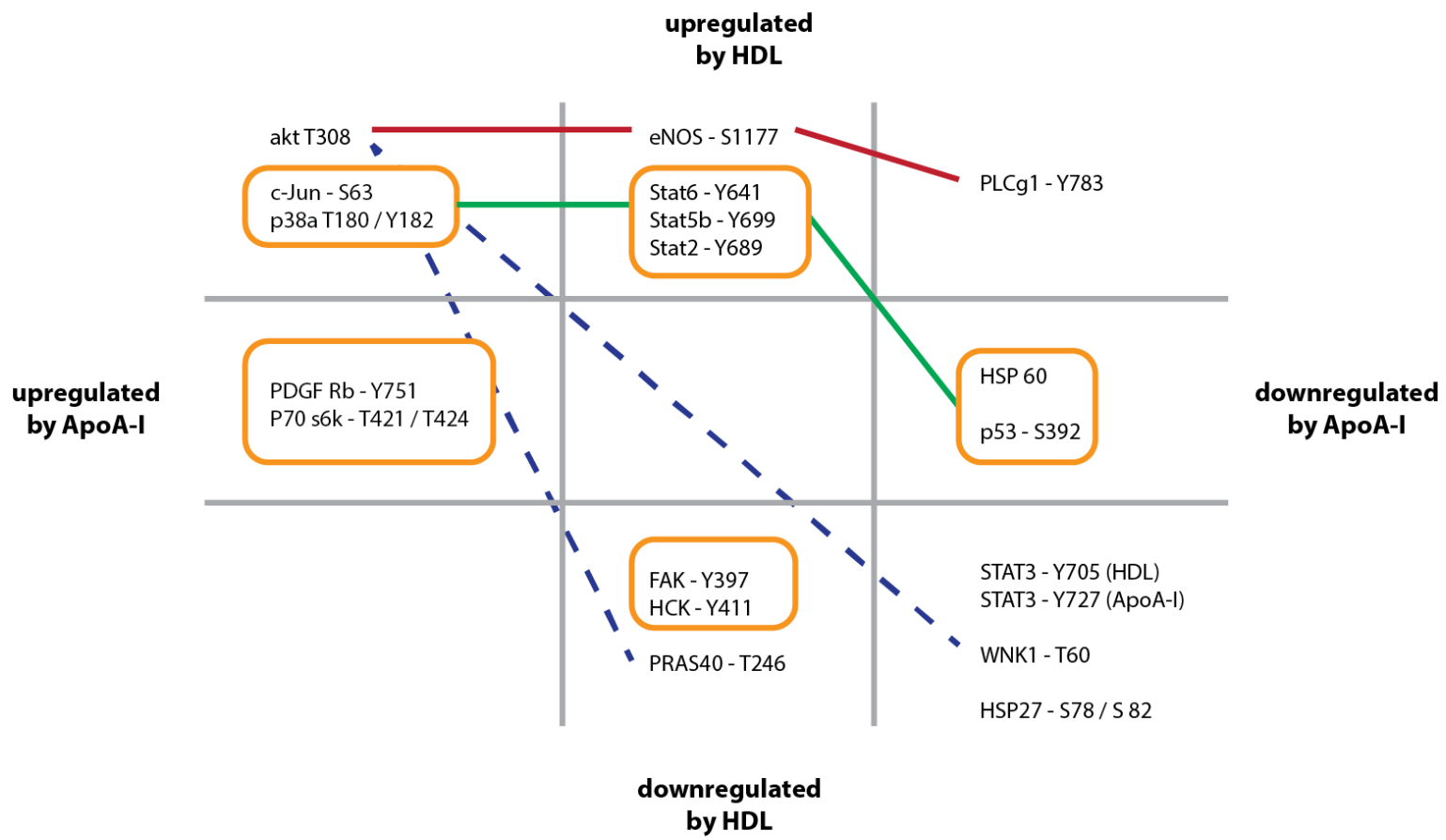

Figure 30: phosphosites regulated by HDL vs ApoA-I in ECs after $30 \mathrm{~min}$ stimulation: the orange boxes indicate possible complex formation and co-signaling. Red lines indicate the known activation of eNOS by akt or PLCg1 whereas the green line links the JAK-stat involved signaling complexes. Akt is also involved in PRAS40 and WNK1 signaling, as indicated by the dashed blue lines

Among the consistently modulated signaling pathways, the phosphorylation of Wnt Kinase (WNT1) T60 was reduced by about $50 \%$ in the presence of HDL. The same pathway was also triggered by ApoA-I although less strongly. Interestingly the WNT kinase pathway is activated by Akt, of which the regulatory sites S473 and T308 are downregulated by HDL and upregulated by HDL and ApoA-I, respectively. Akt is a very well known target of HDL signaling and is phosphorylated by PDK1, which is downstream of SR-BI. HDL/SR-BI interactions are known to elicit signaling through Src, PI3K and Akt as well as MAPK resulting in eNOS activation (Mineo et al. 2003). Furthermore the antiinflammatory and antiatherogenic properties of HDL associated lysosphingolipids are mediated by Akt/NFkB signaling (Schmidt et al. 2006). However, Akt signaling by HDL has not yet been associated with intracellular trafficking and endocytosis.

The Wnt-beta-catenin pathway is highly conserved and involved in organogenesis during development (Akiyama 2000). ARF6 activation during Wnt signaling promotes internalization of growth factor receptors and activation of ERK signaling which destabilizes adherent junctions and lead to an increased pool of internal beta-catenin and E-catherin in epithelial cells (Pellon-Cardenas et al. 2013). The endocytic adapter 
disabled-2 (DAB2), a known inhibitor of WNT/beta-catenin signaling recruits low-density lipoprotein receptor related protein 6 (LRP6) from its normal caveolin association for clathrin mediated endocytosis (Jiang et al. 2012). These signaling events are known to happen in development and stem cell maintenance. However as it is regulating the internalization of several growth factor receptors, it could be also affect HDL uptake. In endothelial cells endocytosis modulation by WNT/beta-catenin has not been much investigated. One group reported that endostatin is inducing autophagy in endothelial cells by reduction of the amount of beta-catenin (Nguyen et al. 2009). There is another report that the molecule wogonin is strongly inhibiting WNT/beta-catenin signaling in endothelial cells thereby modulating endothelial permeability (Song et al. 2013).

Another group of signaling molecules modulated by HDL are SRC, PYK2, EGF receptor, PDGF receptor and PLC gamma 1 which all together are upstream of the focal adhesion kinase FAK1. SRC is known to be activated by HDL via SR-BI (Seetharam et al. 2006) via PDZK (Zhu et al. 2008) and to be involved in EC migration and growth. Its regulatory role for uptake of HDL has not been investigated. PYK2 is closely related to Src and FAK and involved in similar signaling cascades as it can for example compensate for FAK knockout (Sieg et al. 1998). In B lymphocytes PYK2 contributes to S1P induced signaling which can be disrupted by inhibition of PYK2 by its specific inhibitor FP-719 resulting in blocked migration (Tse et al. 2012). Together with Cas and FAK signaling PYK2 is also involved in Yersinia bacteria uptake (Bruce-Staskal et al. 2002). However it has not yet been associated with a ligand-receptor mediated uptake mechanism per se.

Neither is it clear, if HDL mediated modulation of FAK1 modulates HDL uptake into ECs. Like PYK2 FAK has not yet been associated with endocytosis except that it is involved in integrin mediated uptake of bacteria (Alrutz \& Isberg 1998; Bruce-Staskal et al. 2002). However, FAK is crucial for regulating endothelial permeability (Gavard \& Gutkind 2008) cell growth and signaling in RhoA/ROCK pathways (Pirone et al. 2006) which itself is claimed to play a role in HDL uptake (Malaval et al. 2009). Interestingly this group of phosphosites is not much regulated by ApoA-I. Only the PDGF receptor signaling is upregulated by both HDL and ApoA-I. Phosphorylation of Y783 in PLC gamma 1 is even oppositely up-regulated by HDL but down-regulated by ApoA-I.

The third group of HDL influenced phosphosites includes the STATs. HDL increased the phosphorylation of STAT2 Y689, STAT5b Y689 and STAT6 Y641 but decreased STAT3 Y705. ApoA-I elicits less prominent changes in the phosphorylation of STATs. However it also down-regulates the STAT3 Y727 site - which is the second regulatory site on STAT3 (Wakahara et al. 2012). 
One of the targets of STAT3 signaling is LCAT (Feister et al. 2002) which by itself regulates HDL concentrations in plasma as well as its composition (Kostner et al. 1987). It is however not known if STAT3 signaling is affecting HDL uptake directly. The phosphorylation of STAT2, STAT5 and STAT 6 was not changed upon ApoA-I incubation. STATs are integrating a bunch of signals, especially those elcited by cytokines and growth factors. G-CSF, GM-CSF, IL2, IL3, IL4, IL13, INFa, EPO and other stimuli will therefore need to be tested for possible modulation of HDL uptake to ECs. Interestingly, we previously found that IL6 stimulates the binding and transport of HDL trough ECs (Robert et al. 2013). IL6 signals through the JAK/STAT3 pathway. The downregulation of STAT3 by HDL and ApoA-I may indicate a negative feedback regulation mechanism to tightly regulate EC stimulation by cytokines and their effect on HDL interaction and transport. Heat shock protein $27 \mathrm{~S} 78$ / S82 is downregulated by both HDL and ApoA-I. It is initiating the proteasome (Zhang et al. 2010) and is involved in apoptosis signaling (Acunzo et al. 2012) as well as NF-KB modulation resulting e.g. in scavenger receptor A downregulation (Raizman et al. 2013). It has however not yet known that HDL or ApoA-I regulates HSP27. HSP27 is involved in exosome endocytosis (Svensson et al. 2013).

We also observed a slight upregulation of eNOS S1177 by HDL but not ApoA-I, which is the activation site of eNOS. However eNOS S1177 is already strongly phosphorylated at baseline, so that HDL caused only a minor further enhancement. It has already been known that HDL induces the phosphorylation and activation of eNOS (Kuvin et al. 2002), (Rämet et al. 2003). However, it is unknown if eNOS regulates endocytosis in general or specifically HDL and ApoA-I endocytosis.

Future research will have to unravel whether one or more of the signaling events modulated by HDL or apoA-I are related to the endocytosis of HDL. However, in view of the rapid endocytosis of $\mathrm{HDL}$, it is also intriguing to ask, whether vice versa endocytosis of $\mathrm{HDL}$ is upstream of some observed alterations in the phosphorylation of kinases. 


\section{Conclusion and Outlook}

We here complemented our previous mostly biochemical experiments on the uptake and trafficking of HDL and ApoA-I in endothelial cell (EC) monolayers by systematic microscopic studies. We made the following major findings some of which will need elaboration by the proposed subsequent experiments:

I. In agreement with our previous results we found that HDL and ApoA-I are internalized and trafficked by ECs through the same route. This does not exclude that some lipids or specific proteins of HDL beyond are dissociating from the particle during its intracellular itinerary. Double labeling of the protein and lipid moieties for fluorescence microscopy would advance our knowledge. FRET of differently labeled lipids on HDL and on the ECs would give also insight on where they meet across its itinerary and interactions. For both fluorescence and electron microscopy, HDL should be reconstituted using distinct fluorescent lipids and Aurora-Nanogold-Lipids, respectively, for the lipid moiety, as well as different fluorescent dies and nanogold for the labeling of distinct proteins prior to reconstitution.

II. Preliminary live confocal experiments (of limited temporal resolution) show that transcytosis of HDL through the EC monolayer is fast, so that the fluorescence was detected in the basolateral subendothelial matrix even before it started to appear in intracellular vesicles of ECs. We suggest doing sensitive high-speed live microscopy for getting more insight on early steps of HDL uptake. Reduced temperature live microscopy might give further insight. It also remains to be elucidated, if transcytosis of HDL and its uptake and storage are two interlinked processes or independent of each other.

III. HDL fails to co-localize with ABCA1, ABCG1, SR-BI and EL, which were previously found by biochemical experiments to modulate transendothelial transport of ApoA-I and HDL. This supports our previous findings that these known HDL modulators do not directly mediate the uptake of HDL but indirectly modulate uptake by lipidating ApoA-I (ABCA1), changing the cellular cholesterol homeostasis or inducing signals which ultimately activate an as yet unidentified endocytic machinery for HDL uptake. Other candidates known to be expressed by 
endothelial cells and to bind lipoproteins (for example CD36, LOX1) are worth to be investigated for their co-localization with HDL by fluorescence microscopy and for their involvement in HDL uptake by RNA interference experiments. Other candidates for example splice variants of SR-BI and megalin/cubilin have to be checked for their expression before structural and functional experiments are done. In the case of splice variants, gene constructs will have to be expressed for co-localization and functional experiments

IV. Co-localization and pharmacological interference experiments make it unlikely that the classical clathrin- or caveolin 1-dependent endocytosis pathways or the fluid phase mediate the uptake of HDL into ECs. We identified at least three timedependent subcellular distributions of HDL positive vesicles over a period of 5 minutes to 16 hours. Electron microscopy experiments indicate that HDL is effectively sorted through multivesicular bodies (MVB). HDL does not go to lysosomes and is not degraded for up to 4 hours. HDL was co-localized with neither Rab5, Rab7, Rab9, Syntaxin6 nor endoplasmatic reticulum nor golgi. We could however co-localize HDL with WGA at specific times and there is partial overlapping of HDL trafficking with Transferrin and Albumin. Taken together, HDL seems to use atypical entry pathways into ECs but is sorted into common places where also Transferrin and Albumin pass through. To definitely rule out the contribution of clathrin and caveolin-1 it will be important to investigate the uptake of HDL by ECs from knock-out mice lacking clathrin adapter proteins like AP2 and caveolin-1, respectively.

V. Interferences with the cytoskeleton, dynamins, or PI3/4 Kinases did not prevent quantitative HDL uptake but modulated sorting qualitatively. It will be interesting to characterize the altered vesicular distribution by a novel series of co-localization and electron microscopy studies. Biochemical binding, internalization and transport experiments may help to find blockages in the re-secretion of HDL

VI. Finally HDL was found to stimulate its own uptake into ECs. Our subsequent screening identified several HDL and/or apoA-I induced changes in the phosphorylation of signaling molecules including some, which were already known to be modulated by HDL or apoA-I like Akt or eNOS. Others were unknown reactants to HDL or apoA-I. To prove or disprove the involvement of these signal transduction pathways in transendothelial transport of HDL requires pharmacological and genetic interference experiments. 


\section{Acknowledgements,}

I would like to express my gratitude to my advisors Lucia Rohrer and Arnold von Eckardstein for their guidance, patience, enthusiasm and insightful comments during my thesis project. Further I would like to thank my thesis committee, Urs Greber, Felix Tanner and Michael Detmar for their insightful comments and support. Special thanks go to Andres Käch, who introduced me to state of the art electron microscopy sample preparation and Iryna Agarkova for the introduction into cryo-freezing and cutting of tissue samples for immunofluorescence. I am also thankful for sharing the time on my thesis project with my colleagues, in particular Pascale Ohnsorg, Jérôme Robert, Rahel Sibler, Diana Odermatt, Reda Hasballa, Vidya Velagapudi, Wijtske Annema, Paolo Zanoni and Maryam Amin Dabi. I am grateful for the insightful scientific and non-scientific discussions I had with Jérôme Robert, Meliana Riwanto and Alaa Othman keeping the free spirit of research up against all odds. I am thanking Silvija Radosavljevic, Bruno Guhl, Ursula Lüthi, Therese Bruggmann and Gery Barmettler for their technical assistance.

Noteworthy is also the unique experience I was lucky or unlucky to experience with the university hospital zürich moving our labs to an $8 \mathrm{~km}$ off-campus place, which gave me the opportunity to learn how to get organized and organize research needs out of the ordinary. This work was supported by a grant from the Swiss National Science Foundation (31003A-130836/l.) to Arnold von Eckardstein and Lucia Rohrer and CH-COST office (Eigenössisches Amt für Forschung und Technologie). 


\section{List of Figures}

Figure 1: Binding of labeled HDL and ApoA-I competed with $100 \mathrm{x}$ excess of not labeled HDL A monolayer of ECs was pre-cooled for $30 \mathrm{~min}$ at $4^{\circ} \mathrm{C}$ following by a further 30 min incubation with $50 \mu \mathrm{g} / \mathrm{ml} 655-\mathrm{HDL}$ (A) or $50 \mu \mathrm{g} / \mathrm{ml}$ 488-ApoA-I (C) in the absence $(A, C)$ or presence of $5 \mathrm{mg} / \mathrm{ml} \mathrm{HDL}(B, D)$. The monolayers were then fixed with 3.75 $\%$ formaldehyde for 40 min starting at $4{ }^{\circ} \mathrm{C}$ with gradual heat-up to room temperature. Cover slips were also incubated with DAPI for nuclear staining and investigated at fixed exposure.

Figure 2: Comparison of fluorescence staining of endothelial cells by fl-HDL $(A)$ free fluorescence dye (B) A monolayer of ECs was incubated for 30 min at $37^{\circ}$ with 50 $\mu \mathrm{g} / \mathrm{ml} 655-\mathrm{HDL}(\mathrm{A})$ or $18 \mu \mathrm{g} / \mathrm{ml}$ free Atto-655 dye (B), fixed with $3.75 \%$ formaldehyde and counter-stained with DAPI (A only) for nuclear staining. Note the different staining pattern of Atto-655 and 655-HDL.

Figure 3: Time-dependent uptake of fl-HDL by EC monolayers. A monolayer of ECs was incubated for (A) $5 \mathrm{~min}$, (B) $15 \mathrm{~min}$, (C) $30 \mathrm{~min}$ and (D) $60 \mathrm{~min}$ at $37^{\circ}$ with $50 \mu \mathrm{g} / \mathrm{ml}$ 594-HDL, fixed with $3.75 \%$ formaldehyde and counter-stained with DAPI for nuclear staining. The longer fl-HDL is incubated with ECs, the more can be detected intracellular.

Figure 4: ApoA-I co-localizes perfectly with HDL inside ECs A monolayer of ECs was incubated for $30 \mathrm{~min}$ at $37^{\circ}$ with $50 \mu \mathrm{g} / \mathrm{ml}$ of each 488-ApoA-I and 594-HDL, fixed with $3.75 \%$ formaldehyde and counter-stained with DAPI for nuclear staining. In A, the 488-ApoA-I signal is visualized, in $B$ the one of 594-HDL. In C, the merge of $A$ and $B$ shows uniform co-localization of ApoA-I and HDL.

Figure 5: $\mathrm{HDL}$ colocalizes with neither clathrin nor cav1 at $37^{\circ} \mathrm{C}$ or $18^{\circ} \mathrm{C}$ Monolayers of ECs were incubated for $30 \mathrm{~min}$ at $37^{\circ}(\mathrm{A}$ and $\mathrm{B})$ or $18^{\circ} \mathrm{C}(\mathrm{C}$ and $\mathrm{D})$ with $50 \mu \mathrm{g} / \mathrm{ml} \mathrm{fl-}$ $\mathrm{HDL}$, fixed with $3.75 \%$ formaldehyde and stained with anti-Clathrin ( $\mathrm{A}$ and $\mathrm{C}$ ) or antiCav1 ( $B$ and $D$ ) in the corresponding secondary antibody ( $A$ and $B$ - Alexa-594; $C$ and D - Alexa 488) counter-stained with DAPI for nuclear staining. At neither $37^{\circ} \mathrm{C}$ nor $18{ }^{\circ} \mathrm{C} \mathrm{HDL}$ was found colocalized with clathrin or caveolin 1.

Figure 6: partial co-localization of HDL with Transferrin A monolayer of ECs was incubated for $30 \mathrm{~min}$ at $37^{\circ}$ with $50 \mu \mathrm{g} / \mathrm{ml}$ 488-HDL and $5 \mu \mathrm{g} / \mathrm{ml} \mathrm{594-Trf,} \mathrm{fixed} \mathrm{with} 3.75 \%$ formaldehyde and counter-stained with DAPI for nuclear staining. In A, the 488-HDL signal is visualized, in $B$ the one of 594-Transferrin. In $C$ a merge from $A$ and $B$ is showing partial the co-localization between HDL and Transferrin. 
Figure 7: HDL partially co-localizes with Bovine Serum Albumin (BSA) A monolayer of ECs was incubated for $30 \mathrm{~min}$ at $37^{\circ}$ with $50 \mu \mathrm{g} / \mathrm{ml}$ FITC-HDL and $10 \mu \mathrm{g} / \mathrm{ml}$ 546Albumin, fixed with $3.75 \%$ formaldehyde and counter-stained with DAPI for nuclear staining. In A, the FITC-HDL signal is visualized, in B the one of 546-BSA. In C a merge from $A$ and $B$ is showing the partial co-localization between HDL and Transferrin.

Figure 8: HDL uptake cannot be blocked by Amiloride or EIPA and it does not colocalize with $40 \mathrm{kDa}$ Dextran A-C: A monolayer of ECs was preincubated for 30 min with either $10 \mu \mathrm{M}$ Amiloride or $2 \mu \mathrm{M}$ EIPA before $50 \mu \mathrm{g} / \mathrm{ml} 655-\mathrm{HDL}$ was added and incubated for another $30 \mathrm{~min}$, fixed with $3.75 \%$ formaldehyde and counter-stained with DAPI for nuclear staining. D-F: A monolayer of ECs was incubated with $50 \mu \mathrm{gml}$ 655-rHDL together with FITC-40kDa Dextran for 30 min, fixed with $3.75 \%$ formaldehyde and counter-stained with DAPI for nuclear staining

Figure 9: HDL uptake is altered by Wortmannin and Dynasore A monolayer of ECs was preincubated at $37^{\circ} \mathrm{C}$ (panel A-C) or $18^{\circ} \mathrm{C}$ (panel D-F) for 30 min with either $0.2 \mathrm{mM}$ Wortmannin ( $\mathrm{B}$ and $\mathrm{E}$ ) or $80 \mu \mathrm{M}$ Dynasore ( $\mathrm{C}$ and $\mathrm{F}$ ). $50 \mu \mathrm{g} / \mathrm{ml}$ 596-HDL was added (A-F) and incubated for another 30 min, fixed with $3.75 \%$ formaldehyde and counterstained with DAPI for nuclear staining.

Figure 10: HDL colocalizes with WGA in 10-30 min but not after that time A monolayer of ECs was incubated with $1 \mu \mathrm{M}$ 594-WGA for $20 \mathrm{~min}$ and $50 \mu \mathrm{g} / \mathrm{ml}$ 488-HDL for $15 \mathrm{~min}$ (A), $30 \mathrm{~min}(B)$ and $60 \mathrm{~min}(\mathrm{C})$, cells were fixed then with $3.75 \%$ formaldehyde and counter stained with DAPI for nuclear staining.

Figure 11: AcLDL does not colocalize with HDL A monolayer of ECs was incubated for 30 min at $37^{\circ}$ with $50 \mu \mathrm{g} / \mathrm{ml} 655-\mathrm{HDL}$ and $20 \mu \mathrm{g} / \mathrm{ml}$ 488-AcLDL, fixed with $3.75 \%$ formaldehyde and counter-stained with DAPI for nuclear staining. In A, the 655-HDL signal is visualized, in $B$ the one of $488-A c L D L$. In $C$ a merge from $A$ and $B$ is showing almost no co-localization between HDL and AcLDL.

Figure 12: HDL uptake over 5 minutes up to 16 hours. ECs were pre-stimulated with HDL to increase HDL uptake. A monolayer of ECs was incubated for 5 min (A), $10 \mathrm{~min}(B), 15 \mathrm{~min}(C), 30 \mathrm{~min}(D), 60 \mathrm{~min}$ (E), $120 \mathrm{~min}$ (F), $180 \mathrm{~min}$ (G), 240 min (H) and $16 \mathrm{~h}(\mathrm{I})$ as indicated with $50 \mu \mathrm{g} / \mathrm{ml}$ 596-HDL, fixed with $3.75 \%$ formaldehyde and counter-stained with DAPI for nuclear staining. .43

Figure 13: HDL passes through the EC monolayer in less than 2 minutes, much before any vesicles can be detected intracellularly Monolayers of ECs were grown on transwell inserts which were then put on a drop of medium on a petri dish with optical 
glass bottom and scanned from below at a inverse confocal microscope. After the first volume scan, the $488-\mathrm{HDL}$ was given into the transwell and scanning was continued. A shows the first scan, $B$ the $20^{\text {th }}$ scan after 15 minutes of adding $488-\mathrm{HDL}$ to the cell layer

Figure 14: HDL does not colocalize with Lysotracker DND 99 A monolayer of ECs was incubated for $30 \mathrm{~min}$ at $37^{\circ}$ with $50 \mu \mathrm{g} / \mathrm{ml} \mathrm{FITC-HDL}$ and during the last $10 \mathrm{~min}$ additionally with $1 \mu \mathrm{M}$ Lysotracker DND, fixed with $3.75 \%$ formaldehyde and counterstained with DAPI for nuclear staining.

Figure 15: HDL fails to co-localize with Golgi or ER but clusters around the golgi positive vesicles Monolayers of ECs were incubated for $30 \mathrm{~min}$ at $37^{\circ}$ with $50 \mu \mathrm{g} / \mathrm{ml} \mathrm{fl-HDL}$, fixed with $3.75 \%$ formaldehyde and stained with anti-Calnexin (B) or antiGolgi58kProtein (E) and the corresponding secondary antibodies labeled with Alexa488. DAPI was used for nuclear staining. HDL was colocalized with neither the ER (merge in $\mathrm{C}$ ) nor the Golgi (merge in F).

Figure 16: HDL does not colocalize with early (Rab5) and late (Rab7) endosomes Monolayers of ECs were incubated for $30 \mathrm{~min}$ at $37^{\circ}$ with $50 \mu \mathrm{g} / \mathrm{ml} \mathrm{fl-HDL}$, fixed with $3.75 \%$ formaldehyde and stained with anti-Rab5 (B) or anti-Rab7 (E). The secondary antibodies were labeled with Alexa-488. DAPI was used for nuclear staining. Neither the early endosomes (Rab5 - merge in C) nor late endosomes (Rab7 - merge in F) colocalize with fl-HDL

Figure 17: HDL is not recycled in a Rab11a dependent manner Monolayers of ECs were incubated for $30 \mathrm{~min}$ at $37^{\circ}$ with $50 \mu \mathrm{g} / \mathrm{ml} \mathrm{fl}-\mathrm{HDL}$, fixed with $3.75 \%$ formaldehyde and stained with anti-Rab11a (B) and a secondary antibody labeled with Alexa-488. DAPI wa sused for nuclear staining. The recycling endosomes (Rab11a) do not co-localize with fl-HDL (merge in panel C).

Figure 18: HDL does not colocalize with Rab9 or Syntaxin 6 Monolayers of ECs were incubated for $30 \mathrm{~min}$ at $37^{\circ}$ with $50 \mu \mathrm{g} / \mathrm{ml} \mathrm{fl-HDL}$, fixed with $3.75 \%$ formaldehyde and stained with anti-Rab9 (B) or anti-Syntaxin6 (E). The corresponding secondary antibodies were labeled with Alexa-488. DAPI was used for nuclear staining. Neither Rab9 nor Syntaxin 6 colocalize with HDL (merges in C and F).

Figure 19: HDL uptake and trafficking is affected by blocking tubulin and F-actin A monolayer of ECs was preincubated for 30 min with either (B) $5 \mu \mathrm{M}$ Cytochalasin D or (C) $1 \mu \mathrm{M}$ Colchicine before $50 \mu \mathrm{g} / \mathrm{ml} 596-\mathrm{HDL}$ was added and incubated for another 30 min, fixed with $3.75 \%$ formaldehyde and counter-stained with DAPI for nuclear staining. 
Figure 20: Endothelial cells were incubated for one hour with $1.4 \mathrm{~nm} \mathrm{Au-HDL}$ at $37^{\circ} \mathrm{C}$, washed, then high pressure frozen, fixed during freeze substitution with OsO4. A and $B$, samples were processed for TEM and silver enhancement was performed on ultrathin sections. In $C$ and $D$ volume silver enhancement was performed directly after freeze substitution. Dashes in low magnification ( $A$ and $C$ ) help visualize the distribution of the particles. Bar $=500 \mathrm{~nm}$

Figure 21: Endothelial cells were incubated for one hour with $1.4 \mathrm{~nm}$ Au-BSA ( $A$ and B) and $1.4 \mathrm{~nm} \mathrm{Au}-\mathrm{LDL}(\mathrm{C}$ and $\mathrm{D})$, at $37^{\circ} \mathrm{C}$, washed, high pressure frozen, fixed during freeze substitution with $\mathrm{OsO} 4$ and volume silver enhancement was performed as described. Dashes help visualize the distribution of the particles. Bar $=200 \mathrm{~nm}$ .52

Figure 22: Determination of specificity and background: To determine the specificity and background of the volume enhancement protocol, endothelial cells were HPF/FSF after incubation with native (without 1.4-Au label) HDL and then volume enhanced. It shows very low background and auto-nucleation on HPF samples with good ultrastructure conservation ( $A$ and $B)$.

Figure 23: Immunostaining of ABCA1, ABCG1, SR-BI, and EL in ECs Monolayers of ECs were fixed with $3.75 \%$ Formaldehyde, blocked with $5 \%$ Donkey serum and incubated with the antibodies against ABCA1, ABCG1, SR-BI or EL (LIPG) and then with secondary alexa-coupled antibodies. In D, monolayers were incubated for $30 \mathrm{~min}$ with $50 \mu \mathrm{g} / \mathrm{ml}$ 488-HDL prior to fixation for co-localization studies. After indirect immunostaining, a DAPI staining was performed for nuclear localization.

Figure 24: Immunostaining for ABCA1, ABCG1, SR-BI and EL in the endothelium of aortic vasa vasorum $(A$ and $B)$ and aorta $(C$ and $D)$ Bovine aortas were obtained freshly from the slaughter house. Cubes of $5 \times 5 \mathrm{~mm}$ including the endothelium were frozen in OCT upon which they were cryocut at 7-14 um thickness. The cuts were thawn and fixed with $3.75 \%$ formaldehyde and then indirectly immunostained 56

Figure 25: preincubation with antiSR-BI or BLT1 reduce HDL uptake Monolayers of ECs were preincubated with either a blocking antibody $(B)$ or isotype control $(A)$ or BLT1 (D) at $10 \mu \mathrm{M}$ for 20 minutes. Then $50 \mu \mathrm{g} / \mathrm{ml} 594-\mathrm{HDL}$ was added to the cells and further incubated for $30 \mathrm{~min}(A-D)$, the cells were fixed with $3.75 \%$ formaldehyde, counter stained with DAPI.

Figure 26: HDL preincubation increases uptake of HDL Monolayers of ECs were incubated with $100 \mu \mathrm{g} / \mathrm{ml}$ unlabeled HDL (B) prior to 30 minutes incubation with 50 $\mu \mathrm{g} / \mathrm{ml}$ fl-HDL (A and B). The cells were fixed with $3.75 \%$ formaldehyde and counter stained with DAPI for nuclear staining 
Figure 27: Changes in the degree of phosphorylation of kinases and signaling proteins in response to 30 min incubation of ECs with HDL. Data are means + standard deviations of three independent experiments

Figure 28 : Changes in the degree of phosphorylation of kinases and signaling proteins in response to $30 \mathrm{~min}$ incubation of ECs with $100 \mu \mathrm{g} / \mathrm{ml}$ lipid free apoA-I. Data are means + standard deviations of three independent experiments 59

Figure 29: Fast volume enhancement after FSF 62

Figure 30: phosphosites regulated by HDL vs ApoA-I in ECs after 30 min stimulation: the orange boxes indicate possible complex formation and co-signaling. Red lines indicate the known activation of eNOS by akt or PLCg1 whereas the green line links the JAK-stat involved signaling complexes. Akt is also involved in PRAS40 and WNK1 signaling, as indicated by the dashed blue lines

\section{List of Tables}

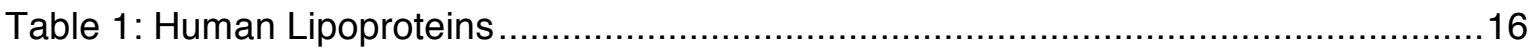

Table 2: Lipoprotein associations and main functions of apolipoproteins ........................17

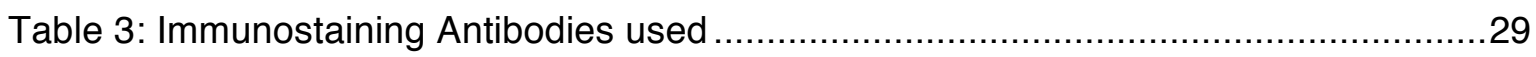




\section{References,}

Acton, S. et al., 1996. Identification of scavenger receptor SR-BI as a high density lipoprotein receptor. Science (New York, N.Y.), 271(5248), pp.518-20. Available at: http://www.ncbi.nlm.nih.gov/pubmed/8560269 [Accessed February 7, 2014].

Acunzo, J., Katsogiannou, M. \& Rocchi, P., 2012. Small heat shock proteins HSP27 (HspB1), aBcrystallin (HspB5) and HSP22 (HspB8) as regulators of cell death. The international journal of biochemistry \& cell biology, 44(10), pp.1622-31. Available at:

http://www.ncbi.nlm.nih.gov/pubmed/22521623 [Accessed July 15, 2014].

Akiyama, T., 2000. Wnt/beta-catenin signaling. Cytokine \& growth factor reviews, 11(4), pp.27382. Available at: http://www.ncbi.nlm.nih.gov/pubmed/10959075 [Accessed July 15, 2014].

Alrutz, M.A. \& Isberg, R.R., 1998. Involvement of focal adhesion kinase in invasin-mediated uptake. Proceedings of the National Academy of Sciences of the United States of America, 95(23), pp.13658-63. Available at:

http://www.pubmedcentral.nih.gov/articlerender.fcgi?artid=24875\&tool=pmcentrez\&rendertype $=$ abstract [Accessed July 15, 2014].

Anderson, R.G., Goldstein, J.L. \& Brown, M.S., 1976. Localization of low density lipoprotein receptors on plasma membrane of normal human fibroblasts and their absence in cells from a familial hypercholesterolemia homozygote. Proceedings of the National Academy of Sciences of the United States of America, 73(7), pp.2434-8. Available at:

http://www.pubmedcentral.nih.gov/articlerender.fcgi?artid=430596\&tool=pmcentrez\&rendertyp $\mathrm{e}=$ abstract.

Annema, W. \& von Eckardstein, A., 2013. High-density lipoproteins. Multifunctional but vulnerable protections from atherosclerosis. Circulation journal : official journal of the Japanese Circulation Society, 77(10), pp.2432-48. Available at: http://www.ncbi.nlm.nih.gov/pubmed/24067275 [Accessed July 15, 2014].

Appenzeller-Herzog, C. \& Hauri, H.-P., 2006. The ER-Golgi intermediate compartment (ERGIC): in search of its identity and function. Journal of cell science, 119(Pt 11), pp.2173-83. Available at: http://www.ncbi.nlm.nih.gov/pubmed/16723730 [Accessed July 15, 2014].

Arkill, K.P. et al., 2012. 3D reconstruction of the glycocalyx structure in mammalian capillaries using electron tomography. Microcirculation (New York, N.Y. : 1994), 19(4), pp.343-51. Available at: http://www.pubmedcentral.nih.gov/articlerender.fcgi?artid=3808814\&tool=pmcentrez\&renderty pe=abstract [Accessed December 2, 2013].

Arkill, K.P. et al., 2011. Similar endothelial glycocalyx structures in microvessels from a range of mammalian tissues: evidence for a common filtering mechanism? Biophysical journal, 101(5), pp.1046-56. Available at:

http://www.pubmedcentral.nih.gov/articlerender.fcgi?artid=3164174\&tool=pmcentrez\&renderty pe=abstract [Accessed December 11, 2013].

Aseem, O. et al., 2013. Cubilin Maintains Blood Levels of HDL and Albumin. Journal of the American Society of Nephrology: JASN, pp.1-9. Available at: http://www.ncbi.nlm.nih.gov/pubmed/24357674 [Accessed February 9, 2014].

Assanasen, C. et al., 2005. Cholesterol binding, efflux, and a PDZ-interacting domain of scavenger receptor-BI mediate HDL-initiated signaling. Journal of Clinical Investigation, 115(4), pp.969977. Available at: http://www.jci.org/articles/view/23858 [Accessed February 7, 2014]. 
Azuma, Y. et al., 2009. Retroendocytosis pathway of ABCA1/apoA-I contributes to HDL formation. Genes to cells: devoted to molecular \& cellular mechanisms, 14(2), pp.191-204. Available at: http://www.ncbi.nlm.nih.gov/pubmed/19170766 [Accessed January 16, 2014].

Barreiro, O. et al., 2008. Endothelial adhesion receptors are recruited to adherent leukocytes by inclusion in preformed tetraspanin nanoplatforms. The Journal of cell biology, 183(3), pp.52742. Available at:

http://www.pubmedcentral.nih.gov/articlerender.fcgi?artid=2575792\&tool=pmcentrez\&renderty pe $=$ abstract [Accessed October 10, 2013].

Barreiro, O. et al., 2005. Endothelial tetraspanin microdomains regulate leukocyte firm adhesion during extravasation. Blood, 105(7), pp.2852-61. Available at:

http://www.ncbi.nlm.nih.gov/pubmed/15591117 [Accessed October 10, 2013].

Barter, P. et al., 2003. High density lipoproteins (HDLs) and atherosclerosis; the unanswered questions. Atherosclerosis, 168(2), pp.195-211. Available at: http://linkinghub.elsevier.com/retrieve/pii/S0021915003000066 [Accessed February 5, 2014].

Barter, P.J. et al., 2004. Antiinflammatory properties of HDL. Circulation research, 95(8), pp.76472. Available at: http://www.ncbi.nlm.nih.gov/pubmed/15486323 [Accessed September 25, 2013].

Basquin, C. \& Sauvonnet, N., 2013. Phosphoinositide 3-kinase at the crossroad between endocytosis and signaling of cytokine receptors. Communicative \& integrative biology, 6(4), p.e24243. Available at:

http://www.pubmedcentral.nih.gov/articlerender.fcgi?artid=3737753\&tool=pmcentrez\&renderty pe=abstract [Accessed June 17, 2014].

Bell, R.D. \& Ehlers, M.D., 2014. Breaching the blood-brain barrier for drug delivery. Neuron, 81(1), pp.1-3. Available at: http://www.ncbi.nlm.nih.gov/pubmed/24411725 [Accessed February 4, 2014].

Bian, F. et al., 2014. CRP promotes atherosclerosis by increasing LDL transcytosis across endothelial cells. British journal of pharmacology, (8627). Available at: http://www.ncbi.nlm.nih.gov/pubmed/24517733 [Accessed February 18, 2014].

Bocharov, A. V et al., 2001. Characterization of a 95 kDa High Affinity Human High Density. , pp.4407-4416.

Bock, J.B. et al., 1997. Syntaxin 6 functions in trans-Golgi network vesicle trafficking. Molecular Biology of the Cell, 8(7), pp.1261-1271. Available at:

http://www.molbiolcell.org/cgi/doi/10.1091/mbc.8.7.1261 [Accessed July 15, 2014].

Bond, H.M. \& Howell, K.E., 1987. A recombinant apoA-1 -protein A hybrid reproduces the binding parameters of $\mathrm{HDL}$ to its receptor. The EMBO journal, 6(11), pp.3253-3260.

Boulakirba, S. et al., 2014. Arf6 exchange factor EFA6 and endophilin directly interact at the plasma membrane to control clathrin-mediated endocytosis. Proceedings of the National Academy of Sciences of the United States of America, 111(26), pp.9473-8. Available at: http://www.ncbi.nlm.nih.gov/pubmed/24979773 [Accessed July 9, 2014].

Brown, M.S. \& Goldstein, J.L., 1979. Receptor-mediated endocytosis: insights from the lipoprotein receptor system. Proceedings of the National Academy of Sciences of the United States of America, 76(7), pp.3330-7. Available at:

http://www.pubmedcentral.nih.gov/articlerender.fcgi?artid=383819\&tool=pmcentrez\&rendertyp $\mathrm{e}=$ abstract. 
Brown, M.S., Kovanen, P.T. \& Goldstein, J.L., 1981. Regulation of plasma cholesterol by lipoprotein receptors. Science (New York, N.Y.), 212(4495), pp.628-35. Available at: http://www.ncbi.nlm.nih.gov/pubmed/6261329 [Accessed February 5, 2014].

Brown, W. V, Levy, R.I. \& Fredrickson, D.S., 1969. Studies of the proteins in human plasma very low density lipoproteins. The Journal of biological chemistry, 244(20), pp.5687-94. Available at: http://www.ncbi.nlm.nih.gov/pubmed/4981584 [Accessed January 27, 2014].

Bruce-Staskal, P.J. et al., 2002. Cas, Fak and Pyk2 function in diverse signaling cascades to promote Yersinia uptake. Journal of cell science, 115(Pt 13), pp.2689-700. Available at: http://www.ncbi.nlm.nih.gov/pubmed/12077360 [Accessed July 15, 2014].

Cao, H. et al., 2007. Dynamin 2 mediates fluid-phase micropinocytosis in epithelial cells. Journal of cell science, 120(Pt 23), pp.4167-77. Available at:

http://www.ncbi.nlm.nih.gov/pubmed/18003703 [Accessed October 18, 2013].

Cavelier, C., Lorenzi, I., et al., 2006. Lipid efflux by the ATP-binding cassette transporters ABCA1 and ABCG1. Biochimica et biophysica acta, 1761(7), pp.655-66. Available at: http://www.ncbi.nlm.nih.gov/pubmed/16798073 [Accessed January 13, 2014].

Cavelier, C. et al., 2012. The $\beta$-chain of cell surface $F(0) F(1)$ ATPase modulates apoA-I and HDL transcytosis through aortic endothelial cells. Arteriosclerosis, thrombosis, and vascular biology, 32(1), pp.131-9. Available at: http://www.ncbi.nlm.nih.gov/pubmed/21979433 [Accessed February 10, 2014].

Cavelier, C., Rohrer, L. \& von Eckardstein, A., 2006. ATP-Binding cassette transporter A1 modulates apolipoprotein A-I transcytosis through aortic endothelial cells. Circulation research, 99(10), pp.1060-6. Available at: http://www.ncbi.nlm.nih.gov/pubmed/17053191 [Accessed February 10, 2014].

Chand, N. \& Altura, B.M., 1981. Acetylcholine and bradykinin relax intrapulmonary arteries by acting on endothelial cells: role in lung vascular diseases. Science (New York, N.Y.), 213(4514), pp.1376-9. Available at: http://www.ncbi.nlm.nih.gov/pubmed/7268440 [Accessed January 29, 2014].

Christoffersen, C. et al., 2012. The plasma concentration of HDL-associated apoM is influenced by LDL receptor-mediated clearance of apoB-containing particles. Journal of lipid research, 53(10), pp.2198-204. Available at:

http://www.pubmedcentral.nih.gov/articlerender.fcgi?artid=3435552\&tool=pmcentrez\&renderty pe $=$ abstract $[$ Accessed February 5, 2014].

Connelly, M. a., 1999. Comparison of Class B Scavenger Receptors, CD36 and Scavenger Receptor BI (SR-BI), Shows That Both Receptors Mediate High Density LipoproteinCholesteryl Ester Selective Uptake but SR-BI Exhibits a Unique Enhancement of Cholesteryl Ester Uptake. Journal of Biological Chemistry, 274(1), pp.41-47. Available at: http://www.jbc.org/cgi/doi/10.1074/jbc.274.1.41 [Accessed February 9, 2014].

D'Souza-Schorey, C. \& Chavrier, P., 2006. ARF proteins: roles in membrane traffic and beyond. Nature reviews. Molecular cell biology, 7(5), pp.347-58. Available at:

http://www.ncbi.nlm.nih.gov/pubmed/16633337 [Accessed July 14, 2014].

Danscher, G., 1981. Histochemical demonstration of heavy metals. Histochemistry, 71(1), pp.1-16. Available at: http://link.springer.com/10.1007/BF00592566 [Accessed October 30, 2013].

Dantuma, N.P. et al., 1998. Electron Microscopic Visualization of Receptor-mediated Endocytosis of Dil-labeled Lipoproteins by Diaminobenzidine Photoconversion. Journal of Histochemistry 
\& Cytochemistry, 46(9), pp.1085-1089. Available at:

http://jhc.sagepub.com/lookup/doi/10.1177/002215549804600913 [Accessed October 17, 2013].

Denis, M. et al., 2004. Molecular and cellular physiology of apolipoprotein A-I lipidation by the ATPbinding cassette transporter A1 (ABCA1). The Journal of biological chemistry, 279(9), pp.7384-94. Available at: http://www.ncbi.nlm.nih.gov/pubmed/14660648 [Accessed February $9,2014]$.

DePina, A.S. \& Langford, G.M., 1999. Vesicle transport: the role of actin filaments and myosin motors. Microscopy research and technique, 47(2), pp.93-106. Available at: http://www.ncbi.nlm.nih.gov/pubmed/10523788 [Accessed July 15, 2014].

Didonato, J. a et al., 2013. Function and distribution of apolipoprotein A1 in the artery wall are markedly distinct from those in plasma. Circulation, 128(15), pp.1644-55. Available at: http://www.ncbi.nlm.nih.gov/pubmed/23969698 [Accessed October 20, 2013].

Drake, C.J. et al., 2004. Differential distribution of cubilin and megalin expression in the mouse embryo. The anatomical record. Part A, Discoveries in molecular, cellular, and evolutionary biology, 277(1), pp.163-70. Available at: http://www.ncbi.nlm.nih.gov/pubmed/14983511 [Accessed February 9, 2014].

Ebong, E.E. et al., 2011. Imaging the endothelial glycocalyx in vitro by rapid freezing/freeze substitution transmission electron microscopy. Arteriosclerosis, thrombosis, and vascular biology, 31(8), pp.1908-15. Available at:

http://www.pubmedcentral.nih.gov/articlerender.fcgi?artid=3141106\&tool=pmcentrez\&renderty pe=abstract [Accessed December 16, 2013].

Eckhardt, E.R.M. et al., 2006. High density lipoprotein endocytosis by scavenger receptor SR-BII is clathrin-dependent and requires a carboxyl-terminal dileucine motif. The Journal of biological chemistry, 281(7), pp.4348-53. Available at: http://www.ncbi.nlm.nih.gov/pubmed/16368683 [Accessed February 4, 2014].

Eckhardt, E.R.M. et al., 2004. High density lipoprotein uptake by scavenger receptor SR-BII. The Journal of biological chemistry, 279(14), pp.14372-81. Available at: http://www.ncbi.nlm.nih.gov/pubmed/14726519 [Accessed October 7, 2013].

Esteve, J. et al., 2003. Ectopic b -chain of ATP synthase is an apolipoprotein A-I receptor in hepatic HDL endocytosis. , 1, pp.75-79.

Favari, E. et al., 2009. Small discoidal pre-beta1 HDL particles are efficient acceptors of cell cholesterol via ABCA1 and ABCG1. Biochemistry, 48(46), pp.11067-74. Available at: http://www.ncbi.nlm.nih.gov/pubmed/19839639 [Accessed February 9, 2014].

Feister, H.A. et al., 2002. Identification of an IL-6 response element in the human LCAT promoter. Journal of lipid research, 43(6), pp.960-70. Available at: http://www.ncbi.nlm.nih.gov/pubmed/12032172 [Accessed July 16, 2014].

Fenske, S.A. et al., 2009. Normal hepatic cell surface localization of the high density lipoprotein receptor, scavenger receptor class $B$, type I, depends on all four PDZ domains of PDZK1. The Journal of biological chemistry, 284(9), pp.5797-806. Available at: http://www.pubmedcentral.nih.gov/articlerender.fcgi?artid=2645830\&tool=pmcentrez\&renderty pe=abstract [Accessed July 15, 2014]. 
Fischer von Mollard, G. et al., 1994. Rab proteins in regulated exocytosis. Trends in biochemical sciences, 19(4), pp.164-8. Available at: http://www.ncbi.nlm.nih.gov/pubmed/8016866 [Accessed February 5, 2014].

Fishman, J.B. et al., 1987. Receptor-mediated transcytosis of transferrin across the blood-brain barrier. Journal of neuroscience research, 18(2), pp.299-304. Available at: http://www.ncbi.nlm.nih.gov/pubmed/3694713 [Accessed February 4, 2014].

Franc, N.C. et al., 1996. Croquemort, a novel Drosophila hemocyte/macrophage receptor that recognizes apoptotic cells. Immunity, 4(5), pp.431-43. Available at: http://www.ncbi.nlm.nih.gov/pubmed/8630729.

Franc, N.C., 1999. Requirement for Croquemort in Phagocytosis of Apoptotic Cells in Drosophila. Science, 284(5422), pp.1991-1994. Available at:

http://www.sciencemag.org/cgi/doi/10.1126/science.284.5422.1991 [Accessed October 18, 2013].

França, A. et al., 2011. Macrophage scavenger receptor A mediates the uptake of gold colloids by macrophages in vitro. Nanomedicine (London, England), 6(7), pp.1175-88. Available at: http://www.ncbi.nlm.nih.gov/pubmed/21675859 [Accessed October 28, 2013].

Friend, D.S. \& Farquhar, M.G., 1967. Functions of coated vesicles during protein absorption in the rat vas deferens. The Journal of cell biology, 35(2), pp.357-76. Available at: http://www.pubmedcentral.nih.gov/articlerender.fcgi?artid=2107144\&tool=pmcentrez\&renderty pe=abstract [Accessed February 4, 2014].

Fuki, I. V et al., 2003. Endogenously produced endothelial lipase enhances binding and cellular processing of plasma lipoproteins via heparan sulfate proteoglycan-mediated pathway. The Journal of biological chemistry, 278(36), pp.34331-8. Available at: http://www.ncbi.nlm.nih.gov/pubmed/12810721 [Accessed February 10, 2014].

Gaidukov, L. et al., 2011. Glycine dimerization motif in the N-terminal transmembrane domain of the high density lipoprotein receptor SR-BI required for normal receptor oligomerization and lipid transport. The Journal of biological chemistry, 286(21), pp.18452-64. Available at: http://www.pubmedcentral.nih.gov/articlerender.fcgi?artid=3099662\&tool=pmcentrez\&renderty pe $=$ abstract [Accessed October 18, 2013].

Gavard, J. \& Gutkind, J.S., 2008. Protein kinase C-related kinase and ROCK are required for thrombin-induced endothelial cell permeability downstream from Galpha12/13 and Galpha11/q. The Journal of biological chemistry, 283(44), pp.29888-96. Available at: http://www.pubmedcentral.nih.gov/articlerender.fcgi?artid=2573073\&tool=pmcentrez\&renderty pe=abstract [Accessed July 15, 2014].

Geoffroy, J.S. \& Becker, R.P., 1984. Endocytosis by endothelial phagocytes: uptake of bovine serum albumin-gold conjugates in bone marrow. Journal of ultrastructure research, 89(3), pp.223-39. Available at: http://www.ncbi.nlm.nih.gov/pubmed/6544888.

Ghaffarian, R. \& Muro, S., 2013. Models and methods to evaluate transport of drug delivery systems across cellular barriers. Journal of visualized experiments : JoVE, (80), p.e50638. Available at: http://www.ncbi.nlm.nih.gov/pubmed/24192611 [Accessed February 4, 2014].

Ghitescu, L. et al., 1986. Specific binding sites for albumin restricted to plasmalemmal vesicles of continuous capillary endothelium: receptor-mediated transcytosis. The Journal of cell biology, 102(4), pp.1304-11. Available at:

http://www.pubmedcentral.nih.gov/articlerender.fcgi?artid=2114181\&tool=pmcentrez\&renderty pe=abstract [Accessed February 3, 2014]. 
Gin, P. et al., 2011. Binding preferences for GPIHBP1, a glycosylphosphatidylinositol-anchored protein of capillary endothelial cells. Arteriosclerosis, thrombosis, and vascular biology, 31(1), pp.176-82. Available at:

http://www.pubmedcentral.nih.gov/articlerender.fcgi?artid=3004026\&tool=pmcentrez\&renderty pe=abstract [Accessed February 10, 2014].

Hammad, S.M., 2000. Megalin Acts in Concert with Cubilin to Mediate Endocytosis of High Density Lipoproteins. Journal of Biological Chemistry, 275(16), pp.12003-12008. Available at: http://www.jbc.org/cgi/doi/10.1074/jbc.275.16.12003 [Accessed February 9, 2014].

Handley, D.A. et al., 1981. Colloidal gold-low density lipoprotein conjugates as membrane receptor probes Cell Biology: PNAS, 78(1), pp.368-371.

He, W. et al., 2007. A freeze substitution fixation-based gold enlarging technique for EM studies of endocytosed Nanogold-labeled molecules. Journal of structural biology, 160(1), pp.103-13. Available at: http://www.pubmedcentral.nih.gov/articlerender.fcgi?artid=2076746\&tool=pmcentrez\&renderty pe=abstract [Accessed October 20, 2013].

Hellerstein, M. \& Turner, S., 2014. Reverse cholesterol transport fluxes. Current opinion in lipidology, 25(1), pp.40-7. Available at: http://www.ncbi.nlm.nih.gov/pubmed/24362356 [Accessed February 6, 2014].

Herzog, V., 1983. Preparation of inside-out thyroid follicles for studies on transcellular transport (transcytosis). Methods in enzymology, 98, pp.447-58. Available at: http://www.ncbi.nlm.nih.gov/pubmed/6669055 [Accessed February 3, 2014].

Hibbs, R.G., Burch, G.E. \& Phillips, J.H., 1958. The fine structure of the small blood vessels of normal human dermis and subcutis. American heart journal, 56(5), pp.662-70. Available at: http://www.ncbi.nlm.nih.gov/pubmed/13582838 [Accessed January 28, 2014].

His, W., 1865. Die Häute und Höhlen des Körpers,

Hohenberg, H., Mannweiler, K. \& Müller, M., 1994. High-pressure freezing of cell suspensions in cellulose capillary tubes. Journal of Microscopy, 175(1), pp.34-43. Available at: http://doi.wiley.com/10.1111/j.1365-2818.1994.tb04785.x [Accessed October 29, 2013].

Hokland, B., Mendez, a J. \& Oram, J.F., 1992. Cellular localization and characterization of proteins that bind high density lipoprotein. Journal of lipid research, 33(9), pp.1335-42. Available at: http://www.ncbi.nlm.nih.gov/pubmed/1328447.

Hong, W. \& Lev, S., 2014. Tethering the assembly of SNARE complexes. Trends in cell biology, 24(1), pp.35-43. Available at: http://www.ncbi.nlm.nih.gov/pubmed/24119662 [Accessed January 24, 2014].

Hossain, M.A. et al., 2012. Lipid-bound apolipoproteins in tyrosyl radical-oxidized HDL stabilize ABCA1 like lipid-free apolipoprotein A-I. BMC biochemistry, 13, p.1. Available at: http://www.pubmedcentral.nih.gov/articlerender.fcgi?artid=3292454\&tool=pmcentrez\&renderty pe=abstract [Accessed February 9, 2014].

loka, R.X. et al., 2003. Expression cloning and characterization of a novel glycosylphosphatidylinositol-anchored high density lipoprotein-binding protein, GPI-HBP1. The Journal of biological chemistry, 278(9), pp.7344-9. Available at: http://www.ncbi.nlm.nih.gov/pubmed/12496272 [Accessed October 21, 2013]. 
Jahangiri, a et al., 2005. Evidence that endothelial lipase remodels high density lipoproteins without mediating the dissociation of apolipoprotein A-I. Journal of lipid research, 46(5), pp.896-903. Available at: http://www.ncbi.nlm.nih.gov/pubmed/15687350 [Accessed February 10, 2014].

Jahn, R. \& Scheller, R.H., 2006. SNAREs--engines for membrane fusion. Nature reviews. Molecular cell biology, 7(9), pp.631-43. Available at: http://www.ncbi.nlm.nih.gov/pubmed/16912714 [Accessed September 16, 2013].

Jiang, Y., He, X. \& Howe, P.H., 2012. Disabled-2 (Dab2) inhibits Wnt/ $\beta$-catenin signalling by binding LRP6 and promoting its internalization through clathrin. The EMBO journal, 31(10), pp.2336-49. Available at:

http://www.pubmedcentral.nih.gov/articlerender.fcgi?artid=3364753\&tool=pmcentrez\& renderty pe=abstract [Accessed July 15, 2014].

Kanai, Y., Wang, D. \& Hirokawa, N., 2014. KIF13B enhances the endocytosis of LRP1 by recruiting LRP1 to caveolae. The Journal of Cell Biology, 204(3), pp.395-408. Available at: http://www.jcb.org/cgi/doi/10.1083/jcb.201309066 [Accessed January 28, 2014].

Kelesidis, T. et al., 2012. Effects of lipid-probe interactions in biochemical fluorometric methods that assess HDL redox activity. Lipids in health and disease, 11, p.87. Available at: http://www.pubmedcentral.nih.gov/articlerender.fcgi?artid=3409024\&tool=pmcentrez\&renderty pe=abstract [Accessed February 6, 2014].

Kellenberger, E., 1991. The potential of cryofixation and freeze substitution: observations and theoretical considerations. Journal of Microscopy, 161(2), pp.183-203. Available at: http://doi.wiley.com/10.1111/j.1365-2818.1991.tb03083.x [Accessed October 30, 2013].

Khan, A.R. \& Ménétrey, J., 2013. Structural biology of Arf and Rab GTPases' effector recruitment and specificity. Structure (London, England: 1993), 21(8), pp.1284-97. Available at: http://www.ncbi.nlm.nih.gov/pubmed/23931141 [Accessed February 5, 2014].

Kikuta, a \& Rosen, S.D., 1994. Localization of ligands for L-selectin in mouse peripheral lymph node high endothelial cells by colloidal gold conjugates. Blood, 84(11), pp.3766-75. Available at: http://www.ncbi.nlm.nih.gov/pubmed/7524748.

Kirkham, M. et al., 2005. Ultrastructural identification of uncoated caveolin-independent early endocytic vehicles. The Journal of cell biology, 168(3), pp.465-76. Available at: http://www.pubmedcentral.nih.gov/articlerender.fcgi?artid=2171740\&tool=pmcentrez\&renderty pe=abstract [Accessed January 22, 2014].

Kishimoto, T. \& Tavassoli, M., 1987. Transendothelial transport (transcytosis) of iron-transferrin complex in the rat liver. The American journal of anatomy, 178(3), pp.241-9. Available at: http://www.ncbi.nlm.nih.gov/pubmed/3578087 [Accessed February 4, 2014].

Kocher, O. \& Krieger, M., 2009. Role of the adaptor protein PDZK1 in controlling the HDL receptor SR-BI. Current opinion in lipidology, 20(3), pp.236-41. Available at: http://www.pubmedcentral.nih.gov/articlerender.fcgi?artid=2849150\&tool=pmcentrez\&renderty pe=abstract [Accessed October 18, 2013].

Kolleck, I. et al., 2002. HDL-holoparticle uptake by alveolar type II cells: effect of vitamin E status. American journal of respiratory cell and molecular biology, 27(1), pp.57-63. Available at: http://www.ncbi.nlm.nih.gov/pubmed/12091246 [Accessed February 9, 2014].

Kostner, G.M. et al., 1987. The role of LCAT and cholesteryl ester transfer proteins for the HDL and LDL structure and metabolism. Advances in experimental medicine and biology, 210, pp.7986. Available at: http://www.ncbi.nlm.nih.gov/pubmed/3591559 [Accessed July 16, 2014]. 
Krieger, M., 1999. CHARTING THE FATE OF THE "GOOD CHOLESTEROL": Identification and Characterization of the High-Density Lipoprotein Receptor SR-BI. Annual Review of Biochemistry, 68, pp.523-558.

Kuvin, J.T. et al., 2002. A novel mechanism for the beneficial vascular effects of high-density lipoprotein cholesterol: Enhanced vasorelaxation and increased endothelial nitric oxide synthase expression. American Heart Journal, 144(1), pp.165-172. Available at: http://linkinghub.elsevier.com/retrieve/pii/S0002870302000595 [Accessed July 15, 2014].

Lampugnani, M.G. et al., 2010. CCM1 regulates vascular-lumen organization by inducing endothelial polarity. Journal of cell science, 123(Pt 7), pp.1073-80. Available at: http://www.ncbi.nlm.nih.gov/pubmed/20332120 [Accessed November 5, 2013].

Le, P.U., 2003. Distinct caveolae-mediated endocytic pathways target the Golgi apparatus and the endoplasmic reticulum. Journal of Cell Science, 116(6), pp.1059-1071. Available at: http://jcs.biologists.org/cgi/doi/10.1242/jcs.00327 [Accessed January 13, 2014].

Levick, J.R. \& Michel, C.C., 2010. Microvascular fluid exchange and the revised Starling principle. Cardiovascular research, 87(2), pp.198-210. Available at: http://www.ncbi.nlm.nih.gov/pubmed/20200043 [Accessed December 16, 2013].

Lim, H.Y. et al., 2013. Lymphatic vessels are essential for the removal of cholesterol from peripheral tissues by SR-BI-mediated transport of HDL. Cell metabolism, 17(5), pp.671-84. Available at: http://www.ncbi.nlm.nih.gov/pubmed/23663736 [Accessed September 17, 2013]

Liu, Y. \& Tang, C., 2012. Regulation of ABCA1 functions by signaling pathways. Biochimica et biophysica acta, 1821(3), pp.522-9. Available at:

http://www.pubmedcentral.nih.gov/articlerender.fcgi?artid=3243790\&tool=pmcentrez\&renderty pe=abstract [Accessed January 16, 2014].

Lorenzi, I. et al., 2008. Lipidation of apolipoprotein A-I by ATP-binding cassette transporter (ABC) A1 generates an interaction partner for ABCG1 but not for scavenger receptor BI. Biochimica et Biophysica Acta (BBA) - Molecular and Cell Biology of Lipids, 1781(6-7), pp.306-313. Available at: http://www.sciencedirect.com/science/article/pii/S1388198108000760.

Luft, J.H., 1961. Improvements in epoxy resin embedding methods. The Journal of biophysical and biochemical cytology, 9, pp.409-414.

Ma, J. et al., 2004. Role of apolipoprotein A-I in protecting against endotoxin toxicity. Acta biochimica et biophysica Sinica, 36(6), pp.419-24. Available at: http://www.ncbi.nlm.nih.gov/pubmed/15188057.

Macia, E. et al., 2006. Dynasore, a cell-permeable inhibitor of dynamin. Developmental cell, 10(6), pp.839-50. Available at: http://www.ncbi.nlm.nih.gov/pubmed/16740485 [Accessed October $17,2013]$.

Malaval, C. et al., 2009. RhoA/ROCK I signalling downstream of the P2Y13 ADP-receptor controls HDL endocytosis in human hepatocytes. Cellular signalling, 21(1), pp.120-7. Available at: http://www.ncbi.nlm.nih.gov/pubmed/18948190 [Accessed October 15, 2013].

Marcel, Y.L., Ouimet, M. \& Wang, M.-D., 2008. Regulation of cholesterol efflux from macrophages. Current opinion in lipidology, 19(5), pp.455-61. Available at:

http://www.ncbi.nlm.nih.gov/pubmed/18769226 [Accessed January 16, 2014]. 
Marcum, J.A. \& Rosenberg, R.D., 1984. Anticoagulantly active heparin-like molecules from vascular tissue. Biochemistry, 23(8), pp.1730-7. Available at: http://www.ncbi.nlm.nih.gov/pubmed/6232950 [Accessed January 29, 2014].

Martel, C. et al., 2013. Lymphatic vasculature mediates macrophage reverse cholesterol transport in mice. , 123(4), pp.1571-1579.

McClure, S.J. \& Robinson, P.J., 1996. Dynamin, endocytosis and intracellular signalling (review). Molecular membrane biology, 13(4), pp.189-215. Available at: http://www.ncbi.nlm.nih.gov/pubmed/9116759.

Mercer, J. \& Helenius, A., 2012. Gulping rather than sipping: macropinocytosis as a way of virus entry. Current opinion in microbiology, 15(4), pp.490-9. Available at: http://www.ncbi.nlm.nih.gov/pubmed/22749376 [Accessed September 24, 2013].

Mercer, J. \& Helenius, A., 2009. Virus entry by macropinocytosis. Nature cell biology, 11(5), pp.510-20. Available at: http://www.ncbi.nlm.nih.gov/pubmed/22749376.

Milici, A.J. et al., 1987. Transcytosis of albumin in capillary endothelium. The Journal of cell biology, 105(6 Pt 1), pp.2603-12. Available at: http://www.pubmedcentral.nih.gov/articlerender.fcgi?artid=2114713\&tool=pmcentrez\&renderty pe=abstract [Accessed December 3, 2013].

Mineo, C. et al., 2003. High density lipoprotein-induced endothelial nitric-oxide synthase activation is mediated by Akt and MAP kinases. The Journal of biological chemistry, 278(11), pp.91429. Available at: http://www.ncbi.nlm.nih.gov/pubmed/12511559 [Accessed October 14, 2013].

Mineo, C. \& Shaul, P.W., 2013. Regulation of signal transduction by HDL. Journal of lipid research, 54(9), pp.2315-24. Available at: http://www.ncbi.nlm.nih.gov/pubmed/23687307 [Accessed October 8, 2013].

Morphew, M. et al., 2008. Silver enhancement of Nanogold particles during freeze substitution for electron microscopy. Journal of microscopy, 230(Pt 2), pp.263-7. Available at: http://www.pubmedcentral.nih.gov/articlerender.fcgi?artid=2722379\&tool=pmcentrez\&renderty pe=abstract [Accessed October 23, 2013].

Morris, R.E. \& Saelinger, C.B., 1984. Visualization of intracellular trafficking: use of biotinylated ligands in conjunction with avidin-gold colloids. Journal of Histochemistry \& Cytochemistry, 32(1), pp.124-128. Available at: http://jhc.sagepub.com/lookup/doi/10.1177/32.1.6690597 [Accessed October 29, 2013].

Mulivor, a W. \& Lipowsky, H.H., 2002. Role of glycocalyx in leukocyte-endothelial cell adhesion. American journal of physiology. Heart and circulatory physiology, 283(4), pp.H1282-91. Available at: http://www.ncbi.nlm.nih.gov/pubmed/12234777.

Nagao, K. et al., 2012. ATP hydrolysis-dependent conformational changes in the extracellular domain of ABCA1 are associated with apoA-I binding. Journal of lipid research, 53(1), pp.126-36. Available at:

http://www.pubmedcentral.nih.gov/articlerender.fcgi?artid=3243469\&tool=pmcentrez\&renderty pe=abstract [Accessed December 17, 2013].

De Nardo, D. et al., 2013. High-density lipoprotein mediates anti-inflammatory reprogramming of macrophages via the transcriptional regulator ATF3. Nature immunology, (December). Available at: http://www.ncbi.nlm.nih.gov/pubmed/24317040 [Accessed December 10, 2013]. 
Navab, M., Anantharamaiah, G.M. \& Fogelman, A.M., 2005. The role of high-density lipoprotein in inflammation. Trends in cardiovascular medicine, 15(4), pp.158-61. Available at: http://www.ncbi.nlm.nih.gov/pubmed/16099381.

$\mathrm{Ng}$, E.L. et al., 2012. Rab GTPases regulating receptor trafficking at the late endosome-lysosome membranes. Cell biochemistry and function, 30(6), pp.515-23. Available at: http://www.ncbi.nlm.nih.gov/pubmed/22473705 [Accessed July 15, 2014].

Nguyen, T.M.B. et al., 2009. Endostatin induces autophagy in endothelial cells by modulating Beclin 1 and beta-catenin levels. Journal of cellular and molecular medicine, 13(9B), pp.3687-98. Available at: http://www.ncbi.nlm.nih.gov/pubmed/19298526 [Accessed July 15, 2014].

Nikolova, G. \& Lammert, E., 2003. Interdependent development of blood vessels and organs. Cell and tissue research, 314(1), pp.33-42. Available at: http://www.ncbi.nlm.nih.gov/pubmed/12898210 [Accessed November 14, 2013].

Nistor, A. \& Simionescu, M., 1986. Uptake of low density lipoproteins by the hamster lung. Interactions with capillary endothelium. The American review of respiratory disease, 134(6), pp.1266-72. Available at: http://www.ncbi.nlm.nih.gov/pubmed/3024539 [Accessed February $3,2014]$.

Norum, K.R. et al., 1983. Transport of cholesterol. Physiological reviews, 63(4), pp.1343-419. Available at: http://www.ncbi.nlm.nih.gov/pubmed/6361811 [Accessed February 6, 2014].

Ohnsorg, P.M. et al., 2011. Carboxyl terminus of apolipoprotein A-I (ApoA-I) is necessary for the transport of lipid-free ApoA-I but not prelipidated ApoA-I particles through aortic endothelial cells. The Journal of biological chemistry, 286(10), pp.7744-54. Available at:

http://www.pubmedcentral.nih.gov/articlerender.fcgi?artid=3048662\&tool=pmcentrez\&renderty pe=abstract [Accessed October 24, 2012].

Palade, G.E. \& Bruns, R.R., 1968. Structural modulations of plasmalemmal vesicles. The Journal of cell biology, 37(3), pp.633-49. Available at:

http://www.pubmedcentral.nih.gov/articlerender.fcgi?artid=2107438\&tool=pmcentrez\&renderty pe=abstract.

Papale, G.A., Hanson, P.J. \& Sahoo, D., 2011. Extracellular disulfide bonds support scavenger receptor class B type I-mediated cholesterol transport. Biochemistry, 50(28), pp.6245-54. Available at: http://www.ncbi.nlm.nih.gov/pubmed/21675794 [Accessed February 7, 2014].

Park, C., Kim, T.M. \& Malik, A.B., 2013. Transcriptional regulation of endothelial cell and vascular development. Circulation research, 112(10), pp.1380-400. Available at:

http://www.ncbi.nlm.nih.gov/pubmed/23661712 [Accessed September 30, 2013].

Pearse, B.M., 1976. Clathrin: a unique protein associated with intracellular transfer of membrane by coated vesicles. Proceedings of the National Academy of Sciences of the United States of America, 73(4), pp.1255-9. Available at:

http://www.pubmedcentral.nih.gov/articlerender.fcgi?artid=430241\&tool=pmcentrez\&rendertyp $\mathrm{e}=$ abstract [Accessed February 4, 2014].

Pearse, B.M. \& Robinson, M.S., 1984. Purification and properties of 100-kd proteins from coated vesicles and their reconstitution with clathrin. The EMBO journal, 3(9), pp.1951-7. Available at:

http://www.pubmedcentral.nih.gov/articlerender.fcgi?artid=557627\&tool=pmcentrez\&rendertyp e=abstract [Accessed February 4, 2014]. 
Pellon-Cardenas, O. et al., 2013. ARF6-regulated endocytosis of growth factor receptors links cadherin-based adhesion to canonical Wnt signaling in epithelia. Molecular and cellular biology, 33(15), pp.2963-75. Available at:

http://www.pubmedcentral.nih.gov/articlerender.fcgi?artid=3719676\&tool=pmcentrez\&renderty pe=abstract [Accessed July 15, 2014].

Pirone, D.M. et al., 2006. An inhibitory role for FAK in regulating proliferation: a link between limited adhesion and RhoA-ROCK signaling. The Journal of cell biology, 174(2), pp.277-88.

Available at:

http://www.pubmedcentral.nih.gov/articlerender.fcgi?artid=2064187\&tool=pmcentrez\&renderty pe=abstract [Accessed July 15, 2014].

Pober, J.S. \& Sessa, W.C., 2007. Evolving functions of endothelial cells in inflammation. Nature reviews. Immunology, 7(10), pp.803-15. Available at:

http://www.ncbi.nlm.nih.gov/pubmed/17893694 [Accessed November 14, 2013].

Pohl, K. \& Stierhof, Y.D., 1998. Action of gold chloride ("gold toning") on silver-enhanced $1 \mathrm{~nm}$ gold markers. Microscopy research and technique, 42(1), pp.59-65. Available at: http://www.ncbi.nlm.nih.gov/pubmed/9712163 [Accessed October 30, 2013].

Predescu, S. a et al., 2005. Cholesterol-dependent syntaxin-4 and SNAP-23 clustering regulates caveolar fusion with the endothelial plasma membrane. The Journal of biological chemistry, 280(44), pp.37130-8. Available at: http://www.ncbi.nlm.nih.gov/pubmed/16118213 [Accessed September 16, 2013].

Prescianotto-Baschong, C. \& Riezman, H., 2002. Ordering of compartments in the yeast endocytic pathway. Traffic (Copenhagen, Denmark), 3(1), pp.37-49. Available at:

http://www.ncbi.nlm.nih.gov/pubmed/11872141.

Radojkovic, C. et al., 2009. Stimulation of cell surface F1-ATPase activity by apolipoprotein A-I inhibits endothelial cell apoptosis and promotes proliferation. Arteriosclerosis, thrombosis, and vascular biology, 29(7), pp.1125-30. Available at:

http://www.ncbi.nlm.nih.gov/pubmed/19372457 [Accessed February 10, 2014].

Raizman, J.E. et al., 2013. Heat shock protein-27 attenuates foam cell formation and atherogenesis by down-regulating scavenger receptor-A expression via NF-kB signaling. Biochimica et biophysica acta, 1831(12), pp.1721-8. Available at: http://www.ncbi.nlm.nih.gov/pubmed/23939398 [Accessed July 15, 2014].

Rämet, M.E. et al., 2003. High-density lipoprotein increases the abundance of eNOS protein in human vascular endothelial cells by increasing its half-life. Journal of the American College of Cardiology, 41(12), pp.2288-2297. Available at:

http://linkinghub.elsevier.com/retrieve/pii/S0735109703004819 [Accessed July 15, 2014].

Rhode, S. et al., 2004. Visualization of the uptake of individual HDL particles in living cells via the scavenger receptor class B type I. Cell biochemistry and biophysics, 41(3), pp.343-56. Available at: http://www.ncbi.nlm.nih.gov/pubmed/15509885.

Rifici, V.A. \& Eder, H.A., 1984. A hepatocyte receptor for high-density lipoproteins specific for apolipoprotein A-I. The Journal of biological chemistry, 259(22), pp.13814-8. Available at: http://www.ncbi.nlm.nih.gov/pubmed/6094531 [Accessed February 6, 2014].

Rigotti, A., Miettinen, H.E. \& Krieger, M., 2003. The role of the high-density lipoprotein receptor SR$\mathrm{BI}$ in the lipid metabolism of endocrine and other tissues. Endocrine reviews, 24(3), pp.35787. Available at: http://www.ncbi.nlm.nih.gov/pubmed/12788804 [Accessed February 6, 2014]. 
Rinninger, F. et al., 1998. Lipoprotein lipase mediates an increase in the selective uptake of high density lipoprotein-associated cholesteryl esters by hepatic cells in culture. Journal of lipid research, 39(7), pp.1335-48. Available at: http://www.ncbi.nlm.nih.gov/pubmed/9684736 [Accessed July 15, 2014].

Rituper, B. et al., 2012. Cholesterol and regulated exocytosis: a requirement for unitary exocytotic events. Cell calcium, 52(3-4), pp.250-8. Available at: http://www.ncbi.nlm.nih.gov/pubmed/22726879 [Accessed February 5, 2014].

Robert, J. et al., 2013. Interleukin 6 stimulates endothelial binding and transport of high-density lipoprotein through induction of endothelial lipase. Arteriosclerosis, thrombosis, and vascular biology, 33(12), pp.2699-706. Available at: http://www.ncbi.nlm.nih.gov/pubmed/24115033 [Accessed January 30, 2014].

Roberts, R.L., Fine, R.E. \& Sandra, a, 1993. Receptor-mediated endocytosis of transferrin at the blood-brain barrier. Journal of cell science, 104 ( Pt 2, pp.521-32. Available at: http://www.ncbi.nlm.nih.gov/pubmed/8505377.

Roberts, R.L. \& Sandra, A., 1994. Transport of transferrin across the blood-thymus barrier in young rats. Tissue \& cell, 26(5), pp.757-66. Available at: http://www.ncbi.nlm.nih.gov/pubmed/9437249 [Accessed January 28, 2014].

Rohrer, L. et al., 2009a. High-Density Lipoprotein Transport Through Aortic Endothelial Cells Involves Scavenger Receptor BI and ATP-Binding Cassette Transporter G1. Circulation Research, 104(10), pp.1142-1150. Available at: http://circres. ahajournals.org/cgi/content/abstract/104/10/1142 [Accessed February 9, 2014].

Rohrer, L. et al., 2009b. High-density lipoprotein transport through aortic endothelial cells involves scavenger receptor $\mathrm{BI}$ and ATP-binding cassette transporter G1. Circulation research, 104(10), pp.1142-50. Available at: http://www.ncbi.nlm.nih.gov/pubmed/19372466 [Accessed October 14, 2013].

Rothberg, K.G. et al., 1992. Caveolin, a protein component of caveolae membrane coats. Cell, 68(4), pp.673-82. Available at: http://www.ncbi.nlm.nih.gov/pubmed/1739974 [Accessed February 4, 2014].

Rothblat, G.H., Bamberger, M. \& Phillips, M.C., 1986. Reverse cholesterol transport. Methods in enzymology, 129, pp.628-44. Available at: http://www.ncbi.nlm.nih.gov/pubmed/3523160 [Accessed February 6, 2014].

Saddar, S. et al., 2013. Scavenger receptor class B type I is a plasma membrane cholesterol sensor. Circulation research, 112(1), pp.140-51. Available at: http://www.ncbi.nlm.nih.gov/pubmed/23023567 [Accessed December 17, 2013].

Saddar, S., Mineo, C. \& Shaul, P.W., 2010. Signaling by the high-affinity HDL receptor scavenger receptor B type I. Arteriosclerosis, thrombosis, and vascular biology, 30(2), pp.144-50. Available at: http://www.ncbi.nlm.nih.gov/pubmed/20089950 [Accessed October 16, 2013].

Sakurai, T. et al., 2010. Measurement of lipoprotein particle sizes using dynamic light scattering. Annals of clinical biochemistry, 47(Pt 5), pp.476-81. Available at: http://www.ncbi.nlm.nih.gov/pubmed/20736248 [Accessed February 5, 2014].

Sandow, S.L. \& Grayson, T.H., 2009. Limits of isolation and culture: intact vascular endothelium and BKCa. American journal of physiology. Heart and circulatory physiology, 297(1), pp.H17. Available at: http://www.ncbi.nlm.nih.gov/pubmed/19411289 [Accessed January 29, 2014]. 
Sartori, N., Richter, K. \& Dubochet, J., 1993. Vitrification depth can be increased more than 10-fold by high-pressure freezing. Journal of Microscopy, 172(1), pp.55-61. Available at: http://doi.wiley.com/10.1111/j.1365-2818.1993.tb03393.x [Accessed October 30, 2013].

Sawaguchi, A. et al., 2001. A simple contrast enhancement by potassium permanganate oxidation for Lowicryl K4M ultrathin sections prepared by high pressure freezing/freeze substitution. Journal of Microscopy, 201(1), pp.77-83. Available at: http://doi.wiley.com/10.1046/j.13652818.2001.00787.x [Accessed October 29, 2013].

Schmidt, A. et al., 2006. The antiatherogenic and antiinflammatory effect of HDL-associated lysosphingolipids operates via Akt -->NF-kappaB signalling pathways in human vascular endothelial cells. Basic research in cardiology, 101(2), pp.109-16. Available at: http://www.ncbi.nlm.nih.gov/pubmed/16450077 [Accessed July 16, 2014].

Schnitzer, J.E., Liu, J. \& Oh, P., 1995. Endothelial Caveolae Have the Molecular Transport Machinery for Vesicle Budding, Docking, and Fusion Including VAMP, NSF, SNAP, Annexins, and GTPases. Journal of Biological Chemistry, 270(24), pp.14399-14404. Available at: http://www.jbc.org/cgi/doi/10.1074/jbc.270.24.14399 [Accessed January 16, 2014].

Schnitzer, J.E., Oh, P. \& McIntosh, D.P., 1996. Role of GTP hydrolysis in fission of caveolae directly from plasma membranes. Science (New York, N.Y.), 274(5285), pp.239-42. Available at: http://www.ncbi.nlm.nih.gov/pubmed/8824187 [Accessed February 4, 2014].

Schwartz, G.G. et al., 2012. Effects of dalcetrapib in patients with a recent acute coronary syndrome. The New England journal of medicine, 367(22), pp.2089-99. Available at: http://www.ncbi.nlm.nih.gov/pubmed/23126252 [Accessed February 7, 2014].

Schweitzer, J.K., Pietrini, S.D. \& D'Souza-Schorey, C., 2009. ARF6-mediated endosome recycling reverses lipid accumulation defects in Niemann-Pick Type C disease. PloS one, 4(4), p.e5193. Available at:

http://www.pubmedcentral.nih.gov/articlerender.fcgi?artid=2664925\&tool=pmcentrez\& renderty pe=abstract [Accessed October 13, 2013].

Seetharam, D. et al., 2006. High-density lipoprotein promotes endothelial cell migration and reendothelialization via scavenger receptor-B type I. Circulation research, 98(1), pp.63-72. Available at: http://www.ncbi.nlm.nih.gov/pubmed/16339487 [Accessed July 15, 2014].

Shah, A.S. et al., 2013. Proteomic diversity of high density lipoproteins: our emerging understanding of its importance in lipid transport and beyond. Journal of lipid research, 54(10), pp.2575-85. Available at: http://www.ncbi.nlm.nih.gov/pubmed/23434634 [Accessed October 2, 2013].

Shao, B. et al., 2010. Oxidation of apolipoprotein A-I by myeloperoxidase impairs the initial interactions with $\mathrm{ABCA} 1$ required for signaling and cholesterol export. Journal of lipid research, 51(7), pp.1849-58. Available at:

http://www.pubmedcentral.nih.gov/articlerender.fcgi?artid=2882738\&tool=pmcentrez\&renderty pe $=$ abstract [Accessed January 16, 2014].

Shao, B., 2012. Site-specific oxidation of apolipoprotein A-I impairs cholesterol export by ABCA1, a key cardioprotective function of HDL. Biochimica et biophysica acta, 1821(3), pp.490-501. Available at:

http://www.pubmedcentral.nih.gov/articlerender.fcgi?artid=3288272\&tool=pmcentrez\&renderty pe=abstract [Accessed February 9, 2014].

Shimada, K. \& Ozawa, T., 1985. Evidence that cell surface heparan sulfate is involved in the high affinity thrombin binding to cultured porcine aortic endothelial cells. The Journal of clinical 
investigation, 75(4), pp.1308-16. Available at:

http://www.pubmedcentral.nih.gov/articlerender.fcgi?artid=425460\&tool=pmcentrez\&rendertyp e=abstract [Accessed January 29, 2014].

Sieg, D.J. et al., 1998. Pyk2 and Src-family protein-tyrosine kinases compensate for the loss of FAK in fibronectin-stimulated signaling events but Pyk2 does not fully function to enhance FAK- cell migration. The EMBO journal, 17(20), pp.5933-47. Available at:

http://www.pubmedcentral.nih.gov/articlerender.fcgi?artid=1170921\&tool=pmcentrez\&renderty pe=abstract [Accessed July 15, 2014].

Skretting, G. et al., 1999. Endocytic mechanisms responsible for uptake of GPI-linked diphtheria toxin receptor. Journal of cell science, 112 ( Pt 2, pp.3899-909. Available at:

http://www.ncbi.nlm.nih.gov/pubmed/10547351.

Smith, B.T. et al., 2006. Targeted disruption of cubilin reveals essential developmental roles in the structure and function of endoderm and in somite formation. BMC developmental biology, 6 , p.30. Available at:

http://www.pubmedcentral.nih.gov/articlerender.fcgi?artid=1533814\&tool=pmcentrez\&renderty pe=abstract [Accessed February 9, 2014].

Song, X. et al., 2013. Wogonin influences vascular permeability via Wnt/ß-catenin pathway. Molecular carcinogenesis. Available at: http://www.ncbi.nlm.nih.gov/pubmed/24136474 [Accessed July 15, 2014].

Sonnenburg, W.K. et al., 2009. GPIHBP1 stabilizes lipoprotein lipase and prevents its inhibition by angiopoietin-like 3 and angiopoietin-like 4. Journal of lipid research, 50(12), pp.2421-9. Available at: http://www.pubmedcentral.nih.gov/articlerender.fcgi?artid=2781314\&tool=pmcentrez\&renderty pe=abstract [Accessed January 31, 2014].

Sorkin, A., 2004. Cargo recognition during clathrin-mediated endocytosis: a team effort. Current opinion in cell biology, 16(4), pp.392-9. Available at: http://www.ncbi.nlm.nih.gov/pubmed/15261671 [Accessed February 4, 2014].

Stierhof, Y.D., Humbel, B.M. \& Schwarz, H., 1991. Suitability of different silver enhancement methods applied to $1 \mathrm{~nm}$ colloidal gold particles: an immunoelectron microscopic study. Journal of electron microscopy technique, 17(3), pp.336-43. Available at: http://www.ncbi.nlm.nih.gov/pubmed/1646315 [Accessed October 30, 2013].

Strauss, J.G. et al., 2002. Endothelial cell-derived lipase mediates uptake and binding of highdensity lipoprotein (HDL) particles and the selective uptake of HDL-associated cholesterol esters independent of its enzymic activity. The Biochemical journal, 368(Pt 1), pp.69-79. Available at: http://www.pubmedcentral.nih.gov/articlerender.fcgi?artid=1222966\&tool=pmcentrez\&renderty pe $=$ abstract [Accessed February 10, 2014].

Sun, B. et al., 2007. Distinct mechanisms for OxLDL uptake and cellular trafficking by class B scavenger receptors CD36 and SR-BI. Journal of lipid research, 48(12), pp.2560-70. Available at: http://www.ncbi.nlm.nih.gov/pubmed/17876058 [Accessed October 16, 2013].

Svensson, K.J. et al., 2013. Exosome uptake depends on ERK1/2-heat shock protein 27 signaling and lipid Raft-mediated endocytosis negatively regulated by caveolin-1. The Journal of biological chemistry, 288(24), pp.17713-24. Available at:

http://www.pubmedcentral.nih.gov/articlerender.fcgi?artid=3682571\&tool=pmcentrez\&renderty pe $=$ abstract [Accessed July 15, 2014] . 
Sweitzer, S.M. \& Hinshaw, J.E., 1998. Dynamin undergoes a GTP-dependent conformational change causing vesiculation. Cell, 93(6), pp.1021-9. Available at:

http://www.ncbi.nlm.nih.gov/pubmed/9635431 [Accessed February 5, 2014].

Tabet, F. \& Rye, K.-A., 2009. High-density lipoproteins, inflammation and oxidative stress. Clinical science (London, England: 1979), 116(2), pp.87-98. Available at:

http://www.ncbi.nlm.nih.gov/pubmed/19076062 [Accessed October 15, 2013].

Tarling, E.J., 2013. Expanding roles of ABCG1 and sterol transport. Current opinion in lipidology, 24(2), pp.138-46. Available at: http://www.ncbi.nlm.nih.gov/pubmed/23340182 [Accessed October 18, 2013].

Tarling, E.J. \& Edwards, P. a, 2011. ATP binding cassette transporter G1 (ABCG1) is an intracellular sterol transporter. Proceedings of the National Academy of Sciences of the United States of America, 108(49), pp.19719-24. Available at:

http://www.pubmedcentral.nih.gov/articlerender.fcgi?artid=3241749\&tool=pmcentrez\&renderty pe=abstract [Accessed October 18, 2013].

Tauber, J.P., Goldminz, D., Vlodavsky, I., et al., 1981. The interaction of the high-density lipoprotein with cultured cells of bovine vascular endothelium. European journal of biochemistry / FEBS, 119(2), pp.317-25. Available at:

http://www.ncbi.nlm.nih.gov/pubmed/6273152.

Tauber, J.P., Goldminz, D. \& Gospodarowicz, D., 1981. Up-regulation in vascular endothelial cells of binding sites of high density lipoprotein induced by 25-hydroxycholesterol. European journal of biochemistry / FEBS, 119(2), pp.327-39. Available at: http://www.ncbi.nlm.nih.gov/pubmed/6273153.

Teien, A.N., Abildgaard, U. \& Höök, M., 1976. The anticoagulant effect of heparan sulfate and dermatan sulfate. Thrombosis research, 8(6), pp.859-67. Available at: http://www.ncbi.nlm.nih.gov/pubmed/134464 [Accessed January 29, 2014].

Tong, H., Knapp, H.R. \& VanRollins, M., 1998. A low temperature flotation method to rapidly isolate lipoproteins from plasma. Journal of lipid research, 39(8), pp.1696-704. Available at: http://www.ncbi.nlm.nih.gov/pubmed/9717731.

Tse, K.W.K. et al., 2012. Small molecule inhibitors of the Pyk2 and FAK kinases modulate chemoattractant-induced migration, adhesion and Akt activation in follicular and marginal zone B cells. Cellular immunology, 275(1-2), pp.47-54. Available at: http://www.ncbi.nlm.nih.gov/pubmed/22507871 [Accessed July 15, 2014].

Tsuji, T., Yoshitomi, H. \& Usukura, J., 2013. Endocytic mechanism of transferrin-conjugated nanoparticles and the effects of their size and ligand number on the efficiency of drug delivery. Microscopy (Oxford, England), 62(3), pp.341-52. Available at: http://www.ncbi.nlm.nih.gov/pubmed/23204307 [Accessed January 28, 2014].

Tucker, I.G., Yang, L. \& Mujoo, H., 2012. Delivery of drugs to the brain via the blood brain barrier using colloidal carriers. Journal of microencapsulation, 29(5), pp.475-86. Available at: http://www.ncbi.nlm.nih.gov/pubmed/22563886 [Accessed February 4, 2014].

Vantourout, P. et al., 2010. Ecto-F 1 -ATPase: A moonlighting protein complex and an unexpected apoA-I receptor. , 16(47), pp.5925-5935.

Vasile, E., Simionescu, M. \& Simionescu, N., 1983. Visualization of the binding, endocytosis, and transcytosis of low-density lipoprotein in the arterial endothelium in situ. The Journal of cell biology, 96(6), pp.1677-89. Available at: 
http://www.pubmedcentral.nih.gov/articlerender.fcgi?artid=2112465\&tool=pmcentrez\&renderty pe $=$ abstract.

Vedhachalam, C. et al., 2007. ABCA1-induced cell surface binding sites for ApoA-I. Arteriosclerosis, thrombosis, and vascular biology, 27(7), pp.1603-9. Available at: http://www.ncbi.nlm.nih.gov/pubmed/17478755 [Accessed October 21, 2013].

Vogel, S.M. et al., 2001. Albumin uptake and transcytosis in endothelial cells in vivo induced by albumin-binding protein. American journal of physiology. Lung cellular and molecular physiology, 281(6), pp.L1512-22. Available at: http://www.ncbi.nlm.nih.gov/pubmed/11704548 [Accessed November 1, 2013].

Wakahara, R. et al., 2012. Phospho-Ser727 of STAT3 regulates STAT3 activity by enhancing dephosphorylation of phospho-Tyr705 largely through TC45. Genes to cells : devoted to molecular \& cellular mechanisms, 17(2), pp.132-45. Available at: http://www.ncbi.nlm.nih.gov/pubmed/22233524 [Accessed June 3, 2014].

Walch-Solimena, C. et al., 1995. The t-SNAREs syntaxin 1 and SNAP-25 are present on organelles that participate in synaptic vesicle recycling. The Journal of cell biology, 128(4), pp.637-45. Available at: http://www.pubmedcentral.nih.gov/articlerender.fcgi?artid=2199899\&tool=pmcentrez\&renderty pe $=$ abstract.

Waldeyer, W., 1900. Kittsubstanz und Grundsubstanz, Epithel und Endothel. Archiv für Mikroskopische Anatomie, 57(1), pp.1-8. Available at: http://link.springer.com/10.1007/BF02975315 [Accessed January 28, 2014].

Wang, N. et al., 2008. ATP-binding cassette transporters G1 and G4 mediate cholesterol and desmosterol efflux to HDL and regulate sterol accumulation in the brain. FASEB journal: official publication of the Federation of American Societies for Experimental Biology, 22(4), pp.1073-82. Available at: http://www.ncbi.nlm.nih.gov/pubmed/18039927 [Accessed October 18, 2013].

Wautier, J.L. et al., 1990. Leukocyte adhesion to endothelial cells. Biorheology, 27(3-4), pp.425-32. Available at: http://www.ncbi.nlm.nih.gov/pubmed/2261508 [Accessed January 29, 2014].

WEIBEL, E.R. \& PALADE, G.E., 1964. NEW CYTOPLASMIC COMPONENTS IN ARTERIAL ENDOTHELIA. The Journal of cell biology, 23, pp.101-12. Available at: http://www.pubmedcentral.nih.gov/articlerender.fcgi?artid=2106503\&tool=pmcentrez\&renderty pe=abstract [Accessed January 28, 2014].

Weinstein, B., 2002. Building the house around the plumbing. BioEssays: news and reviews in molecular, cellular and developmental biology, 24(5), pp.397-400. Available at: http://www.ncbi.nlm.nih.gov/pubmed/12001261 [Accessed November 14, 2013].

Williams, S.K., Greener, D.A. \& Solenski, N.J., 1984. Endocytosis and exocytosis of protein in capillary endothelium. Journal of cellular physiology, 120(2), pp.157-62. Available at: http://www.ncbi.nlm.nih.gov/pubmed/6430919 [Accessed February 3, 2014].

Yamada, E., 1955. The fine structure of the gall bladder epithelium of the mouse. The Journal of biophysical and biochemical cytology, 1(5), pp.445-58. Available at:

http://www.pubmedcentral.nih.gov/articlerender.fcgi?artid=2229656\&tool=pmcentrez\&renderty pe=abstract [Accessed February 4, 2014].

Yan, F. et al., 2013. Transferrin-conjugated, fluorescein-loaded magnetic nanoparticles for targeted delivery across the blood-brain barrier. Journal of materials science. Materials in medicine, 
24(10), pp.2371-9. Available at: http://www.ncbi.nlm.nih.gov/pubmed/23793566 [Accessed February 4, 2014].

Yin, F. et al., 2013. Prooxidative effects of ambient pollutant chemicals are inhibited by HDL. Journal of biochemical and molecular toxicology, 27(2), pp.172-83. Available at: http://www.ncbi.nlm.nih.gov/pubmed/23420698 [Accessed February 6, 2014].

Yokoyama, S., 2006. ABCA1 and biogenesis of HDL. Journal of atherosclerosis and thrombosis, 13(1), pp.1-15. Available at: http://www.ncbi.nlm.nih.gov/pubmed/21835264.

Yokoyama, S., 2005. Assembly of high density lipoprotein by the ABCA1/apolipoprotein pathway. Current opinion in lipidology, 16(3), pp.269-79. Available at: http://www.ncbi.nlm.nih.gov/pubmed/15891387.

Young, S.G. et al., 2011. GPIHBP1, an endothelial cell transporter for lipoprotein lipase. Journal of lipid research, 52(11), pp.1869-84. Available at:

http://www.pubmedcentral.nih.gov/articlerender.fcgi?artid=3196223\&tool=pmcentrez\&renderty pe=abstract [Accessed January 31, 2014].

Yuhanna, I.S. et al., 2001. High-density lipoprotein binding to scavenger receptor-BI activates endothelial nitric oxide synthase. Nature medicine, 7(7), pp.853-7. Available at: http://www.ncbi.nlm.nih.gov/pubmed/11433352.

Zerial, M. \& McBride, H., 2001. Rab proteins as membrane organizers. Nature reviews. Molecular cell biology, 2(2), pp.107-17. Available at: http://www.ncbi.nlm.nih.gov/pubmed/11252952.

Zhai, X.Y. et al., 2000. Cubilin- and megalin-mediated uptake of albumin in cultured proximal tubule cells of opossum kidney. Kidney international, 58(4), pp.1523-33. Available at: http://www.ncbi.nlm.nih.gov/pubmed/11012887 [Accessed February 9, 2014].

Zhang, H. et al., 2010. Selective degradation of aggregate-prone CryAB mutants by HSPB1 is mediated by ubiquitin-proteasome pathways. Journal of molecular and cellular cardiology, 49(6), pp.918-30. Available at:

http://www.pubmedcentral.nih.gov/articlerender.fcgi?artid=2975794\&tool=pmcentrez\&renderty pe=abstract [Accessed July 15, 2014].

Zhu, W. et al., 2008. The scavenger receptor class B type I adaptor protein PDZK1 maintains endothelial monolayer integrity. Circulation research, 102(4), pp.480-7. Available at: http://www.ncbi.nlm.nih.gov/pubmed/18174467 [Accessed October 4, 2013]. 